Marcia de Souza Antunes

\title{
Avaliações sequenciais do perfil de ácidos graxos poli- insaturados leucocitários, plasmáticos e hepáticos após infusão parenteral de emulsão lipídica contendo óleo de peixe em ratos Lewis submetidos à cateterização cirúrgica do sistema venoso central
}

Tese apresentada à Faculdade de Medicina da Universidade de São Paulo para obtenção do título de Doutor em Ciências.

Programa de Ciências em Gastroenterologia

Orientadora: Dra. Raquel Susana Matos de Miranda Torrinhas

São Paulo 
Marcia de Souza Antunes

Avaliações sequenciais do perfil de ácidos graxos poliinsaturados leucocitários, plasmáticos e hepáticos após infusão parenteral de emulsão lipídica contendo óleo de peixe em ratos Lewis submetidos à cateterização cirúrgica do sistema venoso central

Tese apresentada à Faculdade de Medicina da Universidade de São Paulo para obtenção do título de Doutor em Ciências.

Programa de Ciências em Gastroenterologia

Orientadora: Dra. Raquel Susana Matos de Miranda Torrinhas

São Paulo 


\section{Dados Internacionais de Catalogação na Publicação (CIP)}

Preparada pela Biblioteca da

Faculdade de Medicina da Universidade de São Paulo

Creprodução autorizada pelo autor

Antunes, Marcia de Souza

Avaliações sequenciais do perfil de ácidos graxos poli-insaturados leucocitários, plasmáticos e hepáticos após infusão parenteral de emulsão lipídica contendo óleo de peixe em ratos Lewis submetidos à cateterização cirúrgica do sistema venoso central / Marcia de Souza Antunes. -- São Paulo, 2020.

Tese(doutorado)--Faculdade de Medicina da Universidade de São Paulo.

Programa de Ciências em Gastroenterologia.

Orientadora: Raquel Susana Matos de Miranda Torrinhas.

Descritores: 1.Ácidos graxos ômega-3 2.Nutrição parenteral/métodos 3.Cirurgia geral 4. Imunologia 5. Evolução clínica

$\mathrm{USP} / \mathrm{FM} / \mathrm{DBD}-021 / 20$

Responsável: Erinalva da Conceição Batista, CRB-8 6755 
Esta tese está de acordo com as seguintes normas, em vigor no momento desta publicação:

Referências: adaptado de International Committee of Medical Journals Editors (Vancouver).

Universidade de São Paulo. Faculdade de Medicina. Divisão de Biblioteca e Documentação. Guia de apresentação de dissertações, teses e monografias. Elaborado por Anneliese Carneiro da Cunha, Maria Julia de A. L. Freddi, Maria F. Crestana, Marinalva de Souza Aragão, Suely Campos Cardoso, Valéria Vilhena. 3a ed. São Paulo: Divisão de Biblioteca e Documentação; 2011.

Abreviaturas dos títulos dos periódicos de acordo com List of Journals Indexed in Index Medicus. 


\section{SUMÁRIO}

LISTA DE TABELAS

LISTA DE FIGURAS

LISTA DE SIGLAS

LISTA DE ABREVIATURAS

LISTA DE SÍMBOLOS

RESUMO

ABSTRACT

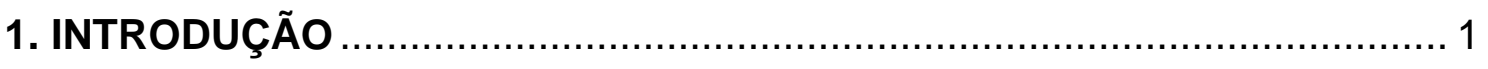

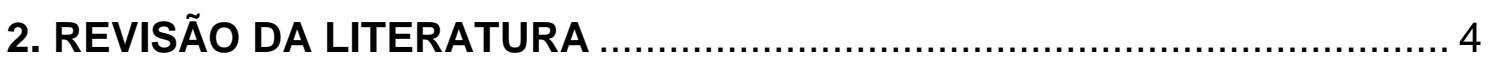

2.1. Propriedades biológicas de interesse clínico de EPA e DHA.................... 4

2.2. Importância da suplementação de EPA e DHA em cirurgia..................... 8

2.3. Importância da via parenteral para a biodisponibilidade orgânica de EPA

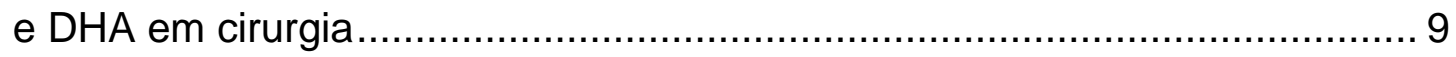

2.4. Resultados clínicos da administração parenteral de óleo de peixe rica em

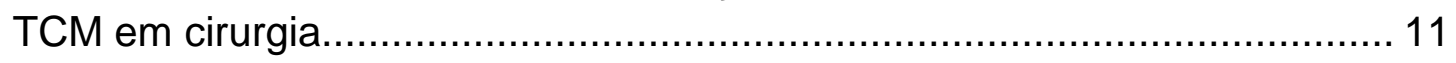

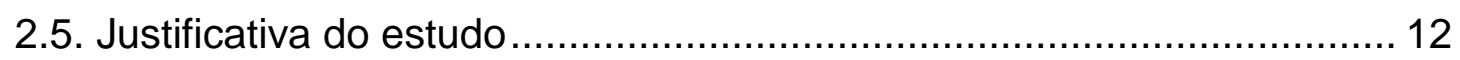

3. OBJETIVOS

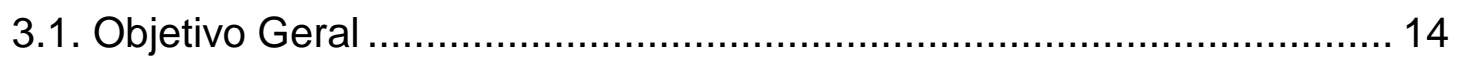

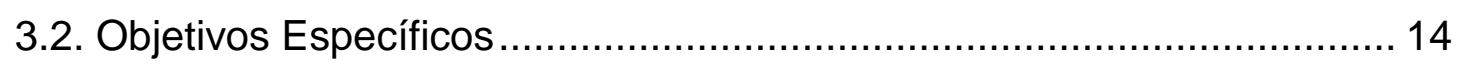

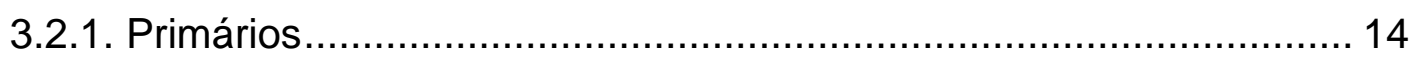

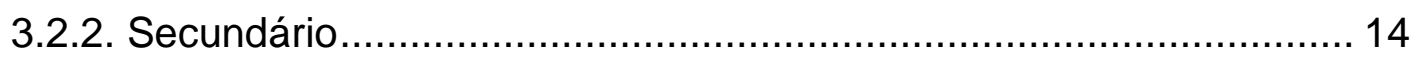

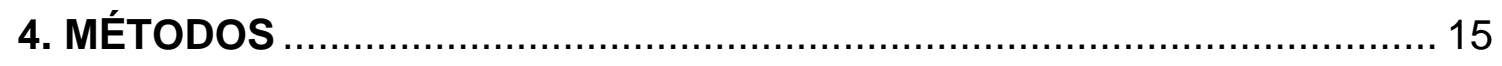

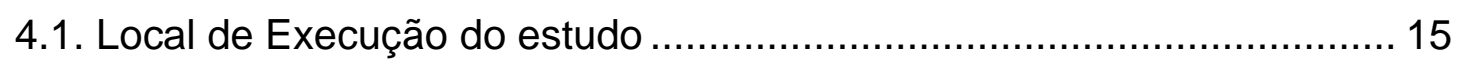

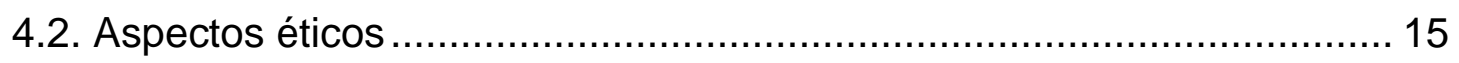

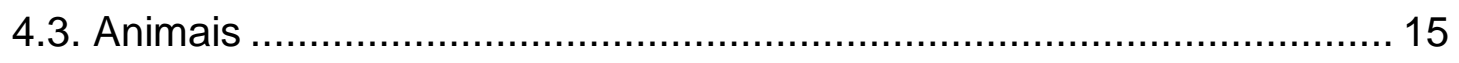

4.4. Técnica cirúrgica para cateterização do sistema venoso central ............ 16

4.5. Infusão Parenteral .......................................................................... 17

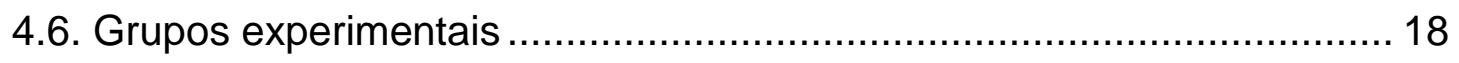

4.7. Obtenção de amostras de plasma, fígado e leucócitos........................... 19

4.8. Peso corpóreo e ingestão de dieta oral............................................... 20 
4.9. Variáveis biológicas estudadas ................................................ 21

4.9.1. Perfil de AGPI plasmáticos, hepáticos e leucocitários ...................... 21

4.9.1.1. Preparo das amostras....................................................... 21

4.9.1.2. Condições da análise cromatográfica ....................................... 22

4.9.1.3. Obtenção dos dados ............................................................. 22

4.10. Análises estatísticas............................................................. 22

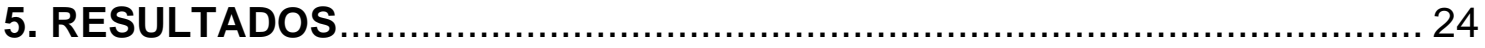

5.1. Peso corpóreo e ingestão de dieta oral............................................... 24

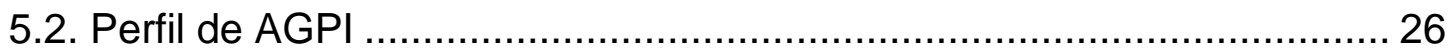

5.2.1. Leucocitário ............................................................. 26

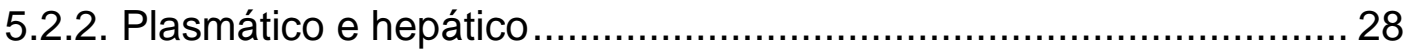

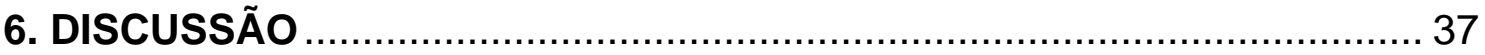

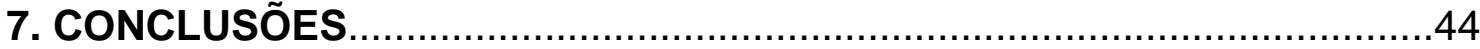

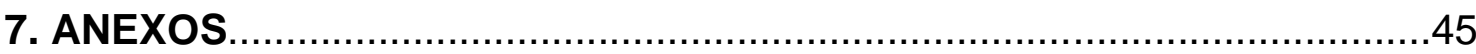

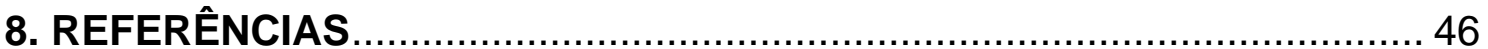




\section{LISTA DE TABELAS}

Tabela 1. Resultados imunomoduladores e clínicos de estudos sobre a infusão pós-operatória de emulsão lipídica com óleo de peixe e rica em triglicerídeos de cadeia média em pacientes cirúrgicos

Tabela 2. Composição de ácidos graxos (\%) das emulsões lipídicas controle (Lipofundin $\AA$ ) e experimental (Lipidem $\AA$ ) 18

Tabela 3. Pesos corpóreos inicial e final de ratos Lewis que receberam ou não infusão parenteral de emulsão lipídica contendo ou não óleo de peixe e sacrificados em tempos distintos de acompanhamento

Tabela 4. Ingestão periódica de dieta oral de ratos Lewis que receberam ou não infusão parenteral de emulsão lipídica contendo ou não óleo de peixe e sacrificados em tempos distintos de acompanhamento idem 25

Tabela 5. Quantidade de ácido eicosapentaenoico (EPA) no plasma e tecido hepático de ratos Lewis submetidos à cateterização cirúrgica do sistema venoso central e sacrificados após 0, 2 e 6 horas da infusão parenteral de emulsão lipídica contendo óleo de peixe 32

Tabela 6. Quantidade de ácido docosaexaenoico (DHA) no tecido hepático de ratos Lewis submetidos à cateterização cirúrgica do sistema venoso central e sacrificados 0, 2, 6 e 12 horas após o término de infusão parenteral de emulsão lipídica contendo ou não óleo de peixe 32

Tabela 7. Quantidade de ácido araquidônico (ARA) no plasma e tecido hepático de ratos Lewis submetidos à cateterização cirúrgica do sistema venoso central e à eutanásia em diferentes tempos após o término de infusão parenteral de emulsão lipídica contendo ou não óleo de peixe 33 


\section{LISTA DE FIGURAS}

Figura 1. Modulação da sinalização proteica por ácidos eicosapentaenoico (EPA) e docosaexaenoico (DHA) via desestruturação de microdomínios de membrana ricos em colesterol .............................................................................. 5

Figura 2. Modulação da transcrição gênica por ácidos graxos poli-insaturados ômega-3 e seus metabólitos 6

Figura 3. Competição para a síntese de mediadores lipídicos entre ácidos graxos ômega-3 e ácido araquidônico (ômega-6)...................................................... 7

Figura 4. Fluxograma dos grupos experimentais, distribuídos de acordo com os procedimentos cirúrgicos (cataterização venosa) e nutricionais 19

Figura 5. Quantidades de ácidos graxos poli-insaturados e razões ômega3:ômega-6 em leucócitos mononucleares de ratos Lewis submetidos à cateterização cirúrgica do sistema venoso central e sacrificados após 0,2 e 6 horas da infusão parenteral de emulsão lipídica contendo ou não óleo de peixe

Figura 6. Quantidades de ácidos graxos poli-insaturados e razões ômega3:ômega-6 em leucócitos polimorfonucleares de ratos Lewis submetidos à cateterização cirúrgica do sistema venoso central e sacrificados após 0,2 e 6 horas da infusão parenteral de emulsão lipídica contendo ou não óleo de peixe

Figura 7. Quantidades de ácidos graxos poli-insaturados e razões ômega3:ômega-6 no plasma de ratos Lewis submetidos à cateterização cirúrgica do sistema venoso central e sacrificados após 0,2 e 6 horas da infusão parenteral de emulsão lipídica contendo ou não óleo de peixe 30

Figura 8. Quantidades de ácidos graxos poli-insaturados e razões ômega3:ômega-6 no fígado de ratos Lewis submetidos à cateterização cirúrgica do sistema venoso central e sacrificados após 0,2 e 6 horas da infusão parenteral de emulsão lipídica contendo ou não óleo de peixe.

Figura 9. Porcentagens de ácidos graxos poli-insaturados e razões ômega3:ômega- 6 em leucócitos mononucleares e polimorfonucleraes do sangue de 
ratos Lewis submetidos à cateterização cirúrgica do sistema venoso central e sacrificados após 0, 2 e 6 horas da infusão parenteral de emulsão lipídica contendo ou não óleo de peixe.

Figura 10. Porcentagens de ácidos graxos poli-insaturados e razões ômega3:ômega-6 no plasma e no fígado de ratos Lewis submetidos à cateterização cirúrgica do sistema venoso central e sacrificados após 0, 2 e 6 horas da infusão parenteral de emulsão lipídica contendo ou não óleo de peixe. 36 


\section{LISTA DE SIGLAS}

AG: $\quad$ Ácido(s) Graxo(s)

AGPI: $\quad$ Ácido(s) Graxo(s) Poli-insaturado(s)

ALN: $\quad$ Ácido Linoleico

ALA: $\quad$ Ácido Alfa-linolênico

ARA: Ácido Araquidônico

CB: $\quad$ Grupo Controle Basal

CD32: Receptores da Fração Constante de Imunoglobulinas

CE: $\quad$ Grupo Emulsão Parenteral Controle

CEMIB: $\quad$ Centro Multidisciplinar para Investigação Biológica

CEP-FMUSP: Comissão de Ética em Pesquisa da Faculdade de Medicina da Universidade de São Paulo

COX: $\quad$ Ciclooxigenase

DHA: $\quad$ Ácido Docosahexaenóico

EL: $\quad$ Emulsão(ões) Lipídica(s)

EPA: Ácido Eicosapentaenóico

EUA: $\quad$ Estados Unidos da América

FID: $\quad$ Detector de lonização em Chama

FMUSP: $\quad$ Faculdade de Medicina da Universidade de São Paulo

GC: $\quad$ Cromatografia Gasosa

HLA-DR: Moléculas do Complexo de Histocompatibilidade Principal classe II tipo HLA-DR.

HPLC: $\quad$ Grau Cromatografia Líquida de Alto Desempenho

IL: Interleucina

LIM-35: Laboratório de Investigação Médica em Nutrição e Cirurgia Metabólica do Aparelho Digestivo

LOX: Lipoxigenase

LT: $\quad$ Leucotrieno

n-3: $\quad$ Ômega-3

n-6: $\quad$ Ômega-6

$\mathrm{NaCl}$ : Cloreto de Sódio

$\mathrm{NaOH}$ : Hidróxido de Sódio

NFkB: $\quad$ Fator Nuclear kappa B 
Nfr2: $\quad$ Fator 2 Relacionado ao Fator Nuclear E2

OP: $\quad$ Grupo Emulsão Parenteral com Óleo de Peixe

OPLS-DA: Projeções Ortogonais Lineares de Estruturas Latentes

PBS: $\quad$ Tampão Fosfato-salina

PCR: $\quad$ Proteína C Reativa

PG: $\quad$ Prostaglandina

PPAR: Receptor Ativado por Proliferador de Peroxissoma

CC: $\quad$ Grupo Controle Geral

SIRS: $\quad$ Síndrome da Resposta Inflamatória Sistêmica

SPM: $\quad$ Mediador(es) Especializado(s) Pró-resolução

SREBP: Proteínas de Ligação ao Elemento Regulador de Esterol

TCL: $\quad$ Triglicéride(s) de Cadeia Longa

TCM: $\quad$ Triglicéride(s) de Cadeia Média

TNF: $\quad$ Fator de Necrose Tumoral

TX: Tromboxano

UNICAMP: Universidade Estadual de Campinas

VEGF: Fator de Crescimento Endotelial Vascular 


\section{LISTA DE ABREVIATURAS}

Cols. Colaboradores

ed. Edição

p. Páginas 


\section{LISTA DE SÍMBOLOS}

\begin{tabular}{|c|c|}
\hline$\%:$ & Por cento \\
\hline$\geq:$ & Maior ou igual \\
\hline$\leq:$ & Menor ou igual \\
\hline$<:$ & Menor \\
\hline$=:$ & Igual \\
\hline$>$ : & Maior \\
\hline$\Delta:$ & Delta \\
\hline$\AA$ : & Marca registrada \\
\hline$\mu \mathrm{m}:$ & Micrômetro(s) \\
\hline $\mathrm{cm}:$ & Centímetro(s) \\
\hline g: & Grama(s) \\
\hline h: & Hora(s) \\
\hline kcal: & Kilocaloria(s) \\
\hline $\mathrm{KCl}:$ & Cloreto de potássio \\
\hline kg: & Kilograma(s) \\
\hline L: & Litro(s) \\
\hline m: & Metro(s) \\
\hline $\min :$ & Minuto(s) \\
\hline $\mathrm{mL}:$ & Microlitro(s) \\
\hline $\mathrm{mm}:$ & Milímetro(s) \\
\hline$\stackrel{\circ}{ } \mathrm{C}:$ & Grau(s) centígrado(s) \\
\hline rpm: & Rotações por minuto \\
\hline seg: & Segundo(s) \\
\hline $\mathrm{v} / \mathrm{v}:$ & Volume por volume \\
\hline
\end{tabular}




\section{RESUMO}

Antunes MS. Avaliações sequenciais do perfil de ácidos graxos poli-insaturados leucocitários, plasmáticos e hepáticos após infusão parenteral de emulsão lipídica contendo óleo de peixe em ratos Lewis submetidos à cateterização cirúrgica do sistema venoso central [tese]. São Paulo: Faculdade de Medicina, Universidade de São Paulo; 2020.

Introdução: Os ácidos graxos poli-insaturados (AGPI) ômega (n)-3 eicosapentaenoico (EPA) e docosaexaenoico (DHA) podem influenciar a resposta imunológica, com efeitos potencialmente anti-inflamatórios. A disponibilidade celular (principalmente leucocitária) de EPA e DHA é fundamental para que esses efeitos imunomoduladores ocorram. Em pacientes cirúrgicos sob terapia nutricional parenteral, a infusão de emulsão lipídica contendo óleo de peixe (ELOP), como fonte de EPA e DHA, pode atenuar efeitos adversos da resposta inflamatória pós-operatória, com melhora de marcadores imunológicos e desfechos clínicos. Entretanto, ausência de benefícios clínicos também é relatada e poderia se associar com tempo insuficiente de infusão de ELOP. Aceita-se que o tempo de infusão parenteral de ELOP seja o necessário para disponibilizar na célula EPA e DHA (cerca de 3 dias), mas este pode não ser suficiente para manter essa disponibilidade ativa durante toda a dinâmica da resposta imunológica pós-operatória. Nesse sentido, faltam diretrizes para orientar essa atuação na área de nutrição clínica. Objetivo: Para contribuir com o planejamento de protocolos em nutrição especializada, o presente estudo avaliou níveis plasmáticos, hepáticos e leucocitários de AGPIs, após diferentes períodos do término da infusão parenteral de ELOP em ratos Lewis submetidos à cateterização cirúrgica do sistema venoso central (CVC). Métodos: Após 5 dias de adaptação em gaiolas metabólicas, 78 ratos Lewis machos (300-450 g) alimentados com dieta oral padrão foram sacrificados (grupo CB; $n=6$ ) ou submetidos apenas à CVC (grupo CC; $n=24$ ) ou também à infusão parenteral (72 horas, 4,3g de gordura/kg de peso corpóreo) de emulsão controle sem óleo de peixe (grupo EC; $n=24$ ) ou de ELOP (grupo OP; $n=24$ ). Os animais submetidos à CVC foram sacrificados 0 (T0), 2 (T2), 6 (T6) e 12 (T12) horas após o período correspondente ao término da infusão de emulsões, de tal forma que cada grupo/tempo foi constituído por 6 animais. Cromatografia gasosa 
determinou a quantidade e porcentagem de EPA, DHA e ácido araquidônico (ARA) e razão n-3:n-6 no plasma, fígado e pools de leucócitos mononucleares e polimorfonucleares do sangue. Testes de Kruskal-Wallis e Wilcoxon analisaram os dados obtidos no plasma e fígado, enquanto os leucocitários foram tratados com análise descritiva. Resultados: Conforme observado no grupo $\mathrm{CB}$, as amostras de plasma, fígado e leucócitos apresentaram ausência de EPA e DHA (exceto por baixa quantidade de EPA em leucócitos mononucleares) e quantidades mensuráveis (plasma e fígado) a altas (leucócitos) de ARA. Imediatamente após a infusão de ELOP (T0), a quantidade desses AGPIs mudou em todas as amostras estudadas, resultando em maior razão n-3:n-6, em comparação aos grupos sem infusão de ELOP $(p<0,05)$. Essas alterações permaneceram até T6 no plasma e T12 no fígado, mas a partir de T2 não houve mais EPA e DHA nos leucócitos, exceto por baixos níveis de EPA em células mononucleares. Em geral, os dados de porcentagem confirmaram esses achados. Conclusões: A infusão de ELOP aumentou a razão n-3:n-6 nas amostras estudadas, sugerindo fenótipo leucocitário menos inflamatório. Entretanto, tomando-se o fígado como referência, houve elevada taxa de utilização de EPA e DHA por leucócitos. A alta labilidade de AGPI n-3 em leucócitos sugere que a infusão de ELOP para fins imunomoduladores em cirurgia deva ser mantida durante toda a dinâmica da resposta imunológica pósoperatória, para favorecer benefícios clínicos.

Descritores: Ácidos graxos ômega-3; Nutrição parenteral/métodos; Cirurgia geral; Imunologia; Evolução clínica. 


\section{ABSTRACT}

Antunes MS. Sequential assessments of the polyunsaturated fatty acid profile of plasma, liver and leukocytes after the parenteral infusion of fish oil-containing lipid emulsion in Lewis rats that had undergone surgical central venous access [thesis]. São Paulo: "Faculdade de Medicina, Universidade de São Paulo"; 2020.

Introduction: The omega ( $n$ )-3 polyunsaturated fatty acids (PUFA) eicosapentaenoic (EPA) and docosaexaenoic (DHA) can influence the immune response, with potential anti-inflammatory effects. Cellular availability (mainly leukocyte) of EPA and DHA is critical for these immunomodulatory effects to occur. In surgical patients under parenteral nutritional therapy, the infusion of fish oil-containing lipid emulsions (FOLE) as a source of EPA and DHA can attenuate adverse effects of the postoperative inflammatory response, with Improvements on immunological markers and clinical outcomes. However, the absence of clinical benefits is also reported and may be associated with insufficient length of the FOLE infusion. It is accepted that the time of parenteral infusion of FOLE is that required to provide cellular availability of EPA and DHA (about 3 days), but this may not be sufficient to maintain this active availability throughout the entire dynamics of the postoperative immune response. In this sense, guidelines are lacking to guide this practice in the area of clinical nutrition. Objective: To contribute to the design of specialized nutrition protocols, the present study evaluated plasma, hepatic and leukocyte levels of PUFA after different periods of FOLE parenteral infusion in Lewis rats submitted to the surgical central venous catheterization (CVC). Methods: After 5-day adaptation in metabolic cages, 78 male Lewis rats (300-450 g) fed standard oral diets were sacrificed (group CB; $\mathrm{n}$ =6) or submitted only to CVC (CC group; $n=24$ ) or also to the parenteral infusion (72 hours, $4.3 \mathrm{~g}$ fat $/ \mathrm{kg}$ body weight) of a control emulsion without fish oil (EC group; $n=24$ ) or FOLE (FO group; $n=24$ ). The animals submitted to CVC were sacrificed 0 (T0), 2 (T2), 6 (T6) and 12 (T12) hours after the emulsion infusion corresponding-period, so that each group / time had 6 animals. Gas chromatography determined the amount and percentage of EPA, DHA and arachidonic acid (ARA) and the $n-3: n-6$ ratio in plasma, liver, and in pools of blood mononuclear and polymorphonuclear leukocytes. Kruskal-Wallis and Wilcoxon tests analyzed the plasma and liver data, while the leukocyte data were treated 
by descriptive analysis. Results: As observed in the CB group, plasma, liver and leukocyte samples exhibited absence of EPA and DHA (except for low amount of EPA in mononuclear leukocytes) and measurable (plasma and liver) to high (leukocytes) amounts of ARA. Immediately after FOLE infusion (T0), the amount of these PUFAs changed in all samples studied, resulting in a higher n-3:n-6 ratio compared to non-FOLE infusion groups $(p<0.05)$. These changes remained until T6 in plasma and T12 in liver, but from T2 there were no more EPA and DHA in leukocytes, except for low levels of EPA in the mononuclear cells. In general, percentage data confirmed these findings. Conclusions: FOLE infusion increased the n-3:n-6 ratio in the studied samples, suggesting a less inflammatory leukocyte phenotype. However, taking the liver as reference, leukocytes highly used EPA and DHA. The high n-3 PUFA lability in leukocytes suggests that FOLE infusion for immunomodulatory purposes in surgery should be maintained throughout the dynamics of the postoperative immune response to favor clinical benefits.

Descriptors: Fatty acids, omega-3; Parenteral nutrition/methods; General surgery; Immunology; Clinical evolution. 


\section{INTRODUÇÃO}

Ácidos graxos poli-insaturados (AGPI) desempenham importantes funções orgânicas em mamíferos. Em particular os ácidos araquidônico (ARA), eicosapentaenoico (EPA) e docosaexaenoico (DHA) influenciam a composição e fluidez de membranas celulares e são precursores de mediadores imunológicos que participam de todas as etapas da inflamação. ${ }^{1} \mathrm{~A}$ disponibilidade orgânica desses AGPI é altamente condicionada à ingestão dietética, uma vez que o organismo de mamíferos não possui a maquinaria enzimática necessária para sua síntese endógena. ${ }^{2}$

O elo entre ingestão de AGPI, inflamação e imunidade pode ser atribuído ao fato de que o perfil lipídico leucocitário sofre influência da composição de ácidos graxos (AG) da dieta. Particularmente, a proporção celular de AGPI ômega (n)- 3 e n-6 é rapidamente modificada por seu conteúdo dietético. ${ }^{3}$ Digno de nota, a dieta humana (principalmente em países ocidentais) tem razões AGPI n-3:n-6 muito baixas ( 1:20), sugerindo que esta seja usualmente baixa no organismo humano. ${ }^{4}$

Em modelos experimentais e em humanos, frente a um estímulo agressor ou antigênico, a alta disponibilidade celular de AGPI n-6 (especialmente ARA) favorece respostas inflamatórias intensas e lesivas. ${ }^{5}$ Por outro lado, a maior ingestão de AGPI n-3 (especialmente EPA e DHA), seja pela dieta ou suplementação, pode aumentar razões celulares de AGPI n-3:n-6. ${ }^{6}$ Essas alterações favorecem respostas imunológicas mais eficientes e menos danosas, em termos de potencial inflamatório. ${ }^{3}$

Nesse contexto, a suplementação de EPA e DHA em pacientes com enfermidades que envolvam inflamação perniciosa, como parte da terapia nutricional especializada, tem sido foco de estudos clínicos da área. Nesses estudos a aderência ao tratamento e sua eficácia podem ser refletidas por seus conteúdos circulantes e celulares, respectivamente; bem como pelas modificações das razões de AGPI n-3:n-6 nesses nichos biológicos. ${ }^{7}$ A principal ferramenta para essas análises é a cromatografia gasosa, considerada como método referência para a identificação quantitativa e qualitativa de $A G .{ }^{8,9}$

Dentre as populações clínicas que podem se beneficiar da suplementação de EPA e DHA, destacam-se pacientes cirúrgicos. Ocorre que 
essa população é susceptível a complicações resultantes de alterações inflamatórias e imunológicas desencadeadas pelo trauma cirúrgico, que podem ser atenuadas por EPA e DHA. ${ }^{10,11}$ Particularmente, em cirurgia eletiva existe a vantagem de suplementar EPA e DHA no pré-operatório, para que células leucocitárias já estejam enriquecidas com esses AGPI n-3 no momento do estresse cirúrgico. ${ }^{12}$

Pacientes cirúrgicos podem receber EPA e DHA como parte de terapia nutricional especializada pelas vias oral, enteral e parenteral; mas sua incorporação celular é comparativamente mais precoce quando suplementados por via parenteral. ${ }^{13}$ Adicionalmente, evidências científicas sugerem que a incorporação celular desses AGPI n-3 pode ser ainda mais rápida quando sua infusão parenteral é combinada com triglicérides de cadeia média (TCM). ${ }^{14,15}$ Portanto, pacientes cirúrgicos com indicação de terapia nutricional parenteral têm a oportunidade de receber a infusão de emulsões lipídicas (EL) contendo óleo de peixe, como fonte de EPA e DHA, e usufruir da rápida disponibilidade celular desses AGPI.

Comparado à infusão de EL convencionais, compostas por óleo de soja ou da sua combinação com TCM ou óleo de oliva, a infusão de EL contendo óleo de peixe tem mostrado favorecer um perfil de citocinas e eicosanoides circulantes menos inflamatório e imunossupressor, bem como atenuar o impacto negativo da cirurgia sobre a função (ex. destruição bacteriana) e biologia (ex. apoptose, expressão de moléculas de superfície com função imunológica) leucocitárias ${ }^{10,16-19}$ Esses benefícios são amplamente acompanhados por melhores desfechos clínicos, embora a ausência de benefícios clínicos também seja relatada. ${ }^{10,20-24}$

A infusão de EL contendo exclusivamente óleo de peixe em pacientes cirúrgicos sem indicação de terapia nutricional parenteral, como um imunofármaco-nutriente, também foi considerada. Essa prática durante os 3 dias préoperatórios foi associada com atenuação da resposta pós-operatória sobre mediadores imunológicos e funções leucocitárias. ${ }^{25}$ Observou-se menor aumento de interleucina (IL)-6 (pró-inflamatória) e maior elevação da antiinflamatória IL-10 no 3ำ dia pós-operatório, seguida de sua diminuição significativa no $6^{\circ}$ dia pós-operatório, em paralelo com a preservação e/ou melhora do burst respiratório e da expressão de moléculas do complexo de 
histocompatibilidade classe II (HLA-DR) e de receptores da fração constante de imunoglobulinas (CD32) na superfície de leucócitos, comparativamente à EL controle rica em TCM. Entretanto, essas alterações não foram acompanhadas por benefícios sobre taxas de infecções e tempo de internação na unidade de terapia intensiva (UTI) e hospitalar. ${ }^{25}$

Razões para benefícios clínicos limitados da administração de EL contendo óleo de peixe em pacientes cirúrgicos, seja como parte da terapia nutricional parenteral ou como imuno-fármaco-nutriente, podem incluir a duração insuficiente de sua infusão, para se usufruir das propriedades biológicas do EPA e DHA. As diretrizes europeias e americanas de referência na área de nutrição clínica especializada não incluem recomendações dessa natureza. ${ }^{26,27}$ Conhecer e caracterizar a dinâmica de incorporação leucocitária de AGPI n-3 após a referida infusão pode ser fundamental para estimar o tempo em que esta deve ser estendida, a fim de que benefícios clínicos sejam mais facilmente alcançados.

Buscando contribuir com evidências que norteiem futuramente 0 planejamento de protocolos clínicos de nutrição especializada, o presente estudo avaliou o perfil leucocitário de AGPI n-3 após diferentes períodos do término da infusão parenteral de EL contendo óleo de peixe e alta quantidade de TCM em ratos Lewis. Sua hipótese considerou que a biodisponibilidade leucocitária de AGPI n-3 após infusão parenteral com EL contendo óleo de peixe é curta, porque estes são ativamente utilizados e se esgotam rapidamente ao longo do tempo. Uma vez confirmada essa hipótese, a referida infusão deveria se estender pelo tempo total da resposta imunológica pós-operatória. 


\section{REVISÃO DA LITERATURA}

\subsection{Propriedades biológicas de interesse clínico de EPA e DHA}

No organismo de mamíferos, os lipídios são substratos para a síntese de energia (9,3 Kcal / g), hormônios esteroides e mediadores inflamatórios, participam do transporte de vitaminas lipossolúveis e da estrutura de membranas celulares e de organelas. ${ }^{28}$ Como parte da membrana celular os lipídios influenciam ainda a distribuição de proteínas de superfície, a sinalização proteica e, consequentemente, a ativação de fatores de transcrição gênica. ${ }^{29}$ Isso significa que, além de suas funções biológicas diretas, os lipídios também podem influenciar indiretamente a sinalização e síntese de proteínas.

Particularmente, EPA e DHA têm efeitos biológicos de interesse clínico, que incluem modulação favorável do metabolismo e da resposta imunológica orgânicos. ${ }^{30}$ Alguns desses efeitos advêm da capacidade que EPA e, principalmente, DHA têm de interferir na sinalização de receptores proteicos, via desestruturação de rafts lipídicos (Figura 1). ${ }^{31}$ Esses microdomínios de membrana se caracterizam por seu alto conteúdo de AG saturados (principalmente colesterol), que conferem uma rigidez necessária para a dimerização de receptores proteicos ao longo da membrana celular fluida, durante a sinalização celular. ${ }^{32}$ 


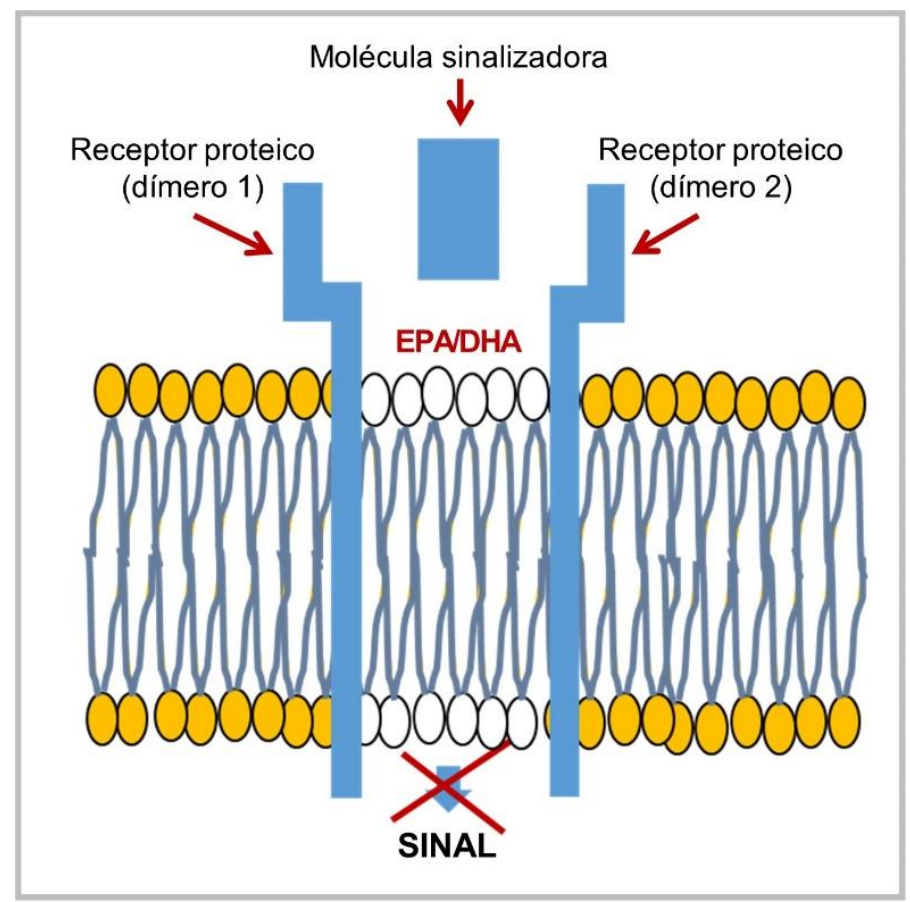

Figura 1. Modulação da sinalização proteica por ácidos eicosapentaenoico (EPA) e docosaexaenoico (DHA) via desestruturação de microdomínios de membrana ricos em colesterol.

Legenda: Parte da sinalização celular depende da junção de dímeros (dimerização) de receptores proteicos (em azul). Microdomínios de membrana (rafts lipídios, em laranja), caracteristicamente rígidos por seu alto conteúdo de colesterol, servem como plataformas para que essa dimerização ocorra. A rigidez desses microdomínios é fundamental para que os dímeros proteicos possam se unir na membrana e sinalizar. Devido ao elevado número de duplas ligações que conferem flexibilidade às suas cadeias carbônicas, ácidos graxos poli-insaturados EPA e, principalmente, DHA interrompem a estrutura rígida de rafts lipídicos ao se incorporarem em membranas celulares, dificultando a dimerização de receptores proteicos e, consequentemente, a sinalização por eles mediada.

EPA, DHA e seus metabólitos podem exercer efeitos anti-inflamatórios e metabólicos favoráveis pela modulação direta e indireta (via rafts lipídicos) da atividade de fatores transcricionais, como o fator nuclear kappa $B(N F \kappa B)$, fator 2 relacionado ao fator nuclear E2 (Nfr2), receptor ativado por proliferador de peroxissoma (PPAR) e proteínas de ligação ao elemento regulador de esterol (SREBP). ${ }^{33-36}$ Essas propriedades permitem que EPA e DHA influenciem a transcrição de genes envolvidos na inflamação, sobrevivência celular, estresse oxidativo e o metabolismo de carboidratos e lipídios (Figura 2). ${ }^{37}$ Por exemplo, através da inibição da atividade de NFkB, EPA e DHA inibem a transcrição de citocinas pró-inflamatórias. ${ }^{3}$ 


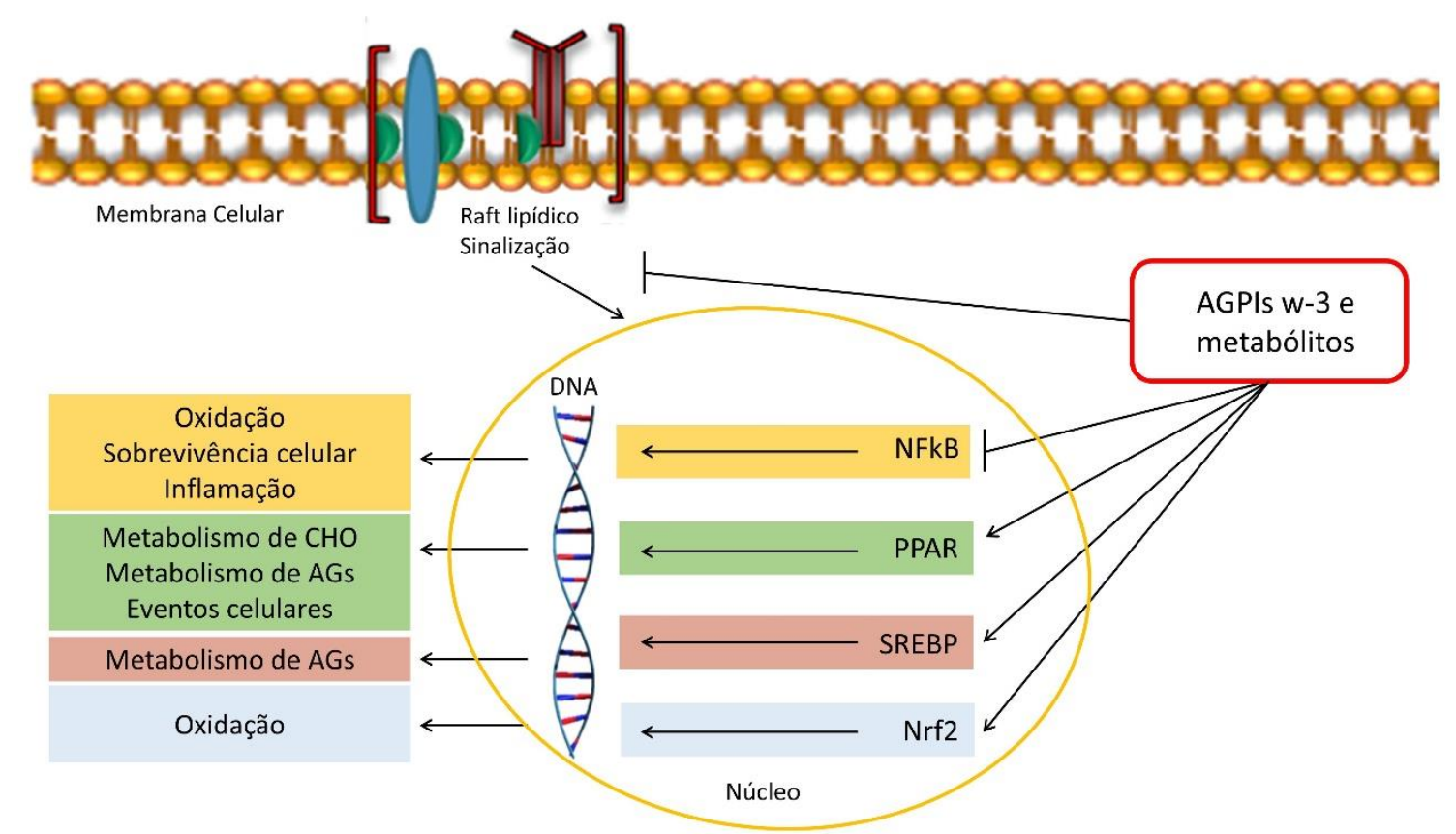

Figura 2. Modulação da transcrição gênica por ácidos graxos poli-insaturados ômega-3 e seus metabólitos.

Legenda: A figura mostra a membrana celular (estrutura superior em amarelo e contorno marrom), com o raft lipídico rico em proteínas de membrana (estruturas em azul e verde) e receptores proteicos (estrutura em cinza e contorno vermelho) destacado num colchete; bem como o núcleo celular (círculo laranja), onde a transcrição gênica ocorre após sucesso da sinalização pelo receptor proteico (mediante dimerização no raft lipídico). Ácidos graxos poliinsaturados ômega-3 (AGPI $\omega$-3) e seus metabólitos podem interferir diretamente ou indiretamente (via desestruturação de rafts lipídicos, com inibição de dimerização de receptores) a sinalização proteica e ativação de fatores de transcrição gênica, como fator nuclear kappa $B$ $\left(N F_{\kappa} B\right)$, receptor ativado por proliferador de peroxissoma (PPAR), proteínas de ligação ao elemento regulador de esterol (SREBP) e o fator nuclear eritroide 2 relacionado ao fator 2 (Nrf2). Esses fatores participam da transcrição de genes que codificam proteínas envolvidas na sobrevivência celular, inflamação, metabolismo de ácidos graxos (AG) e carboidratos (CHO), oxidação, entre outras funções biológicas. Dessa forma AGPI $\omega-3$ podem influenciar 0 metabolismo e a resposta imunológica orgânicos.

Adicionalmente, EPA e DHA são substratos para a síntese de mediadores lipídicos que participam na iniciação e resolução da resposta inflamatória. EPA compete com ARA pelas enzimas lipoxigenase (LOX) e ciclooxigenase (COX) para gerar eicosanoides, mediadores lipídicos envolvidos na ativação da inflamação. ${ }^{3}$ Enquanto ARA é precursor de eicosanóides próinflamatórios, imunossupressores e pró-trombóticos, EPA gera eicosanoides funcionalmente menos intensos e antitrombóticos. Por exemplo, o LTB5 derivado de EPA tem potencial quimiotático 10 a 30 vezes menos potente sobre neutrófilos do que o LTB4 derivado de AA. ${ }^{38}$ EPA e DHA também são precursores de resolvinas e DHA é precursor de protectinas e maresinas. Esses mediadores lipídicos, coletivamente chamados de mediadores especializados 
pró-resolução (SPM), têm papel relevante na resolução da inflamação e na restauração da homeostase. ${ }^{39}$ A Figura 3 ilustra a participação de EPA e DHA na síntese de mediadores inflamatórios lipídicos.

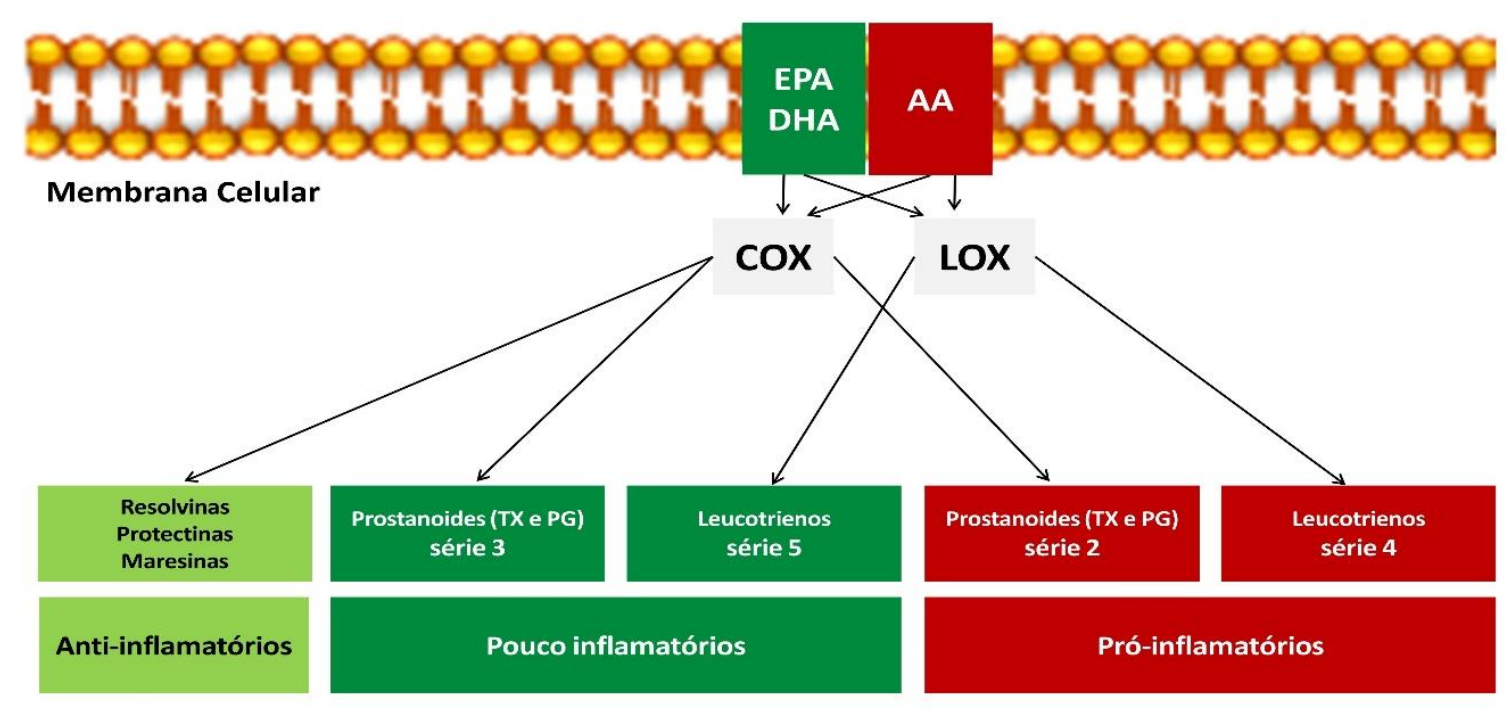

Figura 3. Competição para a síntese de mediadores lipídicos entre ácidos graxos ômega-3 e ácido araquidônico (ômega-6) (Adaptado de: Wendel \& Heller, 2009) $)^{40}$

Legenda: Após quebra de barreira, lesão tecidual ou trauma, eicosanoides são mediadores cruciais dos eventos celulares que iniciam a inflamação. A síntese desses mediadores ocorre através das vias da cicloxigenase (COX) e lipoxigenase (LOX), pelas quais competem o ácido eicosapentaenoico (EPA) e o ácido araquidônico (AA). Consequentemente, a biodisponibilidade celular de EPA diminui a geração de eicosanoides produzidos por AA, que incluem prostaglandinas (PG) E2, tromboxano (TX) 2 e leucotrieno B4. Esses eicosanoides estão envolvidos na vasodilatação e na quimiotaxia e adesão leucocitárias, eventos que estimulam a migração de neutrófilos para o tecido lesado. Como parte da sequência neutrófilos-monócitos da inflamação, os eicosanoides deixam de ser produzidos pra dar início à síntese de resolvinas, protectinas e maresinas, mediadores lipídicos provenientes de EPA e ácido docosaexaenoico (DHA). Esses mediadores lipídicos inibem a ativação e migração de neutrófilos, promovem a migração de monócitos para remoção de resquícios celulares e antígenos remanescentes, inibem a liberação de mediadores inflamatórios e regeneram tecidos lesados, permitindo que estes retornem à homeostase. Portanto, mediadores lipídicos têm papéis cruciais do início à resolução da resposta inflamatória e AGPI n-3 propiciam a produção dos mediadores dessa classe com potencial anti-inflamatório e reparador.

As resolvinas e protectinas são liberadas durante a comunicação célulacélula na fase de resolução inflamatória, via biossíntese transcelular, e participam do controle endógeno da inflamação. ${ }^{39,41-44}$ As maresinas são conjugados de sulfido sintetizados por macrófagos, que também participam da resolução da inflamação aguda e parecem promover regeneração tecidual. ${ }^{45} \mathrm{~A}$ biossíntese de maresina 1 envolve um intermediário ativo (13S,14S-epoxi-DHA), que estimula a conversão de macrófagos com fenótipo M1 para M2. ${ }^{46}$ Essa 
conversão está associada à origem de macrófagos com função reparadora e anti-inflamatória.

Graças às suas propriedades peculiares, resolvinas, protectinas e maresinas provenientes de AGPI n-3 inibem a ativação de leucócitos polimorfonucleares e estimulam o recrutamento de monócitos não inflamatórios, que eliminam resquícios provenientes de apoptose de neutrófilos (eferocitose). Esses SPM participam ainda do sequestro de citocinas pró-inflamatórias e remoção de outros resíduos (como restos de micro-organismos invasores), propiciando que a estrutura normal e homeostase teciduais possam ser restauradas. ${ }^{41-45}$

A falha da resolução inflamatória pode levar ao aumento dos níveis de prostaglandinas e leucotrienos, inflamação crônica e fibrose. Ao contra regular mediadores pró-inflamatórios, SPM reduzem a magnitude e duração da inflamação, e estimulam a re-epitelização, a cicatrização de feridas e a regeneração de tecidos em modelos experimentais. ${ }^{46}$ Notadamente, os SPM se distinguem de agentes anti-inflamatórios já conhecidos por promoverem a defesa orgânica. A descoberta desses mediadores lipídicos fornece novas evidências da participação de AGPI n-3 na homeostase, resolução da inflamação, cicatrização de feridas e prevenção do câncer. ${ }^{46}$

\subsection{Importância da suplementação de EPA e DHA em cirurgia}

Diante da relevância biológica dos lipídios em mamíferos, não surpreende $o$ fato de seus organismos terem maquinarias sofisticadas para a síntese de AG, quando seu suprimento dietético é insuficiente. AG saturados e monoinsaturados podem ser gerados endogenamente a partir de glicose e aminoácidos, através de reações de elongamento enzimático (adição de dois átomos de carbonos) e dessaturação (criação de novas duplas-ligações). ${ }^{28}$ No entanto, a ausência das enzimas $\Delta-12$ e $\Delta$-15 dessaturases em mamíferos impede a adição de duplas-ligações antes do nono carbono que antecede a extremidade carboxílica de ácidos graxos, para a síntese dos AGPI n-6 ácido linoleico (ALN) e n-3 alfa-linolênico (ALA). ${ }^{2}$

Consequentemente, ALN e ALA são obtidos por mamíferos exclusivamente a partir da dieta e, portanto, chamados de AG essenciais. Após 
ingestão, estes competem por processos enzimáticos de elongamento $\mathrm{e}$ dessaturação até sua conversão em ARA a partir de ALN e em EPA e DHA a partir de ALA. ${ }^{2} \mathrm{~A}$ síntese endógena de EPA e DHA a partir de seu percursor ALA é muito baixa em humanos, o que torna a ingestão desses AGPI n-3 importante para promover sua disponibilidade orgânica. ${ }^{47}$ Entretanto, esta é muito baixa em países ocidentais ${ }^{4}$ e sua suplementação pode ser necessária. Particularmente, a suplementação de EPA e DHA como terapia adjuvante no tratamento de diferentes afecções tem sido considerada, principalmente aquelas que envolvem distúrbios inflamatórios.

Em humanos e modelos experimentais, a resposta imunológica à cirurgia se caracteriza por aumento dos níveis sistêmicos de mediadores imunológicos e proteínas de fase aguda, que culminam em inflamação excessiva e consequente aumento do catabolismo e estresse oxidativo.48,49 Uma resposta contrarreguladora também é reportada e pode culminar em disfunções leucocitárias. ${ }^{48,49}$ Por exemplo, níveis elevados de IL-6 são observados após procedimentos cirúrgicos e podem induzir a produção contrarreguladora de prostaglandinas (PG), como a PGE2 (derivada do AGPI n-6 ARA). Os efeitos de PGE2 incluem inibição da mitogênese de células $T$, da produção de IL-2 e da expressão de seus receptores, da síntese de fator de necrose tumoral-alfa (TNFa) e IL-1 por macrófagos e estímulo da liberação excessiva da potente citocina anti-inflamatória IL-10.50,51 Em casos mais graves, essas alterações podem evoluir para o desenvolvimento de síndrome da resposta inflamatória sistêmica (SIRS) e sepse, as maiores causas de mortes pós-operatórias. ${ }^{10}$

Devido às propriedades biológicas de EPA e DHA, potencialmente antiinflamatórias, a suplementação desses AGPI n-3 em cirurgia transcende seu valor nutricional e constitui potencial ferramenta para modular favoravelmente essas respostas ao estresse orgânico. ${ }^{52}$

\subsection{Importância da via parenteral para a biodisponibilidade orgânica de EPA e DHA em cirurgia}

Pacientes cirúrgicos podem receber a suplementação de EPA e DHA pelas vias oral/enteral e parenteral. Entretanto, esses AGPI n-3 são incorporados mais rapidamente em fosfolipídios plasmáticos e células sanguíneas quando 
infundidos por via parenteral (1-3 dias), do que quando obtidos por via oral/enteral (4-7 dias). ${ }^{13}$ Além disso, a infusão parenteral de AGPI n-3 evita perdas decorrentes dos processos digestivos e absortivos que se seguem após sua ingestão oral/enteral. Na prática clínica, a suplementação parenteral de AGPI n3 é feita pela infusão de EL contendo óleo de peixe, comercialmente disponíveis na Europa, Ásia e América do Sul.

EL comerciais contendo óleo de peixe são compostas apenas por óleo de peixe ou por sua combinação com outras gorduras. ${ }^{3}$ Por ser desprovida de AGPI n-6 essenciais, EL composta apenas por óleo de peixe é normalmente fornecida durante a infusão de EL convencionais, compostas apenas por óleo de soja ou por sua mistura com TCM (1:1 v/v) ou óleo de oliva (2:8 v/v). ${ }^{3} \mathrm{~A}$ infusão de EL contendo óleo de peixe visa aumentar a disponibilidade orgânica de EPA e DHA e viabilizar a infusão de menores razões entre os AGPI n-3:n-6 do que aquelas disponibilizadas pela infusão exclusiva de EL convencionais, que contém elevado conteúdo de AGPI n-6. ${ }^{3}$

Atualmente, EL composta por $50 \%$ de TCM, $40 \%$ de óleo de soja e $10 \%$ de óleo de peixe, na concentração de $20 \%$ de gordura (Lipidem/Lipoplus ${ }^{\circledR}$. B. Braun, Melsungen, Alemanha), encontra-se disponível para prática clínica. Seu desenho se ampara no fato de que a infusão combinada de óleo de peixe com TCM pode melhorar a depuração circulatória e a distribuição celular de AGPI n3 , por envolver vias mais eficientes de remoção de partículas lipídicas. ${ }^{15}$ Além disso, AGPI n-3 infundidos na presença de TCM podem ser teoricamente poupados para a síntese de energia, permanecendo disponíveis para outras funções celulares (como para a síntese de mediadores inflamatórios). Ocorre que TCM usualmente dispensam a ação da proteína carnitina para atravessarem a membrana mitocondrial e, portanto, constituem substrato energético lipídico preferencial pela organela. ${ }^{14}$ Ressalta-se que benefícios sobre marcadores de funções imunológicas e inflamatórios após infusão de EL exclusivamente composta por óleo de peixe em ratos foram maiores quando esta foi administrada em associação com EL ricas em TCM, do que de forma isolada. ${ }^{53-57}$ 


\subsection{Resultados clínicos da administração parenteral de óleo de peixe rica em TCM em cirurgia}

A avaliação clínica de Lipidem/Lipoplus ${ }^{\circledR}$ em pacientes cirúrgicos incluiu apenas sua infusão pós-operatória exclusiva, como parte da terapia nutricional parenteral (Tabela 1). Esta foi bem tolerada e, em comparação com a infusão de EL de óleo de soja ou EL contendo mistura de óleo de soja e TCM, se associou ao aumento de níveis de EPA e DHA em fosfolipídios plasmáticos e à incorporação de EPA em hemácias. ${ }^{20,21,58,59}$ A infusão de Lipidem/Lipoplus ${ }^{\circledR}$ se associou ainda a um perfil sistêmico favorável de citocinas, leucotrienos e antioxidantes, com diminuição de IL-6, TNF- $\alpha$ e aumento de leucotrieno (LT) B5 e da razão LTB5:LTB4. ${ }^{20-22,59,60}$

Os estudos ora disponíveis confirmam a capacidade de Lipidem/Lipoplus ${ }^{\circledR}$ de aumentar a biodisponibilidade circulante e celular de EPA e DHA, em relação a EL convencionais sem adição de óleo de peixe. Entretanto, resultados de seu impacto sobre a incidência de infecções, SIRS e tempo de internação hospitalar,

são modestos e heterogêneos. ${ }^{20-22,58} \mathrm{~A}$ infusão de Lipidem/Lipoplus ${ }^{\circledR}$ apenas no pós-operatório pode ter influenciado a ausência de melhores desfechos clínicos em alguns desses estudos, ao considerar que o enriquecimento de células leucocitárias com AGPI estava ausente no momento do estresse cirúrgico.

Entretanto, a heterogeneidade de resultados clínicos reportados após infusão de Lipidem/Lipoplus ${ }^{\circledR}$ pode se relacionar também a um período insuficiente de suplementação para se alcançar uma imunomodulação efetiva. Ocorre que, por participarem de diversas vias biológicas, a utilização leucocitária de AGPI n-3 deve ser elevada. Nesse cenário, a sua biodisponibilidade pode se esgotar em curto prazo e não corresponder ao tempo de duração das alterações imunológicas induzidas pela cirurgia. Essas considerações sugerem um potencial valor clínico de se compreender a dinâmica da biodisponibilidade leucocitária de AGPI n-3 em pacientes cirúrgicos após infusão de EL contendo óleo de peixe, para planejar sua duração. 
Tabela 1. Resultados imunomoduladores e clínicos de estudos sobre a infusão pós-operatória de emulsão lipídica com óleo de peixe e rica em triglicerídeos de cadeia média em pacientes cirúrgicos

\begin{tabular}{|c|c|c|c|}
\hline Referência & $\mathbf{n}$ & Controle & $\begin{array}{l}\text { Resultados imunológicos e de desfechos } \\
\text { clínicos }\end{array}$ \\
\hline 20 & 256 & LCT & $\begin{array}{l}\text { Seguro e bem tolerado, maiores níveis } \\
\text { circulantes de EPA, LTB5 e antioxidantes e } \\
\text { menor tempo de internação hospitalar. }\end{array}$ \\
\hline 21 & 30 & LCT & $\begin{array}{l}\text { Maiores níveis circulantes de LTB5, com } \\
\text { aumento da razão LTB5/LTB4. }\end{array}$ \\
\hline 22 & 64 & LCT/MCT & $\begin{array}{l}\text { Menores níveis circulantes de bilirrubina, IL-6, } \\
\text { TNF-alfa e atividade de NFkB, maior razão de } \\
\text { LTB5/LTB4 e tempo de tromboplastina, sem } \\
\text { diferença nos níveis circulantes de PCR IL-1, } \\
\text { IL-8, IL-10 e VEGF, na distribuição de } \\
\text { subpopulações de células T e em desfechos } \\
\text { clínicos, que incluíram complicações } \\
\text { infecciosas e incidência de SIRS. }\end{array}$ \\
\hline 58 & 16 & LCT/MCT & $\begin{array}{l}\text { Seguro e bem tolerado, maiores níveis } \\
\text { circulantes de EPA e DHA e diminuiçãa não } \\
\text { significativa de tempo de internação na UTI e } \\
\text { hospitalar. }\end{array}$ \\
\hline 59 & 40 & LCT/MCT & $\begin{array}{l}\text { Seguro e bem tolerado, maior incorporação } \\
\text { EPA e DHA nos fosfolípides séricos e de } \\
\text { eritrócitos e sem alteração de ARA nesses } \\
\text { nichos biológicos. }\end{array}$ \\
\hline 60 & 64 & LCT/MCT & $\begin{array}{l}\text { Maior LTB5/LTB4 e índice APACHE, menores } \\
\text { níveis de PCR, taxas de infecções, incidência } \\
\text { de SIRS e tempo de internação hospitalar }\end{array}$ \\
\hline
\end{tabular}

Legenda: IL, interleucina; LCT, emulsão lipídica parenteral de óleo de soja; LCT/MCT, emulsão lipídica parenteral de mistura de óleo de soja e triglicerídeos de cadeia média do óleo de coco; LT; leucotrieno; NFkB, fator de transcrição nuclear kB; PCR, proteína $C$ reativa; SIRS; síndrome da resposta inflamatória sistêmica; TNF, fator de necrose tumoral; VEGF, fator de crescimento endotelial vascular

\subsection{Justificativa do estudo}

Células leucocitárias participam da síntese de mediadores inflamatórios e são susceptíveis a seus efeitos. Estudos disponíveis sobre o efeito da infusão parenteral de EL contendo óleo de peixe em pacientes cirúrgicos sugerem sua relevância em prover biodisponibilidade leucocitária de AGPI n-3, principalmente quando acrescidas de TCM, para atenuação do impacto da cirurgia sobre a 
resposta imunológica. ${ }^{3}$ Sabe-se que o período de 3 dias de infusão parenteral de EL com óleo de peixe é suficiente para promover a incorporação celular de AGPI n-3 em modelos animais e em humanos e que sua biodisponibilidade em pacientes cirúrgicos pode ser relevante para promover melhores desfechos clínicos. ${ }^{13}$ Entretanto, não se conhece o tempo de disponibilidade leucocitária desses AGPI após o término da infusão parenteral de EL contendo óleo de peixe, para determinar o momento em que esta pode ser interrompida sem minimizar benefícios clínicos. O presente estudo pretendeu contribuir com evidências científicas que auxiliem o preenchimento dessa lacuna do conhecimento em terapia parenteral especializada. Como parte da produção acadêmico-científica do Departamento de Cirurgia do Aparelho Digestivo, acredita-se que seus dados possam ser particularmente úteis para aprimorar condutas terapêuticas aplicadas pelo referido Departamento a pacientes com indicação de terapia nutricional parenteral, o que justificou seu desenvolvimento. 


\section{OBJETIVOS}

\subsection{Objetivo Geral}

Avaliar o perfil de ácidos graxos poli-insaturados leucocitários, plasmáticos e hepáticos de ratos Lewis submetidos à cateterização cirúrgica do sistema venoso central, após diferentes tempos do término da infusão parenteral de emulsão lipídica contendo óleo de peixe.

\subsection{Objetivos Específicos}

\subsubsection{Primários:}

Avaliar o conteúdo de EPA, DHA e ARA em leucócitos mono e polimorfonucleares do sangue de ratos Lewis submetidos à cateterização cirúrgica do sistema venoso central, após diferentes tempos do término de infusão parenteral de emulsão lipídica contendo óleo de peixe - como parâmetro para identificar a dinâmica da biodisponibilidade leucocitária desses AGPI após a referida infusão.

Avaliar a razão n-3:n-6 em leucócitos mono e polimorfonucleares do sangue de ratos Lewis submetidos à cateterização cirúrgica do sistema venoso central, após diferentes tempos do término de infusão parenteral de emulsão lipídica contendo óleo de peixe - como parâmetro para compreender o impacto da dinâmica da biodisponibilidade leucocitária de AGPI sobre o fenótipo inflamatório leucocitário.

\subsubsection{Secundário}

Avaliar o conteúdo de EPA, DHA e ARA e a razão n-3:n-6 no plasma e tecido hepático de ratos Lewis submetidos à cateterização cirúrgica do sistema venoso central, após diferentes tempos do término da infusão parenteral de emulsão lipídica contendo óleo de peixe - como parâmetro para caracterizar a dinâmica compartimental orgânica dessas variáveis. 


\section{MÉTODOS}

\subsection{Local de Execução do estudo}

Desenvolveram-se as atividades experimentais do presente estudo no Laboratório de Investigação Médica em Nutrição e Cirurgia Metabólica do Aparelho Digestivo (LIM-35), do Departamento de Gastroenterologia da Faculdade de Medicina da Universidade de São Paulo (FMUSP), em parceria com o Laboratório de Bromatologia da Faculdade de Saúde Pública da Universidade de São Paulo (análises cromatográficas).

\subsection{Aspectos éticos}

Todos os procedimentos intervencionistas envolvidos no presente estudo atenderam às normas de proteção e cuidados aos animais de experimentação da Comissão de Ética em Pesquisa da Faculdade de Medicina da Universidade de São Paulo, que aprovou seu protocolo experimental ( $n^{\circ}$ 126/2012e a atualização de seu título em 26/11/2019 (Anexo 1). Particularmente, procedeuse anestesia geral previamente às intervenções cirúrgicas e sacrifício, através de injeção intraperitoneal de cloridrato de Cetamina $80 \mathrm{mg} / \mathrm{kg}$ (Ketamin-S ${ }$, Cristália, Itapira, Brasil) e cloridrato de Xilazina 8,0 mg/kg (Rompun 2\%®, Bayer, Santana de Parnaíba, Brasil).

\subsection{Animais}

Foram utilizados ratos isogênicos Lewis machos $(n=78)$, provenientes do Biotério do Centro Multidisciplinar para Investigação Biológica (CEMIB) da Universidade Estadual de Campinas (UNICAMP). No Biotério do LIM-35, os referidos animais foram mantidos em gaiolas coletivas, até atingirem a idade adulta e tamanho suficiente para viabilizar a cateterização do sistema venoso central (300-450 gramas). Previamente às intervenções do estudo, procedeu-se período de adaptação ao isolamento e ao protocolo experimental, através da manutenção dos animais por cinco dias em gaiolas individuais, com dieta padrão de referência ${ }^{61}$ (AIN-95M, Rhoster, Araçoiaba da Serra, Brasil), água ad libitum, temperatura controlada $\left(20\right.$ e $\left.25^{\circ} \mathrm{C}\right)$ e ciclos diuturnos de luz. Após ambientação, submeteu-se parte dos animais ao sacrifício por punção cardíaca (método descrito no item 4.7) e parte à cateterização da veia jugular direita externa, conforme técnica cirúrgica padronizada por Yamaguchi e cols. (1990). ${ }^{62}$ 


\subsection{Técnica cirúrgica para cateterização do sistema venoso central}

Perante anestesia e após assepsia local com álcool iodado a $2 \%$, triconomizou-se os animais nas regiões ventral e supraclavicular direita/retroauricular dorsal do pescoço, com auxílio de lâmina de aço comum. Com o animal em decúbito dorsal horizontal, realizou-se incisão transversa $(\sim 1,0$ $\mathrm{cm}$ ) na região supra clavicular direita. Posteriormente, com o animal em decúbito ventral e com auxílio de uma agulha Intracath (Biotecno ${ }^{\circledR}$, Biotecno Produtos Plásticos e Médicos Ltda, São Paulo, Brasil), tunelizou-se o tecido subcutâneo a partir da borda distal da incisão, em direção à região dorsal, com exteriorização a $1,0 \mathrm{~cm}$ da região retro auricular. No interior da agulha Intracath inseriu-se um cateter de silicone com 1,0 mm de diâmetro e 70,0 mm de comprimento (Ciencor®, Ciencor Scientific Ltda, São Paulo, Brasil), o qual foi tracionado pelo túnel em direção à incisão ventral.

Ao cateter de silicone conectou-se um dispositivo intermediário, previamente desenvolvido em parceria com a Escola Politécnica da Universidade de São Paulo63, constituído por agulha anatomicamente adequada para ratos soldada a uma pequena peça metálica, contendo duas asas laterais do tipo "borboleta". As asas laterais possuíam dois orifícios paralelos em cada extremidade, que viabilizaram a fixação da peça intermediária no dorso do animal, por meio de dois pontos separados. Esses pontos foram efetuados com fio mononylon 3-0 estéril, agulhado e não absorvível (Shalon $\AA$, Shalon suturas, São Luís de Montes Belos, Brasil) e atravessaram a pele e tecido subcutâneo.

Posteriormente, com os animais em decúbito dorsal, procedeu-se a identificação, dissecção e reparo da veia jugular direita com fio de algodão torcido 4-0, estéril, pré-cortado, não absorvível e não agulhado (PolycotEthicon®, J\&J ETHICON, Nova Jersey, EUA). A veia jugular externa foi então ligada distalmente e cateterizada na sua porção proximal pelo tubo de silicone posicionado anteriormente, contendo solução fisiológica (BBraun, São Gonçalo, Brasil) com 5\% de heparina (Blau Farmacêutica, Cotia, Brasil). Finalmente, procedeu-se a sutura contínua da incisão cutânea, com fio mononylon 3-0 (Shalon®, Shalon suturas, São Luís de Montes Belos, Brasil), e sua assepsia, com álcool iodado 2\% (Rioquímica, São José do Rio Preto, Brasil). 


\subsection{Infusão Parenteral}

Os animais submetidos à cateterização do sistema venoso central foram distribuídos em gaiolas metabólicas individuais, conectando-se o dispositivo intermediário "borboleta" ao intermediário de infusão, denominado swível. Também previamente desenvolvido pela Escola Politécnica da Universidade de São Paulo63, o swível girava em torno de seu eixo e permitiu a livre movimentação do animal. Ao swível conectou-se um perfusor de infusão gravitacional (Space ${ }^{\circledR}$, BBraun, Melsugen, Alemanha) de $150 \mathrm{~cm}$, específico para a bomba de infusão modelo seringa. Através do uso desses artefatos, procedeu-se infusão parenteral contínua de $6 \mathrm{~mL}$ de solução salina $0,9 \%$, na velocidade de $0,25 \mathrm{~mL} / \mathrm{h}$, durante as primeiras 24 horas após a cateterização, para adaptação ao estresse cirúrgico.

Posteriormente, administrou-se infusão parenteral de EL por mais 72 horas, de maneira a oferecer $4,3 \mathrm{~g}$ de gordura/ $\mathrm{kg}$ de peso corpóreo $(\sim 6 \mathrm{~mL})$ na velocidade de $0,25 \mathrm{~mL} / \mathrm{h}^{64}$. As EL parenterais infundidas foram $\mathrm{EL}$ contendo $50 \%$ de óleo de soja e 50\% de TCM de óleo de coco (TCM/TCL; Lipofundin® $20 \%$, BBraun, Melsugen, Alemanha) e EL contendo $40 \%$ de óleo de soja, $50 \%$ de TCM de óleo de coco e 10\% de óleo de peixe (TCM/TCL/OP; Lipidem ${ }^{\circledR} 20 \%$, BBraun, Melsugen, Alemanha), cujos conteúdos de ácidos graxos em suas formulações encontram-se descritos na Tabela 2. Parte dos animais cateterizados, não recebeu infusão parenteral de nenhuma solução em nenhum momento do estudo, permanecendo 72 horas apenas com dieta oral como fonte nutricional. Durante todo o período do estudo todos os animais permaneceram com dieta oral AIN-93M. 
Tabela 2. Composição de ácidos graxos (\%) das emulsões lipídicas controle (Lipofundin ${ }^{\circledR}$ ) e experimental (Lipidem ${ }^{\circledR}$ )

\begin{tabular}{|c|c|c|}
\hline Ácido Graxo & Lipofundin $\otimes^{*}$ & Lipidem $\AA^{*}$ \\
\hline Ácido Caprílico (C8:0) & 25,6 & 26,2 \\
\hline Ácido Cáprico (C10:0) & 19,3 & 19,7 \\
\hline Ácido Palmítico (C16:0) & 7,2 & 6,1 \\
\hline Ácido Esteárico (C18:0) & 2,8 & 2,6 \\
\hline Ácido Oleico (C18:1n-9) & 13,0 & 11,4 \\
\hline Ácido Linoleico (C18:2n-6) & 26,8 & 21,9 \\
\hline Ácido Alfa-linolênico (C18:3 n-3) & 3,4 & 2,8 \\
\hline Ácido Estearidônico (C18:4 n-3) & - & 0,2 \\
\hline Ácido Eicosatetraenoico (C20:4 n-3) & - & 0,2 \\
\hline Ácido Araquidônico (C20:4 n-6) & 0,3 & 0,4 \\
\hline Ácido Eicosapentaenoico (C20:5 n-3) & - & 3,3 \\
\hline Ácido docosanoico (C22:0) & - & 0,2 \\
\hline Ácido docosapentaenoico (C22:5 n-3) & 0,2 & 0,6 \\
\hline Ácido docosaexaenoico (C22:6 n-3) & & 2,5 \\
\hline Outros & 1,4 & 2,1 \\
\hline \multicolumn{3}{|c|}{ Total $(\mathbf{g} / \mathbf{L})^{\star}$} \\
\hline Triglicerídeos de cadeia média & 97,6 & 97,6 \\
\hline Ácidos graxos monoinsaturados ômega-9 & 23,4 & 20,4 \\
\hline Ácidos graxos poli-insaturados ômega-6 & 48,3 & 39,2 \\
\hline Ácidos graxos poli-insaturados ômega-3 & 6,4 & 17,1 \\
\hline Razão ômega-3:ômega:6 & $1: 7$ & $1: 2,7$ \\
\hline
\end{tabular}

*Valores fornecidos pelo fabricante (BBraun, Melsungen - Alemanha)

\subsection{Grupos experimentais}

Conforme ilustra a Figura 4, de acordo com a presença ou não de cateterização do sistema venoso central, infusão parenteral e tipo de solução infundida, dividiu-se os animais em 4 diferentes grupos: 1. Grupo Controle Basal (CB) - animais sacrificados imediatamente antes após o período de adaptação, não submetidos à cateterização do sistema venoso central $(n=6) ; 2$. Grupo Controle Cirúrgico (CC) - animais submetidos à cateterização e que não 
receberam infusão parenteral $(n=24) ; 3$. Grupo Emulsão Controle $(E C)$ - animais submetidos à cateterização e que receberam infusão parenteral de TCM/TCL (n = 24); 4. Grupo Emulsão Teste (OP) - animais submetidos à cateterização e que receberam infusão parenteral de TCM/TCL/OP $(n=24)$, para enriquecimento celular com AGPI n-3. Sacrificou-se todos os animais submetidos à cateterização do sistema venoso central em 4 períodos distintos: 0 (T0), 2 (T2), 6 (T6) e 12 (T12) horas após o tempo correspondente ao término da infusão parenteral de EL, de tal forma que cada grupo foi constituído de 6 animais (24 animais por grupo / 4 tempos de sacrifício).

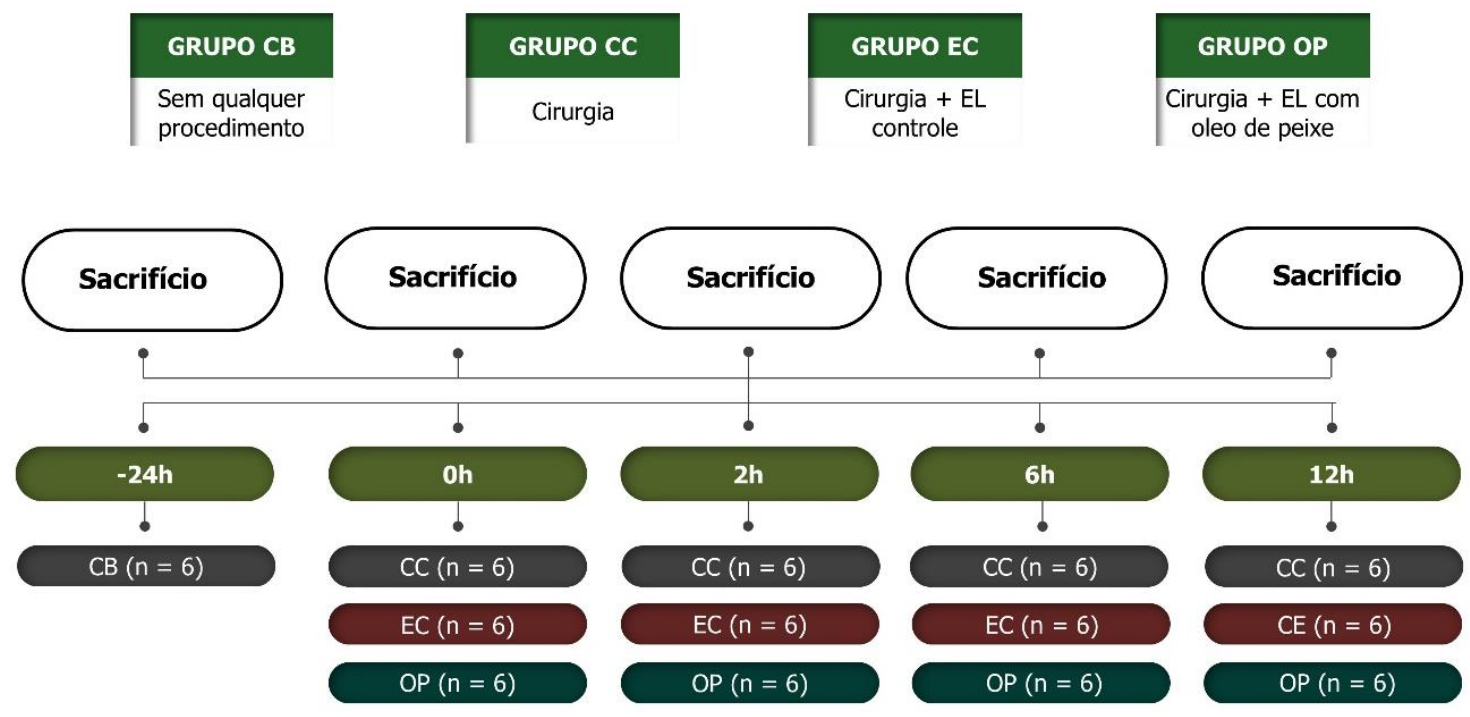

Figura 4. Fluxograma dos grupos experimentais, distribuídos de acordo com os procedimentos cirúrgicos (cataterização venosa) e nutricionais.

Legenda: EL, emulsão lipídica

\subsection{Obtenção de amostras de plasma, fígado e leucócitos}

Os animais foram sacrificados por punção cardíaca, para a coleta de sangue total em tubo seco de coleta a vácuo (Vacutainer, Becton Dickinson Company - BD, Juiz de Fora, Brasil) acrescido de 0,2 $\mathrm{mL}$ de heparina (Heparina, Blau Farmacêutica, Cotia, Brasil). Imediatamente após esse procedimento, procedeu-se incisão ventral e retirada do fígado.

Submeteu-se as amostras de sangue à centrifugação (10 min, 1800 rpm, $20^{\circ} \mathrm{C}$ ), para obtenção de plasma. Parte do plasma foi adicionada a tubo de 10 
$\mathrm{mL}$ (Eppendorf $\circledast$, Eppendorf, São Paulo, Brasil) e imediatamente armazenada à $-80^{\circ} \mathrm{C}$, para futuras análises. A outra parte foi diluída em solução fisiológica (1:1 $\mathrm{v} / \mathrm{v})$, acrescida cuidadosamente a tubos contendo Ficoll Hypaque $(1: 1 \mathrm{v} / \mathrm{v}) \mathrm{com}$ densidades específicas para isolar leucócitos mononucleares (Histopaque® 1083, Sigma-Aldrich, St. Louis, EUA) e polimorfonucleares (Polymorphpred ${ }^{\circledR}$ 1113, Sigma-Aldrich, St. Louis, EUA) e centrifugada (30 min, 1800 rpm, temperatura ambiente). Com o auxílio de pipeta do tipo Pasteur (Kasvi, Importado por Kasvi Brasil, EUA), coletou-se então as nuvens de leucócitos formadas na interface com elementos figurativos do sangue e procedeu-se sua ressuspensão em tampão fosfato-salina-PBS (Kasvi, Importado por Kasvi Brasil, China) e transferência para tubos de $10 \mathrm{~mL}$ (Eppendorf $\circledast$, Eppendorf, São Paulo, Brasil), para armazenamento em freezer à $-80^{\circ} \mathrm{C}$, até o momento de suas análises.

Com o auxílio de lâmina de aço comum, fatiou-se o fígado coletado na sua porção posterior direita, e inseriu-se o fragmento obtido em tubos criogênicos de $2 \mathrm{ml}$ (Kasvi, Importado por Kasvi Brasil, Canadá), para armazenamento em nitrogênio líquido, até o momento de sua análise.

\subsection{Peso corpóreo e ingestão de dieta oral}

Mensurou-se o peso corpóreo e a ingestão de dieta oral com o auxílio de balança analítica (Acrimet, H.K. №211724.0, Barueri, Brasil), tarada pelo peso de recipiente específico para contenção do animal ou de caçapa contentora da dieta, respectivamente.

Aferiu-se o peso corpóreo dos animais imediatamente após o período de adaptação (peso inicial) e no dia específico da eutanásia (peso final). A partir dessas medidas, calculou-se alterações do peso corpóreo, através da aplicação da seguinte fórmula: peso final - peso inicial/peso inicial. Os valores obtidos positivos e negativos indicaram ganho e perda de peso, respectivamente.

Mensurou-se a ingestão de dieta oral imediatamente após o período de adaptação ambiental (pré-operatória), após o período de adaptação ao estresse cirúrgico (pós-operatória) e ao longo de todo o período de infusão parenteral/seguimento até o dia da eutanásia (seguimento), subtraindo-se o peso do conteúdo residual do total de dieta oferecido (sempre 20g). Para fins comparativos, obteve-se uma medida única representativa da ingestão de dieta 
durante o período "seguimento", que correspondeu à média dos dados obtidos dessa variável ao longo de toda a infusão parenteral (grupos CE e OP) / tempo de seguimento pós-operatório (grupo $\mathrm{CC}$ ).

Como os animais do grupo $\mathrm{CB}$ foram submetidos à eutanásia imediatamente após o período de adaptação, obteve-se apenas uma medida de peso corpóreo e de ingestão de dieta oral de cada um de seus integrantes.

\subsection{Variáveis biológicas estudadas}

\subsubsection{Perfil de AGPI plasmáticos, hepáticos e leucocitários}

Avaliou-se o perfil de AGPI de células leucocitárias a partir de duplicatas de pools de 6 ratos por cromatografia gasosa, em aparelho cromatógrafo (Agilent 7890 A GC System ${ }^{\circledR}$, Agilent Technologies, Califórnia, EUA), equipado com coluna capilar de $60 \mathrm{~m} \times 250 \mu \mathrm{m} \times$ 0,15 $\mu \mathrm{m}$ (Agilent 122-2361 J\&W DB-23®, Agilent Technologies, Califórnia, EUA) de alta resolução e detector de ionização em chama (FID). Aplicando-se as mesmas metodologias de esterificação e condições de análise cromatográfica, também se analisou o perfil de AGP de amostras individuais de plasma e fígado individuais (não em pool). Cabe ressaltar, entretanto, que amostras de fígado tiveram uma etapa de processamento adicional às demais para extração de lipídios: previamente à esterificação de ácidos graxos, $100 \mathrm{~g}$ de tecido hepático foram acrescidos de $500 \mu \mathrm{L}$ de solução $\mathrm{KCl}$ a $0,88 \%$ (Synth $\AA$, Synth, Diadema, Brasil) e homogeneizados em mini turrax.

\subsubsection{Preparo das amostras}

Para obtenção dos ésteres metílicos de ácidos graxos das amostras utilizou-se metodologia proposta por Shirai e cols. (2005) ${ }^{65}$. Em um tubo de 15 $\mathrm{mL}$ adicionou-se $1 \mathrm{~mL}$ de solução $\mathrm{NaOH}$ 0,5 M (Synth ${ }^{\circledR}$, São Paulo, Brasil) em metanol (Synth ${ }^{\circledR}$, Synth, Diadema, Brasil) a $500 \mu \mathrm{L}$ de amostra e se procedeu homogeneização com uso de vórtex (15 seg), aquecimento em banho maria à $100 \mathrm{C}$ (5 min) e resfriamento à temperatura ambiente. Foram então adicionados $2 \mathrm{~mL}$ de BF3-Metanol (14\%, Sigma ${ }^{\circledR}$, Sigma-Aldrich, St. Louis, EUA), seguido por agitação em vórtex (15 seg), aquecimento em banho maria à $100 \stackrel{\circ}{\circ}$ (30 min) e resfriamento à temperatura ambiente. Em seguida, adicionou-se $1 \mathrm{~mL}$ de 
isoctano e efetuou-se agitação em vórtex (30 seg). Adicionou-se então $5 \mathrm{~mL}$ de solução saturada de $\mathrm{NaCl}$ (Synth ${ }^{\circledR}$, Synth, São Paulo, Brasil) e procedeu-se agitação manual vigorosa (30 seg). Após separação de fases, transferiu-se a camada superior obtida para tubo eppendorf, para proceder a evaporação do isoctano com nitrogênio gasoso. Ressuspendeu-se o resíduo seco com $120 \mu \mathrm{L}$ de hexano grau HPLC (Cer®, Merck, São Paulo, Brasil) e homogeneização em vórtex (30 seg).

\subsubsection{Condições da análise cromatográfica}

As condições cromatográficas empregadas foram feitas de acordo com Iverson e cols. $(2001)^{66}$. Algumas adaptações específicas foram necessárias para promover as análises das amostras do estudo, de acordo com parâmetros de seletividade, linearidade, precisão e exatidão, limites de detecção e quantificação, e incluíram: injeção em modo split 50:1; temperatura do injetor $250^{\circ} \mathrm{C}$; temperatura do detector $280^{\circ} \mathrm{C}$. As condições de operação da coluna corresponderam à temperatura inicial de $80^{\circ} \mathrm{C}$ ( 1 minuto) e posterior de $230^{\circ} \mathrm{C}$ ( 5 minutos), com tempo total da corrida de 45 minutos.

\subsubsection{Obtenção dos dados}

Os AG foram obtidos por padronização externa, utilizando seus padrões comerciais de referência (Sigma ${ }^{\circledR}$, Sigma Aldrich, Missouri, EUA) para construção da curva de calibração. A análise comparativa entre os picos e áreas dessa curva com os dos cromatogramas gerados durante as análises cromatográficas possibilitou a identificação e quantificação dos AG presentes na amostra, respectivamente. Essas análises buscaram determinar: 1. quantidade e porcentagem (em relação ao conteúdo total de AG) de EPA e DHA; 2. quantidade e porcentagem de ARA; 3. razão AGPI n-3:n-6, cujo cálculo implicou na análise da quantidade de ALA e ALN. Para que os dados gerados fossem incluídos no estudo, os valores de todos os $A G$ estudados precisavam ser obrigatoriamente similares entre as duplicatas de cada amostra.

\subsection{Análises estatísticas}

Devido à utilização de abordagem em pool, com geração de apenas um resultado representativo para cada grupo estudado, as análises do conteúdo leucocitário de AGPI constituíram em avaliações estritamente descritivas. Para 
as demais amostras (plasma e fígado) a análise temporal do conteúdo de AGPI foi efetuada numa abordagem intragrupo e em comparação com seu conteúdo basal (grupo CB). Gráficos das análises descritivas (leucócitos) e comparativas (plasma e fígado) do conteúdo de AGPI foram gerados. Como animais do grupo CB foram sacrificados em apenas um tempo (T0), comparações estatísticas com esse grupo ao longo do tempo foram efetuadas com os dados obtidos nesse único período. A análise temporal (intra e intergrupos) das variáveis de peso corpóreo e ingestão de dieta oral também foi efetuada. Todas as análises comparativas desses dados foram realizadas pela aplicação de pré-teste Kruskal Wallis, seguida do teste das alterações significativas nele encontradas por Wilcoxon. Essas análises e a geração de gráficos foram feitas com auxílio do programa R (versão 3.2.2; R Core Team, Vienna, Austria), considerando-se nível de significância de $5 \%$. 


\section{RESULTADOS}

\subsection{Peso corpóreo e ingestão de dieta oral}

Animais do grupo CB apresentaram peso inicial entre $350-380 \mathrm{~g}$, com valor mediano de $362 \mathrm{~g}$. Os dados de pesos corpóreos observados no dia da cirurgia (inicial) e no momento da eutanásia (final) dos grupos CC, CE e OP nos distintos períodos estudados encontram-se descritos na Tabela 3. O peso corpóreo inicial não diferiu significativamente entre todos os grupos em nenhum dos tempos estudados, exceto que animais do grupo $\mathrm{CC}$ apresentaram maior peso inicial que animais do grupo OP no T6 $(p=0,037)$. Em comparação ao peso corpóreo inicial, animais do grupo CC, OP e CE apresentaram diminuição significativa dessa medida final nos T2, T6 ou T12, respectivamente ( $p \leq 0,035)$. Adicionalmente, animais do grupo CC apresentaram perda de peso significativamente maior do que os do grupo CE no T2 $(p=0,013)$.

Tabela 3. Pesos corpóreos inicial e final de ratos Lewis que receberam ou não infusão parenteral de emulsão lipídica contendo ou não óleo de peixe e sacrificados em tempos distintos de acompanhamento

\begin{tabular}{llccc}
\hline \multirow{2}{*}{ Tempo*$^{*}$} & \multicolumn{3}{c}{ Grupo } \\
\cline { 2 - 5 } & Período & CC & CE & OP \\
\hline \multirow{2}{*}{0 horas } & Cirurgia & $364(358-382)$ & $356(350-377)$ & $354(348-366)$ \\
& Eutanásia & $369(357-390)$ & $357(349-374)$ & $353(345-366)$ \\
\multirow{2}{*}{ horas } & Cirurgia & $367(350-380)$ & $354(316-361)$ & $353(339-370)$ \\
& Eutanásia & $357(349-362)$ & $351(316-368)$ & $357(330-369)$ \\
\multirow{2}{*}{6 horas } & Cirurgia & $373(357-379)$ & $353(315-377)$ & $344(314-370)$ \\
& Eutanásia & $360(353-377)$ & $349(310-371)$ & $340(310-367)$ \\
& Cirurgia & $365(352-380)$ & $389(340-421)$ & $352(312-426)$ \\
& Eutanásia & $359(354-377)$ & $387(335-420)$ & $350(309-423)$ \\
\hline
\end{tabular}

Legenda: *Horas após o último dia de acompanhamento pós-operatório (CC) ou o término da infusão lipídica (grupos CE e OP). Dados expressos como mediana (mínimomáximo) de peso corpóreo em gramas, obtida a partir de 6 animais de cada grupo. CC, animais submetidos à cateterização do sistema venoso central e que não receberam infusão parenteral; CE, animais submetidos à cateterização do sistema venoso central e que receberam infusão parenteral de emulsão lipídica controle, sem óleo de peixe em sua formulação; OP, animais submetidos à cateterização do sistema venoso central e que receberam infusão parenteral de emulsão lipídica contendo óleo de peixe rico em ácidos graxos poli-insaturados ômega-3 em sua formulação. 
No dia imediatamente após o período de adaptação, animais do grupo CB apresentaram ingestão de dieta oral entre $17-20 \mathrm{~g}$, com valor mediano de $19 \mathrm{~g}$. Os dados de ingestão de dieta oral dos grupos CC, CE e OP nos distintos períodos estudados encontram-se descritos na Tabela 4. Todos os animais dos demais grupos comeram menos no primeiro dia pós-operatório, em comparação ao pré-operatório $(p<0,0001)$. Ainda em relação ao pré-operatório, as análises comparativas mostraram uma diminuição da ingestão de dieta oral durante os dias de infusão parenteral/seguimento em animais dos grupos CC (nos T1, T2, T6 e T12; $p \leq 0,035$ ), OP (nos T0, T1, T2 e T6; $p \leq 0,035$ ) e CE (nos T2 e T6; $p$ $\leq 0,035$ ). Além disso, animais do grupo OP tiveram uma menor ingestão de dieta oral que animais do grupo CC no T0 $(p=0,0007)$.

Tabela 4. Ingestão periódica de dieta oral de ratos Lewis que receberam ou não infusão parenteral de emulsão lipídica contendo ou não óleo de peixe e sacrificados em tempos distintos de acompanhamento

\begin{tabular}{cccccc}
\hline \multirow{2}{*}{ Período } & \multicolumn{5}{c}{ Tempo $^{*}$} \\
\cline { 2 - 6 } & Grupo & $\mathbf{0}$ horas & $\mathbf{2}$ horas & $\mathbf{6}$ horas & $\mathbf{1 2}$ horas \\
\hline \multirow{3}{*}{ Pré-operatório } & CC & $20(20-20)$ & $20(20-20)$ & $20(20-20)$ & $20(20-20)$ \\
& CE & $20(20-20)$ & $20(20-20)$ & $20(20-20)$ & $20(20-20)$ \\
& OP & $20(20-20)$ & $20(20-20)$ & $20(20-20)$ & $20(20-20)$ \\
Pós-operatório & CC & $15(07-20)$ & $12(11-15)$ & $13(10-15)$ & $13(11-15)$ \\
& CE & $13(10-20)$ & $15(07-20)$ & $09(09-20)$ & $20(18-20)$ \\
& OP & $13(02-20)$ & $19(15-20)$ & $14(11-20)$ & $20(14-20)$ \\
Sacrifício** $^{*}$ & CC & $20(14-20)$ & $18(17-19)$ & $17(16-18)$ & $17(17-19)$ \\
& CE & $10(04-20)$ & $18(04-19)$ & $16(12-18)$ & $20(19-20)$ \\
& OP & $09(04-16)$ & $17(08-19)$ & $16(15-18)$ & $18(14-20)$ \\
\hline
\end{tabular}

*Horas após o último dia de acompanhamento pós-operatório (CC) ou o término da infusão lipídica (grupos CE e OP). ${ }^{* *}$ Média de 4 dias de ingestão de dieta. Dados expressos como mediana (mínimo-máximo) de peso de dieta oral em gramas obtida a partir de 6 animais de cada grupo. CC, animais submetidos à cateterização do sistema venoso central e que não receberam infusão parenteral; CE, animais submetidos à cateterização do sistema venoso central e que receberam infusão parenteral de emulsão lipídica controle, sem óleo de peixe em sua formulação; OP, animais submetidos à cateterização do sistema venoso central e que receberam infusão parenteral de emulsão lipídica contendo óleo de peixe rico em ácidos graxos poli-insaturados ômega-3 em sua formulação. 


\subsection{Perfil de AGPI}

\subsubsection{Leucocitário}

As quantidades de AGPI identificadas em leucócitos mononucleares e polimorfonucleares do sangue de ratos Lewis em todos os grupos e tempos estudados encontram-se na Figura 5 e Figura 6, respectivamente. Ambas as populações leucocitárias apresentaram quantidades basais muito baixas de EPA, ausentes de DHA e altas de ARA, de acordo com a análise do grupo CB. Entretanto, esses AGPI e suas razões foram sensíveis à cirurgia e ao tipo de EL infundida.

Comparativamente aos animais do grupo CB, no T0 observou-se maior quantidade de DHA em ambas as populações leucocitárias e menor quantidade de EPA na população mononuclear no grupo CC, enquanto o grupo CE apresentou maior quantidade de EPA e DHA nos leucócitos mononucleares e o grupo OP apresentou maior quantidade de DHA nas duas populações leucocitárias e menor de EPA na população mononuclear. Por outro lado, no T2 apenas o grupo OP apresentou quantidades mensuráveis de EPA, enquanto os demais grupos apresentaram ausência de EPA e DHA em ambas as populações leucocitárias. No T6 quantidades leucocitárias de EPA e DHA já estavam ausentes em todos os grupos estudados e, por isso, quantidades de AGPI não foram avaliadas em leucócitos no T12.

Comparativamente aos animais do grupo CB, todos os grupos apresentaram quantidades leucocitárias mais baixas de ARA, após a cirurgia e/ou infusão de EL. Entretanto, a dinâmica dessa alteração diferiu ao longo deles: menores quantidades de ARA foram observadas no T2 (mononucleares) e T0 (polimorfonucleares) no grupo CC, em T2 (ambas as populações leucocitárias) no grupo CE e no T0 (ambas as populações leucocitárias) no grupo FOLE. Especificamente, nos leucócitos mononucleares, a quantidade de ARA foi maior no grupo SC no T0 e T2 do que a observada nos outros grupos nesses períodos.

As alterações observadas nas quantidades de EPA, DHA e ARA resultaram em alterações da razão n-3:n-6 leucocitária. Comparativamente aos animais do grupo CB, no T0 observou-se maior razão n-3:n-6 em ambas as populações de leucócitos nos grupos OP e CC e apenas em leucócitos 
mononucleares no grupo CE. Entretanto, a relação n-3:n-6 foi maior no grupo OP do que nos demais grupos em ambos T0 (ambas populações de leucócitos) e T2 (leucócitos mononucleares).

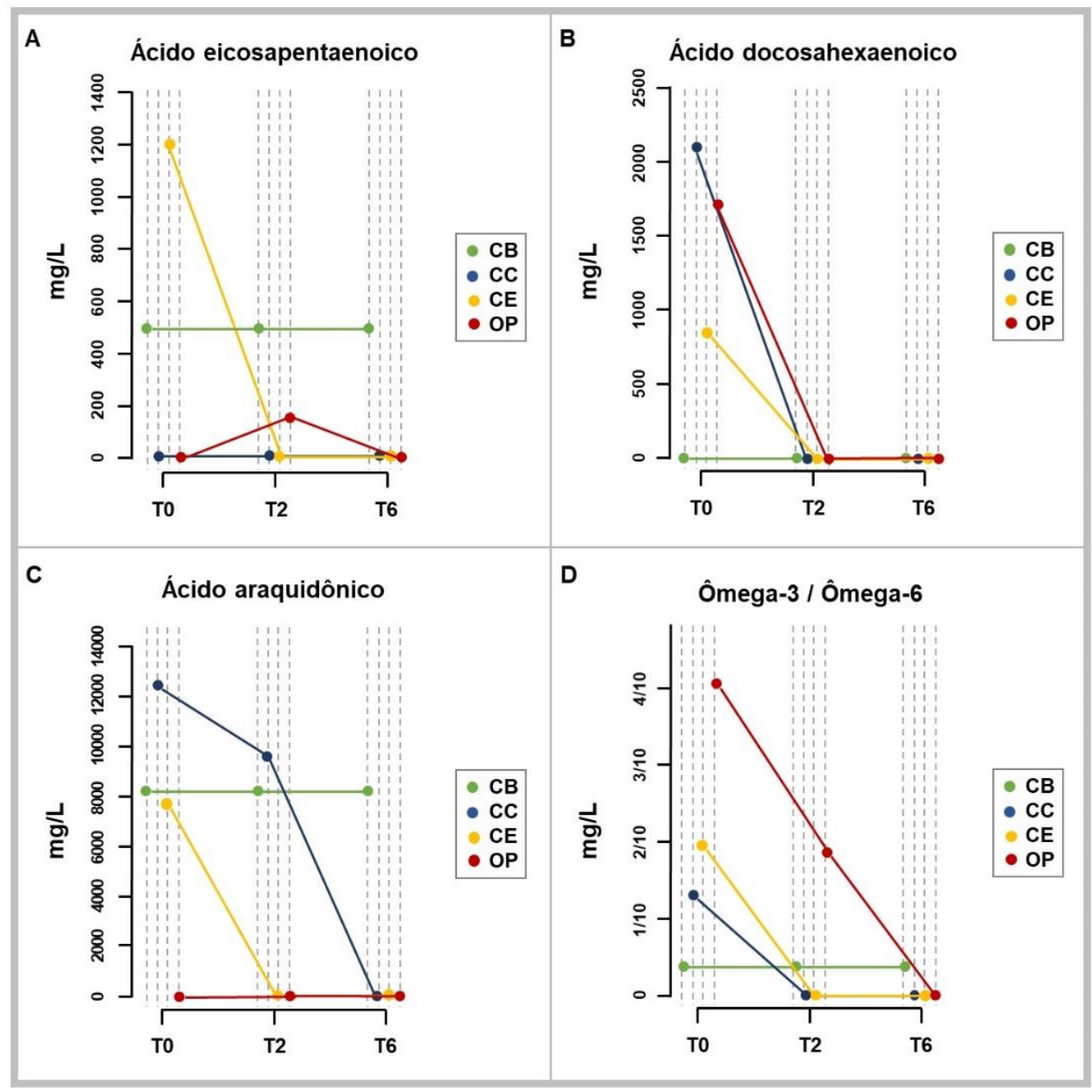

Figura 5. Quantidades de ácidos graxos poli-insaturados e razões ômega3:ômega-6 em leucócitos mononucleares de ratos Lewis submetidos à cateterização cirúrgica do sistema venoso central e sacrificados após 0, 2 e 6 horas da infusão parenteral de emulsão lipídica contendo ou não óleo de peixe

Legenda: Quantidades de ácidos eicosapentaenoico (EPA; A), docosaexaenoico (DHA, B) e araquidônico (ARA, C) e razões ômega-3:ômega-6 (n-3:n-6; D) foram determinadas por cromatografia gasosa em pools de células leucocitárias mononucleares e apresentam-se expressas em $\mathrm{mg} / \mathrm{L}$ (eixo $\mathrm{Y}$ ) e número de horas $(\mathrm{T})$ entre o término de infusão parenteral e o sacrifício (eixo x). CB, animais sem qualquer intervenção cirúrgica ou nutricional, que serviram de controle das quantidades e razões basais dessas variáveis (linha verde), CC, animais submetidos à cateterização cirúrgica do sistema venoso central (CVC) e que não receberam infusão parenteral, servindo como controle da dinâmica das quantidades e razões dessas variáveis em resposta à cirurgia (linha azul); CE, animais submetidos à CVC e que receberam infusão parenteral de emulsão lipídica controle, sem óleo de peixe (linha amarela); OP, animais submetidos à CVC e que receberam infusão parenteral de emulsão lipídica contendo óleo de peixe, rico em EPA e DHA (linha vermelha). 


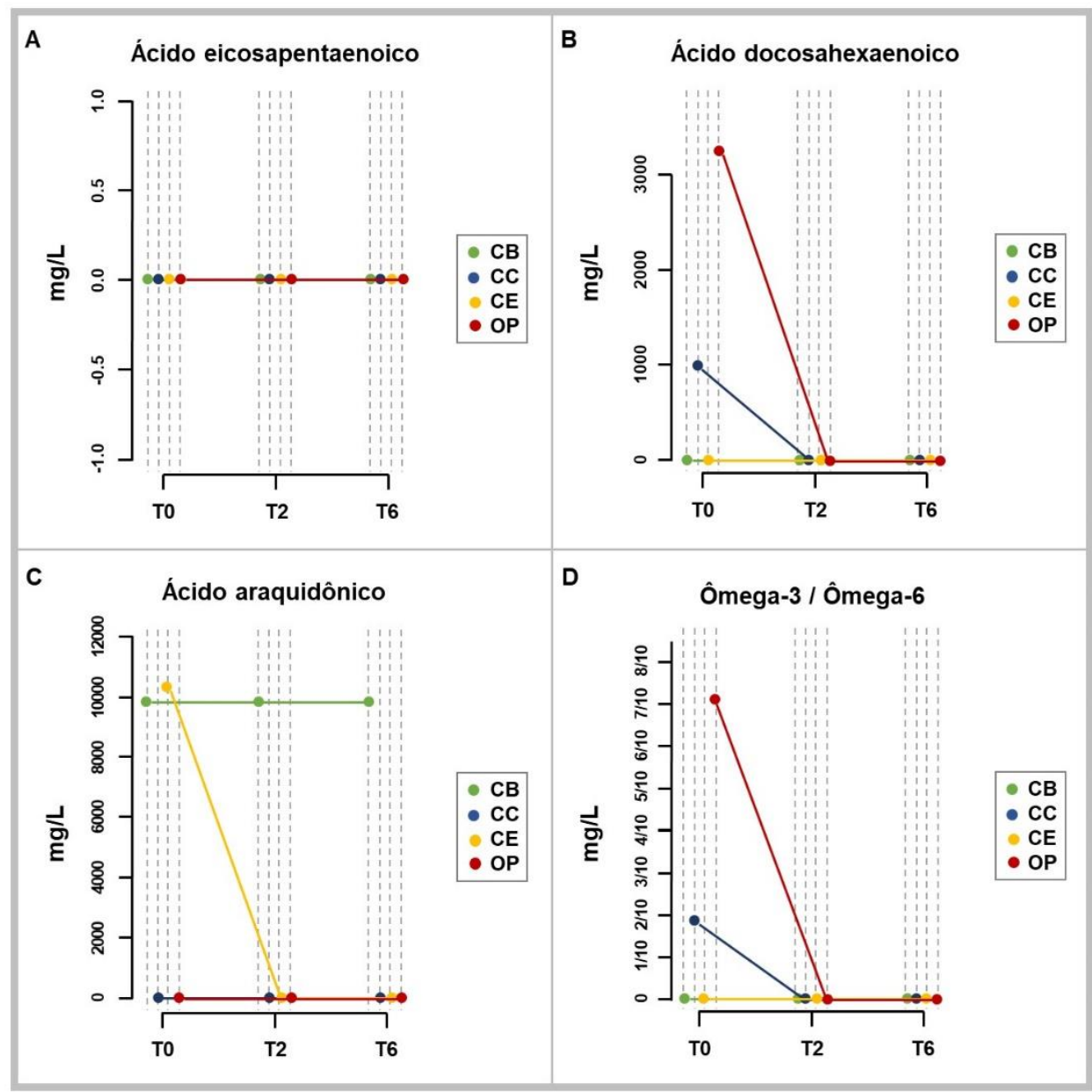

Figura 6. Quantidades de ácidos graxos poli-insaturados e razões ômega3:ômega- 6 em leucócitos polimorfonucleares de ratos Lewis submetidos à cateterização cirúrgica do sistema venoso central e sacrificados após 0,2 e 6 horas da infusão parenteral de emulsão lipídica contendo ou não óleo de peixe

Legenda: Quantidades de ácidos eicosapentaenoico (EPA; A), docosaexaenoico (DHA, B) e araquidônico (ARA, C) e razões ômega-3:ômega-6 (n-3:n-6; D) foram determinadas por cromatografia gasosa em pools de células leucocitárias polimorfonucleares e apresentam-se expressas em $\mathrm{mg} / \mathrm{L}$ (eixo $\mathrm{Y}$ ) e número de horas $(\mathrm{T})$ entre o término de infusão parenteral e o sacrifício (eixo x). $C B$, animais sem qualquer intervenção cirúrgica ou nutricional, que serviram de controle das quantidades e razões basais dessas variáveis (linha verde), CC, animais submetidos à cateterização cirúrgica do sistema venoso central (CVC) e que não receberam infusão parenteral, servindo como controle da dinâmica das quantidades e razões dessas variáveis em resposta à cirurgia (linha azul); CE, animais submetidos à CVC e que receberam infusão parenteral de emulsão lipídica controle, sem óleo de peixe (linha amarela); OP, animais submetidos à CVC e que receberam infusão parenteral de emulsão lipídica contendo óleo de peixe, rico em EPA e DHA (linha vermelha).

\subsubsection{Plasmático e hepático}

As quantidades de AGPI identificadas em amostras de plasma e tecido hepático de ratos Lewis em todos os grupos e tempos estudados encontram-se 
na Figura 7 e Figura 8, respectivamente. Ambas as amostras apresentaram ausência de quantidades basais de EPA e DHA, mas presença de quantidades basais de ARA, de acordo com a análise do grupo CB. Entretanto, em semelhança ao observado em leucócitos, esses AGPI e suas razões foram sensíveis à cirurgia e ao tipo de EL infundida.

Após as intervenções cirúrgicas e nutricionais, a quantidade de EPA plasmática foi maior no grupo OP nos T0 e T2 $(p=0,003)$ e a hepática foi maior em todos os momentos estudados $(p=0,002)$, em comparação com as quantidades de EPA encontrada nos demais grupos. No plasma, a quantidade de DHA foi ausente em todos os grupos e tempos estudados. No fígado, a quantidade de DHA foi maior no grupo OP em todos os tempos estudados $(p=$ $0,002)$ e no grupo CE no T0 ( $p=0,002)$, do que nos grupos CB e CC. Entretanto, a quantidade hepática de DHA foi maior no grupo OP do que no grupo CE nos T2, T6 e T12 ( $p$ 0,050). Quantidades plasmáticas mensuráveis de EPA e DHA foram observadas até T6, enquanto no fígado as quantidades desses AGPI n-3 permaneceram mensuráveis até $T 12$, mas apenas no grupo OP. A análise comparativa intragrupo mostrou uma diminuição tempo-dependente (ou seja, a medida do tempo anterior foi sempre significativamente maior do que aquela encontrada nos tempos posteriores) das quantidades plasmáticas e hepáticas de EPA (exceto entre T2 e T6 no fígado; Tabela 5) e das quantidades hepáticas de DHA no grupo OP (Tabela 6). O mesmo foi observado nas quantidades hepáticas de DHA no grupo CE (Tabela 6).

Após as intervenções cirúrgicas e nutricionais, as quantidades de ARA no plasma e fígado foram maiores nos grupos OP e CE do que no grupo CB no T0 $(p=0,003)$ e menores no grupo $C C$ do que em todos os outros grupos em todos os momentos estudados $(p \leq 0,005)$. No entanto, em comparação com o grupo $\mathrm{CE}$, a quantidade plasmática de ARA foi menor no grupo OP no T2 $(p=0,002)$ e a hepática foi maior no grupo OP nos T0, T2 e T6, mas menor no T12 ( $\leq \leq 0,005)$. A análise comparativa intragrupo mostrou que, tanto no plasma quanto no fígado, as quantidades de ARA diminuíram de T0 para T2 nos grupos OP e CE ( $p=$ 0,002), mas apenas o grupo OP apresentou uma diminuição tempo-dependente das quantidades plasmáticas e hepáticas de ARA, exceto entre T2 e T6 no fígado (Tabela 7). Especificamente no tecido hepático, o grupo CC apresentou maiores concentrações de ARA no T2 do que no T0 (Tabela 7). 


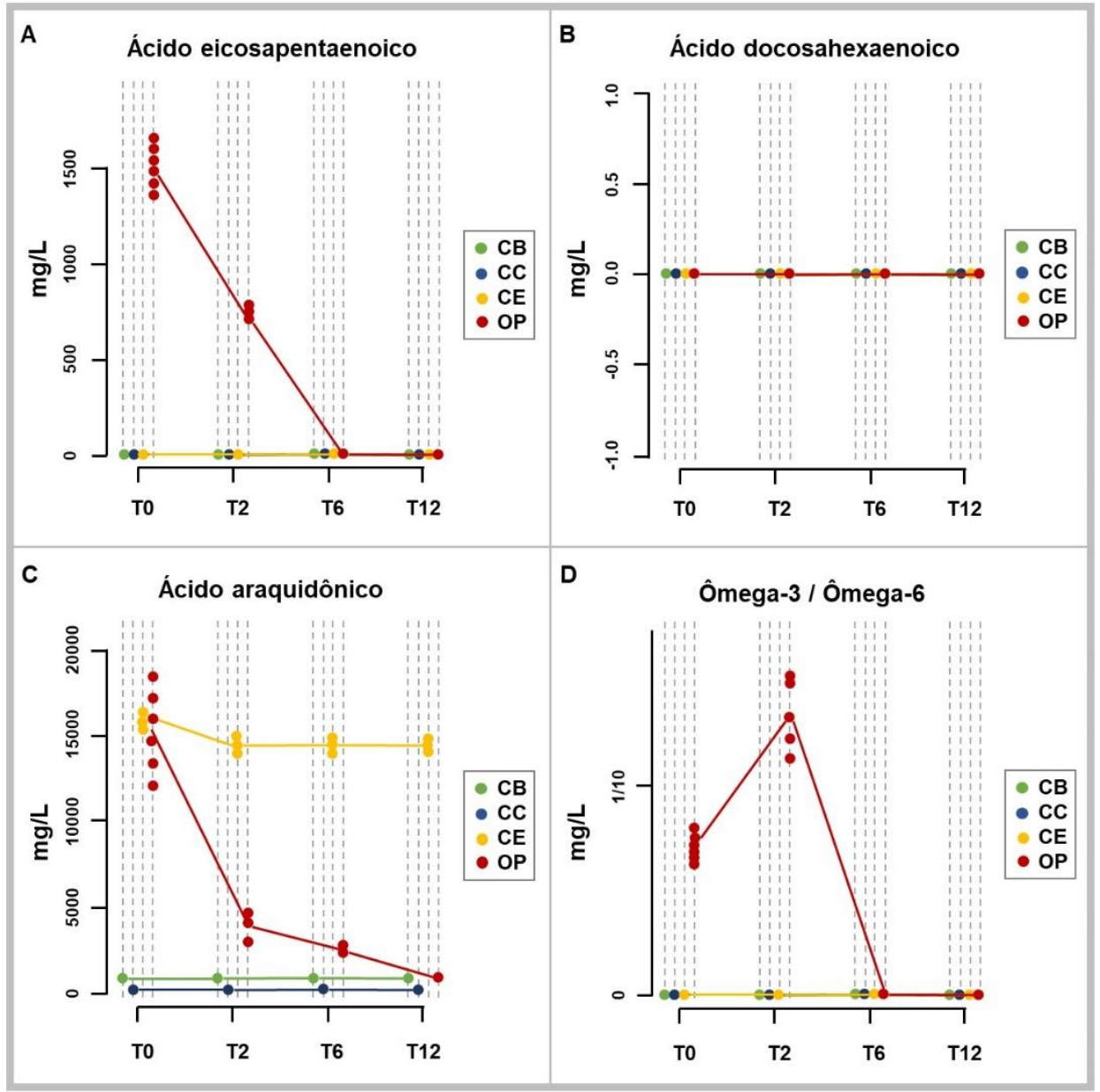

Figura 7. Quantidades de ácidos graxos poli-insaturados e razões ômega3:ômega- 6 no plasma de ratos Lewis submetidos à cateterização cirúrgica do sistema venoso central e sacrificados após 0,2 e 6 horas da infusão parenteral de emulsão lipídica contendo ou não óleo de peixe

Legenda: Quantidades de ácidos eicosapentaenoico (EPA; A), docosaexaenoico (DHA, B) e araquidônico (ARA, C) e razões ômega-3:ômega-6 (n-3:n-6; D) foram determinadas por cromatografia gasosa em amostras individuais de plasma e apresentam-se expressas em $\mathrm{mg} / \mathrm{L}$ (eixo $\mathrm{Y}$ ) e número de horas (T) entre o término de infusão parenteral e o sacrifício (eixo x). $C B$, animais sem qualquer intervenção cirúrgica ou nutricional, que serviram de controle das quantidades e razões basais dessas variáveis (linha verde), $\mathrm{CC}$, animais submetidos à cateterização cirúrgica do sistema venoso central (CVC) e que não receberam infusão parenteral, servindo como controle da dinâmica das quantidades e razões dessas variáveis em resposta à cirurgia (linha azul); $\mathrm{CE}$, animais submetidos à CVC e que receberam infusão parenteral de emulsão lipídica controle, sem óleo de peixe (linha amarela); OP, animais submetidos à CVC e que receberam infusão parenteral de emulsão lipídica contendo óleo de peixe, rico em EPA e DHA (linha vermelha). 


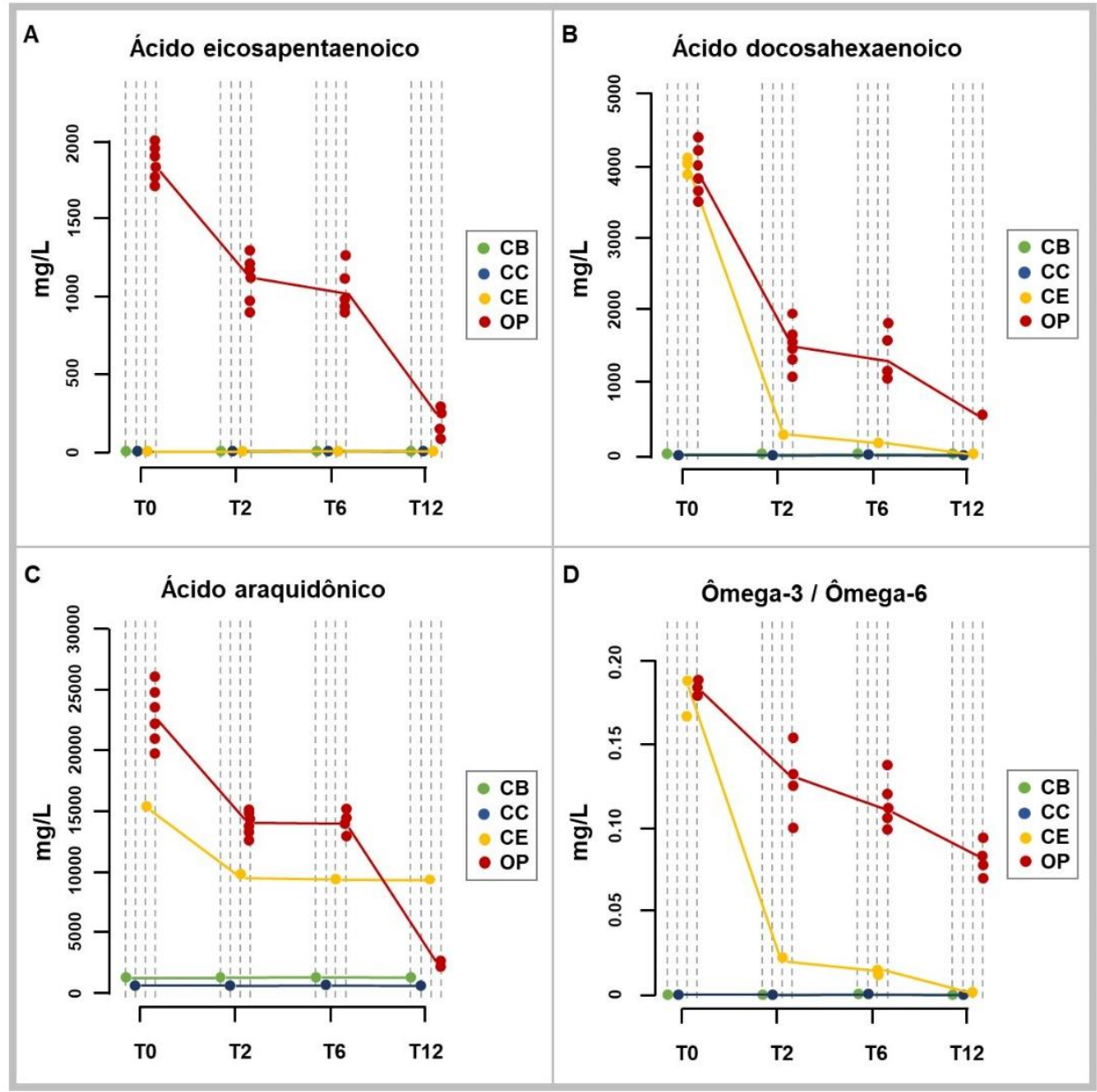

Figura 8. Quantidades de ácidos graxos poli-insaturados e razões ômega3:ômega- 6 no fígado de ratos Lewis submetidos à cateterização cirúrgica do sistema venoso central e sacrificados após 0,2 e 6 horas da infusão parenteral de emulsão lipídica contendo ou não óleo de peixe

Legenda: Quantidades de ácidos eicosapentaenoico (EPA; A), docosaexaenoico (DHA, B) e araquidônico (ARA, C) e razões ômega-3:ômega-6 (n-3:n-6; D) foram determinadas por cromatografia gasosa em amostras individuais de tecido hepático e apresentam-se expressas em mg/L (eixo $\mathrm{Y}$ ) e número de horas (T) entre o término de infusão parenteral e o sacrifício (eixo x). $C B$, animais sem qualquer intervenção cirúrgica ou nutricional, que serviram de controle das quantidades e razões basais dessas variáveis (linha verde), $\mathrm{CC}$, animais submetidos à cateterização cirúrgica do sistema venoso central (CVC) e que não receberam infusão parenteral, servindo como controle da dinâmica das quantidades e razões dessas variáveis em resposta à cirurgia (linha azul); $\mathrm{CE}$, animais submetidos à CVC e que receberam infusão parenteral de emulsão lipídica controle, sem óleo de peixe (linha amarela); OP, animais submetidos à CVC e que receberam infusão parenteral de emulsão lipídica contendo óleo de peixe, rico em EPA e DHA (linha vermelha). 
Tabela 5. Quantidade de ácido eicosapentaenoico (EPA) no plasma e tecido hepático de ratos Lewis submetidos à cateterização cirúrgica do sistema venoso central e sacrificados após 0,2 e 6 horas da infusão parenteral de emulsão lipídica contendo óleo de peixe

\begin{tabular}{lccc}
\hline \multicolumn{1}{c}{ Variável } & Análise & Plasma $(\mathbf{m g} / \mathbf{L})$ & Fígado $(\mathbf{m g} / \mathbf{L})$ \\
\hline \multirow{3}{*}{ Tempo* $^{*}$} & 0 & $1513(1366-1661)$ & $1867(1720-2015)$ \\
& 2 & $717(705-775)$ & $1153(911-1295)$ \\
& 6 & 0 & $988(908-1270)$ \\
& 12 & 0 & $201(100-284)$ \\
Valor de $\mathrm{p}^{\#}$ & T0 vs. T2 & 0,002 & 0,002 \\
& T0 vs. T6 & 0,003 & 0,005 \\
& T0 vs. T12 & 0,003 & 0,002 \\
& T2 vs. T6 & 0,003 & 0,378 \\
& T2 vs. T12 & 0,003 & 0,002 \\
& T6 vs. T12 & - & 0,005 \\
\hline
\end{tabular}

Legenda: *Número de horas entre o término da infusão parenteral/tempo de acompanhamento e a eutanásia; "Teste de Wilcoxon. Dados expressos como mediana (mínimo-máximo).

Tabela 6. Quantidade de ácido docosaexaenoico (DHA) no tecido hepático de ratos Lewis submetidos à cateterização cirúrgica do sistema venoso central e sacrificados 0, 2, 6 e 12 horas após o término de infusão parenteral de emulsão lipídica contendo ou não óleo de peixe

\begin{tabular}{llcc}
\hline \multicolumn{2}{c}{ Variável } & Grupo CE $(\mathbf{m g} / \mathbf{L})$ & Grupo OP $(\mathbf{m g} / \mathbf{L})$ \\
\hline \multirow{4}{*}{ Tempo* } & 0 & $4088(3938-4120)$ & $3938(3490-4387)$ \\
& 2 & $288(253-298)$ & $1509(1065-1957)$ \\
& 6 & $168(141-190)$ & $1167(1058-1825)$ \\
\multirow{5}{*}{ Valor de $\mathrm{p}^{\#}$} & 12 & 0 & $538(524-596)$ \\
& T0 vs. T2 & 0,002 & 0,002 \\
& T0 vs. T6 & 0,005 & 0,002 \\
& T0 vs. T12 & 0,003 & 0,002 \\
& T2 vs. T6 & 0,005 & 0,394 \\
& T2 vs. T12 & 0,003 & 0,002 \\
& T6 vs. T12 & 0,003 & 0,002 \\
\hline
\end{tabular}

Legenda: *Horas após o término da infusão lipídica; \#Teste de Wilcoxon. Dados expressos como mediana (mínimo-máximo). Grupo $\mathrm{CE}$, animais submetidos à cateterização do sistema venoso central e que receberam infusão parenteral de emulsão lipídica sem óleo de peixe; Grupo OP, animais submetidos à cateterização do sistema venoso central e que receberam infusão parenteral de emulsão lipídica contendo óleo de peixe. 
Tabela 7. Quantidade de ácido araquidônico (ARA) no plasma e tecido hepático de ratos Lewis submetidos à cateterização cirúrgica do sistema venoso central e à eutanásia em diferentes tempos após o término de infusão parenteral de emulsão lipídica contendo ou não óleo de peixe

\begin{tabular}{|c|c|c|c|c|c|}
\hline & & \multicolumn{2}{|c|}{ Plasma (mg/L) } & \multicolumn{2}{|c|}{ Fígado (mg/L) } \\
\hline \multicolumn{2}{|c|}{ Variável } & Grupo CE & Grupo OP & Grupo CE & Grupo OP \\
\hline \multirow{4}{*}{ Tempo* } & 0 & $\begin{array}{c}15285 \\
(16575-15284)\end{array}$ & $\begin{array}{c}12111 \\
(18459-259)\end{array}$ & $\begin{array}{c}15249 \\
(14876-15503)\end{array}$ & $\begin{array}{c}22902 \\
(19728-26076)\end{array}$ \\
\hline & 2 & $\begin{array}{c}14010 \\
(14999-4278)\end{array}$ & $\begin{array}{c}3015 \\
(4684-276)\end{array}$ & $\begin{array}{c}9636 \\
(9100-9957)\end{array}$ & $\begin{array}{c}14169 \\
(12553-14984)\end{array}$ \\
\hline & 6 & $\begin{array}{c}14109 \\
(14717-2495)\end{array}$ & $\begin{array}{c}2321 \\
(2743-263)\end{array}$ & $\begin{array}{c}9185 \\
(9023-9680)\end{array}$ & $\begin{array}{c}14051 \\
(12974-14973)\end{array}$ \\
\hline & 12 & $\begin{array}{c}14047 \\
(14903-880)\end{array}$ & $\begin{array}{c}808 \\
(984-250)\end{array}$ & $\begin{array}{c}9348 \\
(9047-9658)\end{array}$ & $\begin{array}{c}2466 \\
(2187-2670)\end{array}$ \\
\hline \multirow{6}{*}{ Valor $\mathrm{p}^{\#}$} & T0 vs. T2 & 0,002 & 0,002 & 0,002 & 0,002 \\
\hline & T0 vs. T6 & 0,002 & 0,002 & 0,002 & 0,002 \\
\hline & T0 vs. T12 & 0,002 & 0,002 & 0,002 & 0,002 \\
\hline & T2 vs. T6 & 1,000 & 0,002 & 0,132 & 0,937 \\
\hline & T2 vs. T12 & 0,589 & 0,002 & 0,132 & 0,002 \\
\hline & T6 vs. T12 & 0,589 & 0,002 & 0,589 & 0,002 \\
\hline
\end{tabular}

Legenda: *Horas após o término da infusão lipídica; \#Teste de Wilcoxon. Dados expressos como mediana (mínimo-máximo). Grupo CE, animais submetidos à cateterização do sistema venoso central e que receberam infusão parenteral de emulsão lipídica sem óleo de peixe; Grupo OP, animais submetidos à cateterização do sistema venoso central e que receberam infusão parenteral de emulsão lipídica contendo óleo de peixe.

Alterações nas concentrações plasmáticas e hepáticas de EPA, DHA e ARA influenciaram suas razões n-3:n-6. No plasma, foi encontrada uma maior razão n-3:n-6 no grupo OP nos T0 e T2, em comparação com aquela encontrada nos demais grupos $(p \leq 0,005)$. No fígado, a razão $n-3: n-6$ foi maior em todos os momentos estudados no grupo OP $(p=0,003)$ e nos T0, T2 e T6 no grupo CE ( $p=0,003$ ), em comparação com os do CB grupos $C C$. No entanto, essa relação foi significativamente maior no grupo OP do que no grupo CE a partir do T2 ( $p=$ 0,002). As análises intragrupo mostraram que a razão n-3:n-6 no plasma foi maior no grupo OP nos T0 e T2 do que nos T6 e T12 ( $p \leq 0,003)$; no entanto, foi menor no T0 do que no T2 ( $p=0,002)$. No fígado, as análises intragrupo 
mostraram que a razão n-3:n-6 diminuiu significativamente e de maneira tempodependente no grupo OP a partir do T2 $(p=0,002)$, exceto entre T2 e T6 ( $p$ > 0,050 ). Também foi observada uma diminuição tempo-dependente na relação $n-$ 3:n-6 hepática no grupo CE $(p \leq 0,003)$.

As análises intragrupo mostraram que no plasma de animais do grupo OP a razão n-3:n-6 foi maior nos T0 e T2 do que nos T6 e T12 ( $p \leq 0,003)$; entretanto ela foi menor em T0 do que em T2 ( $p=0,002)$. No tecido hepático, as análises intragrupo mostraram que essa razão diminuiu significativamente e de forma tempo-dependente em animais dos grupos CE $(p \leq 0,003)$ e OP $(p=0,002)$ a partir de T2. Tal observação só não foi verdadeira entre T2 e T6 para a razão n3:n-6 nos animais do grupo OP $(p>0,050)$.

As análises de porcentagem mostraram que as alterações das quantidades de AGPI encontradas resultaram em mudanças significativas de suas proporções dentro do conteúdo total lipídico, tanto em leucócitos (Figura 9), como no plasma e tecido hepático (Figura 10) 


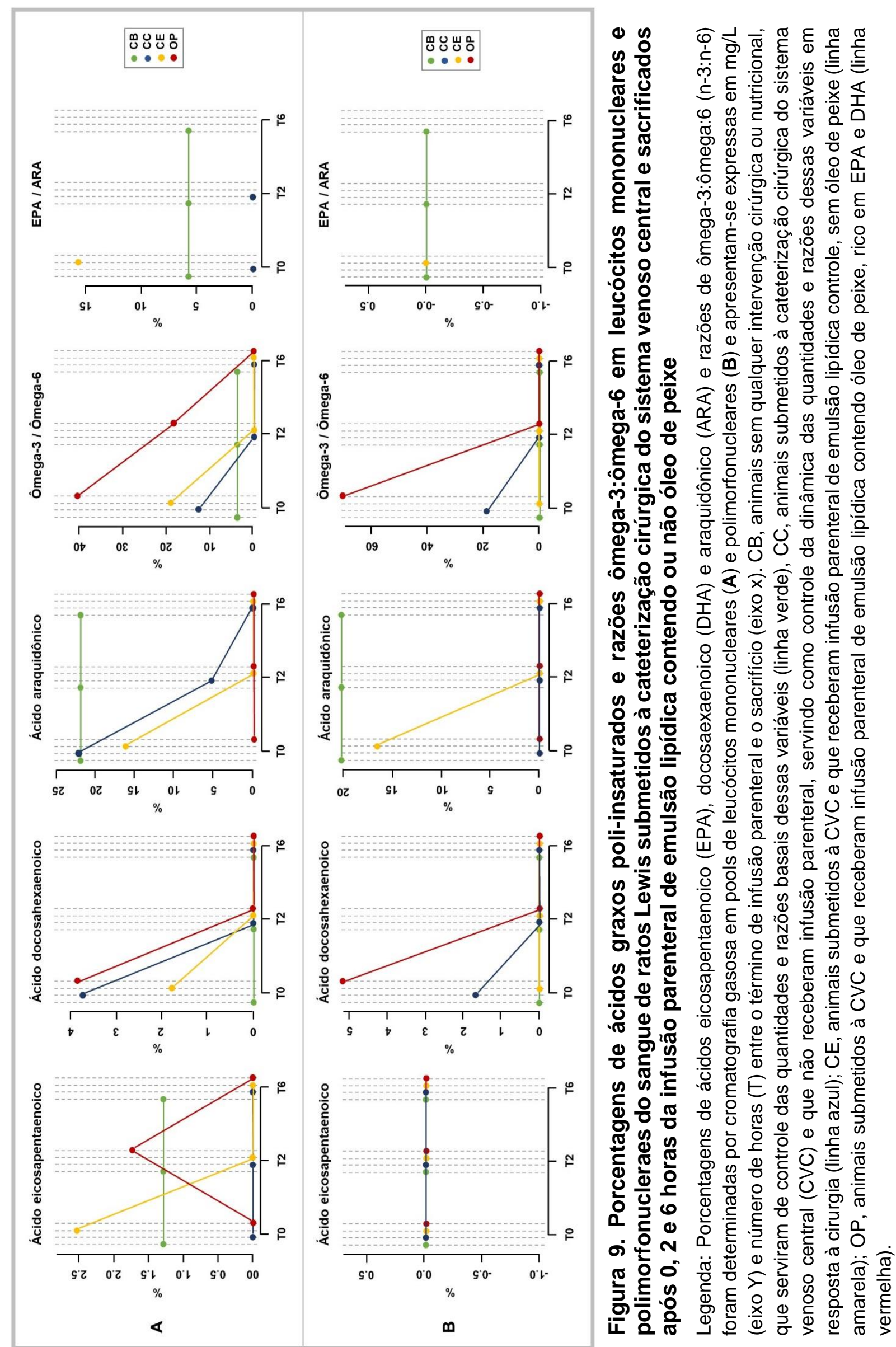




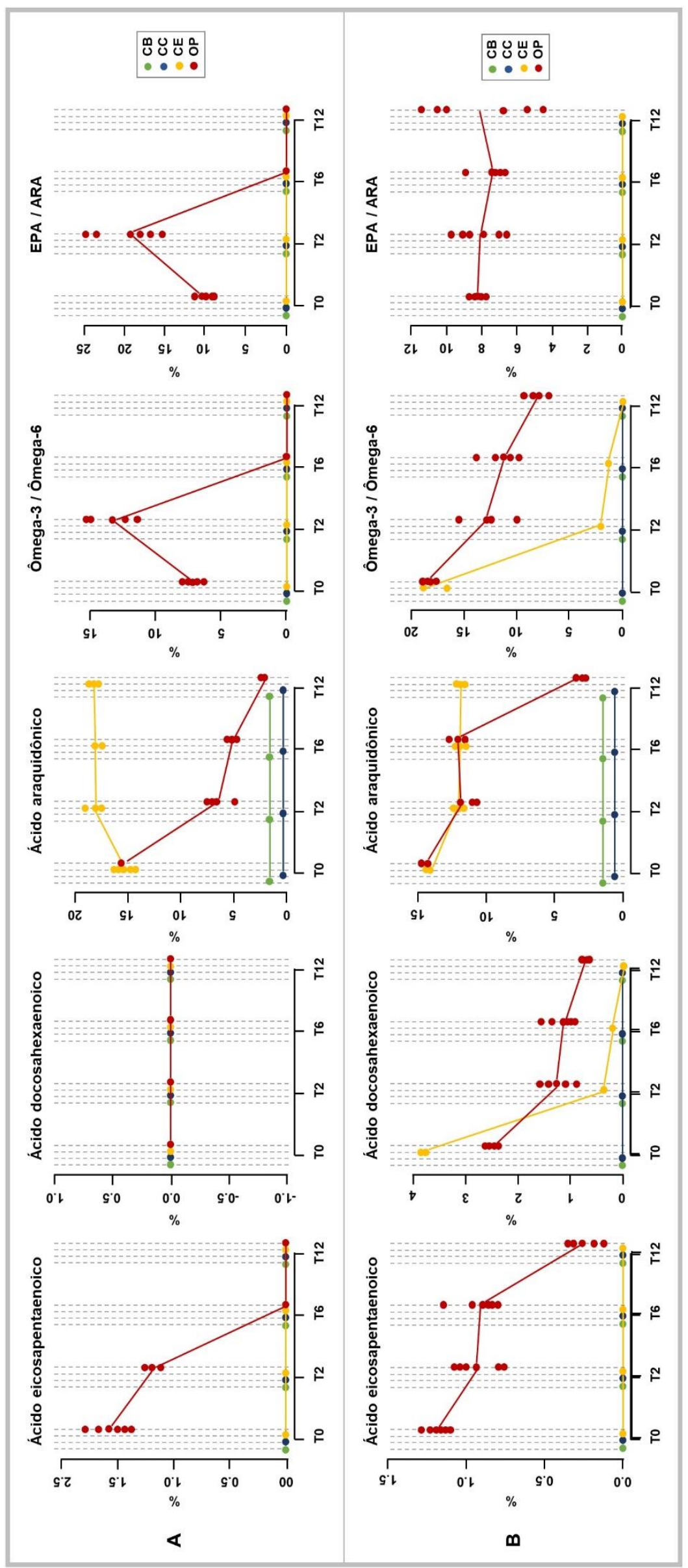

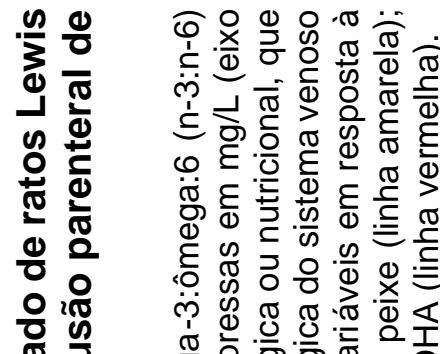

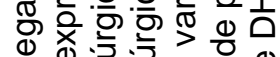

๕

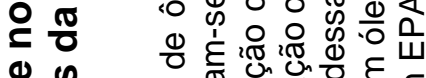

0 \&

है 을

N 0 过

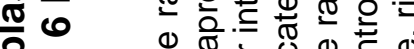

응 0 ब

ㅇ

ó 0

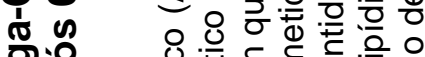

ㅇํㅇ 은 은

屯잉

잉

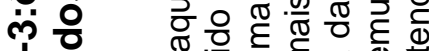

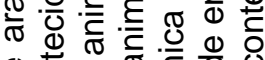

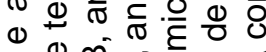

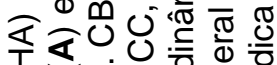

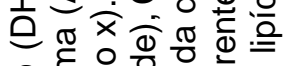

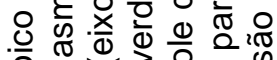

응

बٓ

0.

W

응 0 . त 0

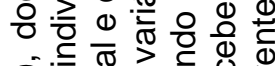
矢 들.

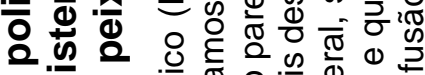
幺 ब 임잉 స ర \& ธ

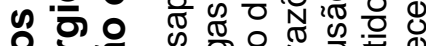
늠

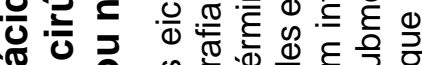
๙ 0 \%

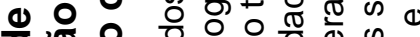

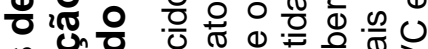
की ఏNㅡㄴ Ð 母

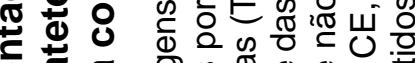
ब đ

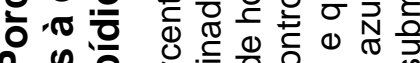

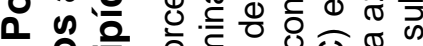

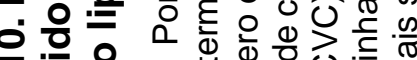
車 深 


\section{DISCUSSÃO}

O enriquecimento leucocitário com AGPI n-3 previamente a intervenções cirúrgicas é postulado como uma boa estratégia para se atingir benefícios clínicos, decorrentes da atenuação da resposta imunológica ao trauma. ${ }^{67,68}$ Entretanto, o presente estudo mostrou pela primeira vez que a biodisponibilidade leucocitária de AGPI n-3 após infusão parenteral de EL contendo óleo de peixe é muito curta, sugerindo seu elevado uso por células imunológicas. Nesse contexto, seus dados sugerem que benefícios imunológicos por EL parenterais contendo óleo de peixe possam não ser efetivos se estas forem infundidas apenas no período pré-operatório e/ou por períodos pós-operatórios que não contemplem toda a dinâmica da resposta imunológica ao trauma cirúrgico. Essas informações podem ser úteis para nortear o desenho de protocolos de terapia nutricional parenteral especializada com AGPI n-3 em pacientes cirúrgicos.

$\mathrm{Na}$ presente investigação, ratos Lewis foram alimentados com dieta padrão contendo óleo de soja como fonte de gordura e, portanto, uma relação de AGPI n-3:n-6 relativamente baixa (1: 7), semelhante ao padrão dietético ocidental humano. ${ }^{14,69}$ Conforme observado no grupo $\mathrm{CB}$, as amostras de plasma, fígado e leucócitos desses animais apresentaram ausência de quantidades basais de EPA e DHA (exceto por uma baixa quantidade de EPA em leucócitos mononucleares) e quantidades basais mensuráveis (plasma e fígado) a altas (leucócitos) de ARA. Entretanto, esses AGPI foram sensíveis à infusão de EL contendo óleo de peixe: maior razão n-3:n-6 foi observada após sua infusão em todos as amostras estudadas, comparado a animais que não a receberam.

Portanto, o presente estudo confirmou um aumento da disponibilidade orgânica de AGPI n-3 após infusão de EL de óleo de peixe. Como AGPI n-3 competem com AGPI n-6 para incorporação celular, comparativamente ao grupo $\mathrm{CB}$, a diminuição de ARA também foi observada em animais que receberam a referida infusão e se estendeu até o último tempo analisado após seu término. Entretanto, as razões leucocitárias de AGPI n-3:n-6 desses animais permaneceram aumentadas por períodos que variaram entre as amostras: até 12 horas pós-infusão no fígado, 2 horas no plasma e leucócitos mononucleares, 
e apenas imediatamente pós-infusão nos leucócitos polimorfonucleares. Essas observações sugerem que leucócitos (especialmente polimorfonucleares) utilizam AGPI n-3 em taxas muito elevadas, tomando-se o fígado como referência.

Nesse contexto, os dados obtidos no presente estudo confirmaram sua hipótese de que a disponibilidade leucocitária de AGPI n-3 após infusão de EL contendo óleo de peixe é lábil e questionam o real benefício desta prática no préoperatório de pacientes cirúrgicos eletivos, dado seu elevado custo relativamente a EL convencionais. Entretanto, estudo retrospectivo clássico na área, envolvendo 256 pacientes cirúrgicos, mostrou que ambas as infusões pósoperatória exclusiva e perioperatória de EL contendo óleo de peixe diminuíram taxas de readmissão na unidade de terapia intensiva (UTI); mas apenas sua infusão perioperatória também se associou com diminuição da frequência de ventilação mecânica, do tempo de internação hospitalar e até de taxas de mortalidade. ${ }^{70} \mathrm{~A}$ interpretação de dados do presente estudo deve ser, portanto, transposta para a prática clínica com cautela.

Pacientes cirúrgicos frequentemente apresentam patologias que envolvem alterações da resposta imunológica (ex. câncer, doenças inflamatórias intestinais) e, portanto, podem ser ávidos por AGPI n-3, principalmente ao considerar que sua ingestão é usualmente baixa. ${ }^{71}$. Há que se considerar ainda que as propriedades biológicas de AGPI n-3 com interesse clínico não se resumem a seus efeitos imunomoduladores, modulações metabólicas também são atribuídas a esses AGPI. O conjunto dessas propriedades tem potencial clínico relevante em pacientes cirúrgicos, já que a cirurgia pode resultar em desequilíbrios de ambas as respostas inflamatória e metabólica.

Em particular, o fígado tem papel metabólico central no metabolismo humano e na síntese de proteínas de fase aguda. Níveis aumentados da proteína de fase aguda proteína $\mathrm{C}$ reativa (PCR) são observados aproximadamente 4 a 12 horas após intervenção cirúrgica. ${ }^{72}$ Benefícios metabólicos e até imunológicos podem ocorrer, portanto, se houver disponibilidade hepática de AGPI n-3 no momento da cirurgia. De acordo com os dados do presente estudo, esta pode ser uma meta mais factível de ser alcançada na prática clínica. A disponibilidade hepática de AGPI n-3, embora tenha decaído significativamente ao longo dos 
tempos estudados, permaneceu ainda detectável até 12 horas após a infusão de EL contendo óleo de peixe.

Nesse contexto, a infusão pré-operatória de EL contendo óleo de peixe em pacientes com indicação de terapia nutricional parenteral pode ser importante para diminuir sua debilidade clínica geral previamente ao trauma. Coerentemente com essa possiblidade, estudo recente mostrou que a suplementação oral pré-operatória exclusiva AGPI n-3 se associou com maior perda de peso no pré-operatório de pacientes bariátricos e esse benefício se acompanhou de menores níveis de dor e de PCR no pós-operatório. ${ }^{73}$ Portanto, os dados do presente estudo não podem excluir a importância da infusão préoperatória de EL de óleo contendo peixe como fonte de PUFA n-3 no período pré-operatório, mas chamam a atenção para a necessidade potencial de se estender essa intervenção por períodos pós-operatórios adequados para alcançar benefícios imunomoduladores.

Refletindo uma falta de padronização de protocolos de nutrição parenteral com EL contendo óleo de peixe, estudos disponíveis que avaliaram seu efeito sobre desfechos clínicos incluíram períodos de infusão que variaram de 4 a 7 dias pós-operatórios. $O$ efeito da referida infusão por 4 dias pós-operatórios foi avaliado em apenas um estudo e não se associou à melhora significativa do tempo de internação na UTI e hospitalar pós-operatório. ${ }^{58}$ Por outro lado, a infusão de EL contendo óleo de peixe por 5 dias pós-operatórios se associou à diminuição significativa da incidência de infecções pós-operatórias (3/6 estudos) e do tempo de internação hospitalar (5/8 estudos), mas não influenciou o tempo de UTI ( $1 / 1$ estudo) e taxas de mortalidade (3/3 estudos). ${ }^{20,24,60,74-79}$ Similarmente, desfechos clínicos associados à infusão pós-operatória de EL contendo óleo de peixe por 7 dias incluíram diminuição significativa de complicações infecciosas (6/8 estudos) e diminuição de tempo de internação hospitalar (5/6 estudos), sem efeito significativo sobre o tempo de internação na UTI (1/1 estudo) e a taxa de mortalidade (3/3 estudos). ${ }^{16,22,80-83}$

Tomadas em conjunto, essas observações sugerem que o tempo de infusão parenteral de $E L$ contendo óleo de peixe por período $\leq$ a 4 dias pode não ser suficiente para melhorar desfechos clínicos e indicam potencial benefício de se estender essa infusão por período superior a 5 dias, mas sem efeito no tempo 
de permanência de UTI e mortalidade. Chama atenção que apenas 1 estudo nessa área incluiu a infusão pré-operatória de EL contendo óleo peixe e sua extensão por 5 dias pós-operatórios. ${ }^{10} \mathrm{O}$ referido estudo reportou menores taxas de infecção severa e de tempo de internação, além de diminuição significativa do tempo de UTI após essa prática (a mortalidade não foi estuda). ${ }^{10}$ Apesar de evidências que suportam um potencial benefício de fornecer AGPI n-3 previamente ao trauma, a infusão perioperatória de $E L$ de óleo contendo peixe é pouco explorada pela comunidade científica da área, o que vem sendo questionado por alguns autores. ${ }^{12}$

Chama a atenção ainda que os resultados clínicos disponíveis são heterogêneos, mesmo ao longo de tempos idênticos de infusão parenteral. Essa observação deve ser atribuída à heterogeneidade da dinâmica da resposta imunológica pós-operatória: ambas as respostas imunológicas humoral e celular pós-operatórias são sujeitas a diferentes fatores que influenciam seu curso. Sabidamente, o tipo de procedimento cirúrgico empregado (convencional ou laparoscópico) é um deles ${ }^{84}$, mas outros fatores também são potencialmente relevantes, como idade, doença de base e seu estágio de desenvolvimento.

O período de infusão de EL contendo óleo de peixe usado no presente estudo foi baseado no estudo de Hagi e cols. ${ }^{64}$, que relatou que a biodisponibilidade de AGPI n-3 em esplenócitos atingiu seu platô após 3 dias em ratos sacrificados imediatamente depois da referida infusão. As quantidades de ARA observadas nos animais do grupo controle cirúrgico (SC) imediatamente após a infusão de EL contendo óleo de peixe foram muito baixas no plasma e 0 fígado, mas altas nos leucócitos mononucleares. Esses achados sugerem que 4 dias após uma intervenção cirúrgica moderada, ARA permanecia requisitado por leucócitos, provavelmente para síntese de mediadores inflamatórios.

Em leucócitos, ARA compete com EPA para a síntese de eicosanoides envolvidos na ativação da resposta inflamatória. ${ }^{1,3}$ Comparado ao grupo $\mathrm{CB}$, as quantidades plasmáticas e hepáticas de ARA no T0 foram altas nos grupos CE e OP, mas os animais do grupo CE apresentaram menor quantidade hepática de ARA do que os animais do grupo OP. Em paralelo, quantidades leucocitárias elevadas de ARA foram observadas no grupo CE no T0, enquanto ARA estava ausente em leucócitos de animais do grupo OP. Essas observações sugerem 
que o ARA foi mais requisitado pelos leucócitos do que pelo fígado em animais do grupo $C E$, enquanto o contrário ocorreu em animais do grupo OP. Por outro lado, leucócitos do grupo OP permaneceram com quantidades muito baixas de EPA em T0, enquanto esta aumentou em leucócitos mononucleares do grupo $\mathrm{CE}$ (vs. grupo $\mathrm{CB}$ ). Considerando-se que o grupo OP recebeu infusão parenteral de quantidades de EPA muito maiores que o grupo CE, essas observações sugerem alta taxa de utilização desse AGPI n-3 por leucócitos mononucleares do grupo OP.

Tomados em conjunto, os dados do presente estudo sugerem que, em semelhança ao grupo CC, leucócitos do grupo CE requisitaram ARA para síntese de mediadores inflamatórios; enquanto leucócitos do grupo OP utilizaram mais EPA para esse propósito, especialmente os mononucleares. Uma vez que eicosanoides derivados do EPA têm um potencial pró-inflamatório menor do que os derivados da ARA, é possível inferir que os animais que receberam infusão de EL contendo óleo de peixe têm maior probabilidade de desenvolver uma resposta inflamatória menos prejudicial. ${ }^{1,3}$ Ressalta-se que ambas as EL controle e EL contendo óleo de peixe possuem óleo de soja em sua formulação, embora em quantidades diferentes, o que pode explicar o aumento de quantidades plasmáticas e hepáticas de ARA nos animais do grupo CE e OP após suas infusões.

No presente estudo observou-se ainda ausência de DHA circulante imediatamente após a infusão de EL contendo óleo de peixe, mas quantidades desse AGPI n-3 estavam presentes nos leucócitos mononucleares e polimorfonucleares. O DHA tem um papel estrutural único, conferindo uma alta fluidez às membranas celulares, necessária para a fagocitose. ${ }^{85}$ É possível que a rápida depuração circulante do DHA possa ter sido requerida para sustentar a síntese de novos leucócitos, o que é compatível com atividade imunológica e pode ser uma vantagem após a infusão de EL contendo óleo de peixe como fonte de DHA.

A alta necessidade de DHA para síntese leucocitária poderia explicar o porquê de leucócitos mononucleares dos grupos $\mathrm{CC}$ e $\mathrm{CE}$ e polimorfonucleares do grupo CE também terem apresentado quantidades mais altas de DHA do que as encontradas no grupo CB. Tanto a dieta oral ofertada aos animais desses 
grupos, quanto a EL controle contém óleo de soja. O óleo de soja é rico em AGPI n-6, mas também contém alguma quantidade do percursor de DHA em sua composição (ALA) ${ }^{86}$ Portanto, a reciclagem leucocitária pode ter sido sustentada pelas quantidades de DHA sintetizadas endogenamente a partir de ALA do óleo de soja componente da dieta oral pelo grupo $\mathrm{CC}$ e da dieta oral e EL controle pelo grupo $C E$. Visto que leucócitos polimorfonucleares tem uma meia-vida mais curta (ex. minutos para neutrófilos) do que os leucócitos mononucleares (ex. meses para linfócitos) ${ }^{87}$, sua taxa de reciclagem é mais elevada e explicaria 0 porquê do grupo $\mathrm{CC}$ não ter apresentado maiores quantidades de DHA nessa população leucocitária (vs. $\mathrm{CB}$ ): O grupo $\mathrm{CC}$ tinha fonte única e escassa desse AGPI n-3, para que pudesse utilizá-lo em repetidas reciclagens celulares.

Como pontos-fortes, o protocolo experimental do presente estudo incluiu diferentes grupos que controlaram a disponibilidade natural plasmática, hepática e leucocitária de AGPI de ratos Lewis (grupo CB), bem como os efeitos gerados pelo procedimento cirúrgico para acesso venoso central sobre essa variável (grupo CC). Além disso, a EL contendo óleo de peixe estudada tinha alto potencial para promover a incorporação de AGPI n-3 (devido ao seu elevado conteúdo de TCM) e seus efeitos foram controlados pela infusão de EL com perfil lipídico muito similar, à exceção de seus conteúdos de EPA e DHA (grupo CE). Nossa principal limitação metodológica foi analisar leucócitos em pool, mas o pequeno-porte dos ratos nos impediu de obter uma quantidade de leucócitos suficiente para viabilizar análises cromatográficas individuais. Por outro lado, o uso de animais isogênicos permitiu uma resposta mais uniforme, reduzindo o viés da análise em pool. Além disso, todas as análises cromatográficas do plasma e tecido hepático foram realizadas individualmente, ajudando a entender a dinâmica endógena de AGPI e, consequentemente, os achados leucocitários.

Embora várias metanálises venham confirmando que EL parenterais contendo óleo de peixe podem melhorar desfechos clínicos de pacientes cirúrgicos, o tempo de infusão necessário para alcançar esses benefícios permanece desconhecido. ${ }^{88-92}$ Nossos dados sugerem que a disponibilidade de AGPI n-3 em leucócitos após esta prática é altamente lábil e, portanto, a infusão de EL contendo óleo de peixe deveria cobrir todo o período da dinâmica da resposta imuno-inflamatória pós-operatória. Estudos sobre essa dinâmica 
podem ajudar no planejamento de protocolos personalizados de terapia nutricional parenteral especializada, de acordo com o tipo de intervenção cirúrgica e a condição clínica específica do paciente. 


\section{CONCLUSÕES}

Nas condições da presente pesquisa, em ratos Lewis submetidos ao acesso cirúrgico do sistema venoso central, pode-se concluir que a infusão de EL contendo óleo de peixe:

1. Aumentou a biodisponibilidade leucocitária de AGPI n-3, enquanto diminuiu a de ARA.

2. Resultou no aumento da razão n-3:n-6 em leucócitos e, portanto, em fenótipos leucocitários com menor potencial inflamatório.

3. Teve efeito muito lábil sobre o perfil de AGPI de leucócitos, em comparação com o tecido hepático, e praticamente indetectável após 2 horas de seu término, mesmo mediante a disponibilidade de níveis circulantes remanescentes de AGPI n-3.

Corolário: Em modelo cirúrgico de cateterização do sistema venoso central, EL contendo óleo de peixe teve efeito benéfico, mas muito lábil, sobre o perfil de AGPI de leucócitos, sugerindo que sua infusão deva se estender ao longo de toda a dinâmica da resposta imuno-inflamatória pós-operatória para favorecer 0 alcance de benefícios clínicos. 


\section{ANEXO 1}

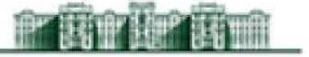 \\ MEDICINA \\ TSP \\ COMISSÃO DE ÉTICA NO USO DE ANIMAIS}

A CEUA da Faculdade de Medicina da Universidade de São Paulo, em 20/03/2018 APROVOU o documento abaixo mencionado para o protocolo de pesquisa $\mathrm{n}^{\circ} \mathbf{1 2 6 / 1 2}$ intitulado "Avaliações sequenciais do perfil de ácidos graxos poli-insaturados leucocitários e seus metabólitos plasmáticos e hepáticos, após infusão parenteral de emulsão lipídica contendo óleo de peixe em ratos Lewis" apresentado pelo Departamento de Gastroenterologia.

- Alteração de título para: “Avaliações sequenciais do perfil de ácidos graxos poli-insaturados leucocitários e seus metabólitos plasmáticos e hepáticos, após infusão parenteral de emulsão lipídica contendo óleo de peixe em ratos Lewis submetidos à cateterização cirúrgica do sitema venoso central"

Pesquisador Responsável: Raquel S M M Torrinhas

CEUA-FMUSP, 26 de Novembro de 2019

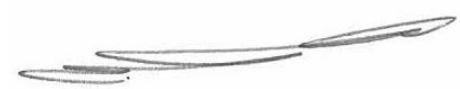

Dr. Eduardo Pompeu

Coordenador

Comissão de Ética no Uso de Animais

Comissão de Ética no Uso de Animais da FMUSP

e-mail: ceua@fm.usp.br 


\section{REFERÊNCIAS}

1. Calder PC. Functional Roles of Fatty Acids and Their Effects on Human Health. JPEN J Parenter Enteral Nutr. 2015;39:18S-32S.

2. Calder PC, Deckelbaum RJ. Dietary lipids: more than just a source of calories, Curr Opin Clin Nutr Metab Care. 1999;2:105-7.

3. Waitzberg DL, Torrinhas RS. Fish oil lipid emulsions and immune response: what clinicians need to know. Nutr Clin Pract. 2009;24:487-99

4. Bhardwaj K, Verma N, Trivedi RK, Bhardwaj S, Shukla N. Significance of Ratio of Omega-3 and Omega-6 in Human Health with Special Reference to Flaxseed Oil. Int J Biolo Chem. 2016;10:1-6.

5. Calder PC. n-3 polyunsaturated fatty acids, inflammation, and inflammatory diseases. Am J Clin Nutr. 2006;83:1505S-19S.

6. Healy, D. A., Wallace, F. A., Miles, E. A., Calder, P. C., \& Newsholm, P. (2000). Effect of low-to-moderate amounts of dietary fish oil on neutrophil lipid composition ad function. Lipids. 2000;35:763-8.

7. Silva $V$, Barazzoni $R$, Singer $P$. Biomarkers of fish oil omega-3 polyunsaturated fatty acids intake in humans. Nutr Clin Pract. 2014;29: 6372.

8. Tang B, Row KH. Development of Gas Chromatography Analysis of Fatty Acids in Marine Organisms. J Chromatogr Sci. 2013;51:599-607.

9. Dorman FL1, Whiting JJ, Cochran JW, Gardea-Torresdey Gas chromatography. J Anal Chem. 2010;82:4775-85.

10. Weiss G, Meyer F, Matthies B, Pross M, Koenig W, Lippert $H$. Immunomodulation by perioperative administration of $\mathrm{n}-3$ fatty acids. $\mathrm{Br} \mathrm{J}$ Nutr. 2002;87:S89-94.

11. Gentile LF, Cuenca AG, Efron PA, Ang D, Bihorac A, McKinley BA, Moldawer LL, Moore FA. Persistent inflammation and immunosuppression: a common syndrome and new horizon for surgical intensive care. J Trauma Acute Care Surg. 2012; 72:1491-501.

12. Calder PC. Rationale and use of $n-3$ fatty acids in artificial nutrition. Proc. Nutr. Soc. 2010; 69:565-73. 
13. van der Meij BS, van Bokhorst-de van der Schueren MA, Langius JA, Brouwer IA, van Leeuwen PA. n-3 PUFAs in cancer, surgery, and critical care: a systematic review on clinical effects, incorporation, and washout of oral or enteral compared with parenteral supplementation. Am J Clin Nutr. 2011;94:1248-65.

14. Waitzberg DL, Torrinhas RS, Jacintho TM. New parenteral lipid emulsions for clinical use. JPEN J Parent Enteral Nutr. 2006;30:351-67.

15. Carpentier YA, Portois L, Malaisse WJ. Rapid enrichment of cell phospholipids in long-chain polyunsaturated $\omega-3$ fatty acids after a bolus intravenous injection of a medium-chain triacylglycerol: fish oil emulsion in humans. JPEN J Parenter Enteral Nutr. 2012;36:671-6.

16. Liang B, Wang S, Ye Ying-Jiang, Yang Xiao-Dong, Wang You-Li, Qu J, Xie Qi-Wei, Yin Mu-Jun Impact of postoperative omega-3 fatty acidsupplemented parenteral nutrition on clinical outcomes and immunomodulations in colorectal cancer patients. World J Gastroenterol. 2008;14:2434-9.

17. Schauder P, Röhn U, Schäfer G, Korff G, Schenk HD. Impact of fish oil enriched total parenteral nutrition on DNA synthesis, cytokine release and receptor expression by lymphocytes in the postoperative period. Br J Nutr. 2002;87:S103-10.

18. Cury-Boaventura MF, Torrinhas RS, Godoy AB, Curi R, Waitzberg DL. Human Leukocyte Death After a Preoperative Infusion of Medium/LongChain Triglyceride and Fish Oil Parenteral Emulsions: A Randomized Study in Gastrointestinal Cancer Patients. JPEN J Parenter Enteral Nutr. 2012;6:677-84.

19. Long $H$, Yang $H$, Lin Y, Situ D, Liu W. Fish oil-supplemented parenteral nutrition in patients following esophageal cancer surgery: effect on inflammation and immune function. Nutr Cancer. 2013;65:71-5.

20. Wichmann MW, Thul P, Czarnetzki HD, Morlion BJ, Kemen M, Jauch KW. Evaluation of clinical safety and beneficial effects of a fish oil containing lipid emulsion (Lipoplus, MLF541): data from a prospective, randomized, multicenter trial. Crit Care Med. 2007;35:700-6. 
21. Köller M, Senkal M, Kemen M, König W, Zumtobel V, Muhr G. Impact of omega-3 fatty acid enriched TPN on leukotriene synthesis by leukocytes after major surgery. Clin Nutr. 2003;22:59-64.

22. Zhang CH, Li N, Wang XY, Li GL, Fan CG, Li JS. Influence of Lipoplus fat emulsion on postoperative nutritional status and early inflammatory response in patients with gastrointestinal malignancies. Zhonghua Wei Chang Wai Ke Za Zhi. 2012;15:448-51.

23. Schade I, Röhm KD, Schellhaass A, Mengistu A, Boldt J, Piper SN. Inflammatory response in patients requiring parenteral nutrition: comparison of a new fish oil containing emulsion (SMOFlipid®) versus an olive/soybean oil-based formula. Crit Care. 2008;12:S56-7.

24. Grimm H, Mertes N, Goeters C, Schlotzer E, Mayer K, Grimminger F, Fürst P. Improved fatty acid and leukotriene pattern with a novel lipid emulsion in surgical patients. Eur J Nutr. 2006;45:55-60.

25. de Miranda Torrinhas RS, Santana R, Garcia T, Cury-Boaventura MF, Sales MM, Curi R, Waitzberg DL. Parenteral fish oil as a pharmacological agent to modulate post-operative immune response: a randomized, double-blind, and controlled clinical trial in patients with gastrointestinal cancer. Clin Nutr. 2013;32:503-10.

26. McClave SA, Taylor BE, Martindale RG, Warren MM, Johnson DR, Braunschweig C, McCarthy MS, Davanos E, Rice TW, Cresci GA, Gervasio JM, Sacks GS, Roberts PR, Compher C; Society of Critical Care Medicine; American Society for Parenteral and Enteral Nutrition. Guidelines for the Provision and Assessment of Nutrition Support Therapy in the Adult Critically III Patient: Society of Critical Care Medicine (SCCM) and American Society for Parenteral and Enteral Nutrition (A.S.P.E.N.).JPEN J Parenter Enteral Nutr. 2016;40:159-211.

27. Braga $M$, Ljungqvist $O$, Soeters $P$, Fearon $K$, Weimann $A$, Bozzetti $F$; ESPEN. ESPEN Guidelines on Parenteral Nutrition: surgery. Clin Nutr. 2009;28:378-86. 
28. De Nardi LC, Torrinhas RS, Antunes MS, Waiztberg DL. Gorduras. In: Waitzberg DL, editor. Nutrição oral, enteral e parenteral na prática clínica. 5aㅡ ed. Rio de Janeiro: Atheneu; 2017. v.1, p.134-59.

29. Eyster KM. The membrane and lipids as integral participants in signal transduction: lipid signal transduction for the non-lipid biochemist. Adv Physiol Educ. 2007;31:5-16.

30. Yates CM, Calder PC, Ed Rainger G. Pharmacology and therapeutics of omega-3 polyunsaturated fatty acids in chronic inflammatory disease. Pharmacol Ther. 2014;141:272-82.

31. Siddiqui RA, Harvey KA, Zaloga GP, Stillwell W. Modulation of lipid rafts by Omega-3 fatty acids in inflammation and cancer: implications for use of lipids during nutrition support. Nutr Clin Pract. 2007;22:74-88.

32. Simons K, Toomre D. Lipid rafts and signal transduction. Nat Rev Mol Cell Biol. 2000;1:31-9.

33. Daak AA, Elderdery AY, Elbashir LM, Mariniello K, Mills J, Scarlett G, Elbashir MI, Ghebremeskel K. Omega 3 (n-3) fatty acids down-regulate nuclear factor-kappa B (NF-kB) gene and blood cell adhesion molecule expression in patients with homozygous sickle cell disease. Blood Cells Mol Dis. 2015;55:48-55.

34.Zgórzyńska E, Dziedzic B, Gorzkiewicz A, Stulczewski D, Bielawska K, Su KP, Walczewska A. Omega-3 polyunsaturated fatty acids improve the antioxidative defense in rat astrocytes via an Nrf2-dependent mechanism. Pharmacol Rep. 2017;69:935-42.

35. Shysh AM, Nagibin VS, Kaplinskii SP, Dosenko VE. N-3 long chain polyunsaturated fatty acids increase the expression of PPARy-target genes and resistance of isolated heart and cultured cardiomyocytes to ischemic injury. Pharmacol Rep. 2016;68:1133-9.

36. Ebrahimi M, Rajion MA, Meng GY, Soleimani Farjam A. Omega-3 fatty acid enriched chevon (goat meat) lowers plasma cholesterol levels and alters gene expressions in rats. Biomed Res Int. 2014;2014:ID749341.

37. Deckelbaum RJ, Worgall TS, Seo T. n-3 fatty acids and gene expression. Am J Clin Nutr. 2006;83:1520S-5S. 
38. Strasser T, Fischer S, Weber, PC. Leukotriene B5 is formed in human neutrophils after dietary supplementation with eicosapentaenoic acid. Proc Natl Acad Sci USA. 1985;82:1540-3.

39. Bannenberg GL, Chiang N, Ariel A, Arita M, Tjonahen E, Gotlinger KH, Hong S, Serhan CN. Molecular circuits of resolution: formation and actions of resolvins and protectins. J Immunol. 2005;174:4345-55.

40. Wendel M, Heller AR. Anticancer Actions of Omega-3 Fatty Acids Current State and Future Perspectives. Anti-Cancer Agents Med Chem. 2009;9:457-70.

41. Fredman G, Serhan CN. Specialized proresolving mediator targets for RvE1 and RvD1 in peripheral blood and mechanisms of resolution. Biochem J. 2011;437:185-97.

42. Spite M, Norling LV, Summers L, Yang R, Cooper D, Petasis NA, Flower RJ, Perretti M, Serhan CN. Resolvin D2 is a potent regulator of leukocytes and controls microbial sepsis. Nature. 2009;461:1287-91.

43. Hasturk H, Kantarci A, Goguet-Surmenian E, Blackwood A, Andry C, Serhan CN, Van Dyke TE. Resolvin E1 regulates inflammation at the cellular and tissue level and restores tissue homeostasis in vivo. $J$ Immunol. 2007;179:7021-29.

44. Titos E, Rius B, González-Périz A, López-Vicario C, Morán-Salvador E, Martínez-Clemente M, Arroyo V, Clària J. Resolvin D1 and Its Precursor Docosahexaenoic Acid Promote Resolution of Adipose Tissue Inflammation by Eliciting Macrophage Polarization toward an M2-Like Phenotype. J Immunol. 2011;187:5408-18.

45. Serhan CN, Yang R, Martinod K, Kasuga K, Pillai PS, Porter TF, Oh SF, Spite M.Maresins: novel macrophage mediators with potent antiinflammatory and proresolving actions. J Exp Med. 2009;206:15-23.

46. Dalli J, Ramon S, Norris PC, Colas RA, Serhan CN. Novel proresolving and tissue-regenerative resolvin and protectin sulfido-conjugated pathways. FASEB J. 2015;29:2120-36. 
47. Gerster H. Can adults adequately convert alpha-linolenic acid (18:3n-3) to eicosapentaenoic acid (20:5n-3) and docosahexaenoic acid (22:6n-3)? Int J Vitam Nutr Res. 1998;68:159-73.

48. Alazawi W, Pirmadjid N, Lahiri R, Bhattacharya S. Inflammatory and Immune Responses to Surgery and Their Clinical Impact. Ann Surg. 2016;264:73-80.

49. Shankar Hari M, Summers $C$. Major surgery and the immune system: from pathophysiology to treatment. Curr Opin Crit Care. 2018;24:588-93.

50. Phipps RP, Stein SH, Roper RL. A new view of prostaglandin E regulation of the immune response. Immunol Today. 1991; 12:349-52.

51. Klava A, Windsor AC, Farmery SM, Woodhouse LF, Reynolds JV, Ramsden CW, Boylston AW, Guillou PJ. Interleukin-10: a role in the development of postoperative immunosuppression. Arch Surg. 1997; 132:425-29.

52. Waitzberg DL, Torrinhas RS. The complexity of prescribing intravenous lipid emulsions. World Rev Nutr Diet. 2015;112:150-62.

53. Torrinhas RS, Jacintho T, Goto H, Gidlund M, Sales MM, Oliveira PA, Waitzberg DL. Cell activation state influences the modulation of HLA-DR surface expression on human monocytes/macrophages by parenteral fish oil lipid emulsion. Nutr Hosp. 2011;26:311-6.

54. Manzoni Jacintho T, Gotho H, Gidlund M, García Marques C, Torrinhas R, Mirtes Sales M, Linetzky Waitzberg D. Anti-inflammatory effect of parenteral fish oil lipid emulsion on human activated mononuclear leukocytes. Nutr Hosp. 2009;24:288-96.

55. De Nardi L, Bellinati-Pires R, Torrinhas RS, Bacchi CE, Arias V, Waitzberg DL. Effect of fish oil containing parenteral lipid emulsions on neutrophil chemotaxis and resident-macrophages' phagocytosis in rats. Clin Nutr. 2008;27:283-8.

56. Campos FG, Waitzberg DL, Habr-Gama A, Logullo AF, Noronha IL, Jancar $S$, Torrinhas RS, Fürst $P$. Impact of parenteral n-3 fatty acids on experimental acute colitis. Br J Nutr. 2002;87:S83-8. 
57. Cukier C, Waitzberg DL, Logullo AF, Bacchi CE, Travassos VH, Torrinhas RS, Soares SR, Saldiva PH, Oliveira TS, Heymsfield S. Lipid and lipid-free total parenteral nutrition: differential effects on macrophage phagocytosis in rats. Nutrition. 1999;15:885-9.

58. Berger MM, Tappy L, Revelly JP, Koletzko BV, Gepert J, Corpataux JM, Cayeux MC, Chiolero RL. Fish oil after abdominal aorta aneurysm surgery. Eur J Clin Nutr. 2008;62:1116-22.

59. Senkal M, Geier B, Hannemann M, Deska T, Linseisen J, Wolfram G, Adolph M. Supplementation of omega-3 fatty acids in parenteral nutrition beneficially alters phospholipid fatty acid pattern. JPEN J Parenter Enteral Nutr. 2007;31:12-7.

60. Wang J, Yu JC, Kang WM, Ma ZQ. Superiority of a fish oil-enriched emulsion to medium-chain triacylglycerols/long-chain triacylglycerols in gastrointestinal surgery patients: a randomized clinical trial. Nutrition. 2012;28:623-9.

61. Reeves PG1, Nielsen FH, Fahey GC Jr. AIN-93 purified diets for laboratory rodents: final report of the American Institute of Nutrition ad hoc writing committee on the reformulation of the AIN-76A rodent diet. $J$ Nutr. 1993;123:1939-51.

62. Yamaguchi N, Lima-Gonçalves E, Waitzberg DL, Diniz Filho AM, Goffi FS. Effects of parenteral nutrition on tumor growth: experimental aspects. Rev Hosp Clin Fac Med Sao Paulo. 1990;45:115-22.

63. Galizia MS, Alves CC, Tamanaha EM, Torrinhas RS, Leite FC, Neto AH, Gama-Rodrigues J, Waitzberg DL. A new swivel model for parenteral and enteral infusion in rats. J Surg Res. 2005;128:3-8.

64. Hagi A, Nakayama M, Shinzaki W, Haji S, Ohyanagi H. Effects of the omega-6:omega-3 fatty acid ratio of fat emulsions on the fatty acid composition in cell membranes and the anti-inflammatory action. JPEN $J$ Parenter Enteral Nutr. 2010;34:263-70.

65. Shirai T, Matsuzaki K, Kuzumoto M, Nagahisa K, et.al. Precise metabolic flux analysis of coryneform bacteria by gas chromatography-mass 
spectrometry and verification by nuclear magnetic resonance. $J$ Biosci Bioeng. 2006;102:413-24.

66. Iverson SJ. Comparison of the Bligh and Dyer and Folch methods for total lipid determination in a broad range of marine tissue. Lipids. 2001;36:1283-7.

67. Braga M, Gianotti L, Nespoli L, Radaelli G, Di Carlo V. Nutritional approach in malnourished surgical patients: a prospective randomized study. Arch Surg. 2002;137:174-80.

68. Gianotti L, Braga M, Nespoli L, Radaelli G, Beneduce A, Di Carlo V. A randomized controlled trial of preoperative oral supplementation with a specialized diet in patients with gastrointestinal cancer. Gastroenterology. 2002;12:1763-70.

69. Simopoulos AP. The importance of the ratio of omega-6/omega-3 essential fatty acids. Biomed Pharmacother. 2002;56:365-79.

70. Tsekos E, Reuter C, Stehle P, Boeden G. Perioperative administration of parenteral fish oil supplements in a routine clinical setting improves patient outcome after major abdominal surgery. Clin Nutr. 2004;23:325-30.

71. Simopoulos AP, Bourne PG, Faergeman O.Bellagio Report on Healthy Agriculture, Healthy Nutrition, Healthy People. Nutr Hosp. 2013;28:17619.

72. Ohzato H, Yoshizaki K, Nishimoto N, Ogata A, Tagoh H, Monden M, Gotoh M, Kishimoto T, Mori T. Interleukin-6 as a new indicator of inflammatory status: detection of serum levels of interleukin-6 and C-reactive protein after surgery. Surgery. 1992;111:201-09.

73. Ruiz-Tovar J, Blanca M, Garcia A, Gonzalez J, Gutierrez S, Paniagua A, Prieto MJ, Ramallo L, Llanos L, Duran M. Preoperative administration of Omega-3 fatty acids on postoperative pain and acute-phase reactants in patients undergoing Roux-en-Y gastric bypass: A randomized clinical trial. Clin Nutr. 2018;29: S0261-5614(18)31228-7.

74. Heller AR, Rössel T, Gottschlich B, Tiebel O, Menschikowski M, Litz RJ, Zimmermann T, Koch T. Omega-3 fatty acids improve liver and pancreas function in postoperative cancer patients. Int J Cancer. 2004;111:611-6. 
75. Mertes N, Grimm H, Fürst P, Stehle P. Safety and efficacy of a new parenteral lipid emulsion (SMOFlipid) in surgical patients: a randomized, double-blind, multicenter study. Ann Nutr Metab. 2006;50:253-9.

76. Badía-Tahull MB, Llop-Talaverón JM, Leiva-Badosa E, Biondo S, FarranTeixidó L, Ramón-Torrell JM, Jódar-Masanes $\mathrm{R}$. A randomised study on the clinical progress of high-risk elective major gastrointestinal surgery patients treated with olive oil-based parenteral nutrition with or without a fish oil supplement. Br J Nutr. 2010;104:737-41.

77. Zhang B, Wei G, Li R, Wang Y, Yu J, Wang R, Xiao H, Wu C, Leng C, Zhang $B$, Chen XP. n-3 fatty acid-based parenteral nutrition improves postoperative recovery for cirrhotic patients with liver cancer: $A$ randomized controlled clinical trial. Clin Nutr. 2017;36:1239-44.

78. Gong Y, Liu Z, Liao Y, Mai C, Chen T, Tang H, Tang Y. Effectiveness of w-3 Polyunsaturated Fatty Acids Based Lipid Emulsions for Treatment of Patients after Hepatectomy: A Prospective Clinical Trial. Nutrients. 2016;8:E357.

79. Pan D, Chen H, Li L. Application of a lipid emulsion for parenteral nutrition support in intensive care patients following gastrointestinal surgeries. Nan Fang Yi Ke Da Xue Xue Bao. 2015;35:1312-5.

80. Zhu MW, Tang DN, Hou J, Wei JM, Hua B, Sun JH, Cui HY. Impact of fish oil enriched total parenteral nutrition on elderly patients after colorectal cancer surgery. Chin Med J (Engl). 2012;125:178-81.

81. Zhu XH, Wu YF, Qiu YD, Jiang CP, Ding YT. Liver-protecting effects of omega-3 fish oil lipid emulsion in liver transplantation. World $\mathrm{J}$ Gastroenterol. 2012;18:6141-7.

82. Zhu X, Wu Y, Qiu Y, Jiang C, Ding Y. Effects of $\omega-3$ fish oil lipid emulsion combined with parenteral nutrition on patients undergoing liver transplantation. JPEN J Parenter Enteral Nutr. 2013;37:68-74.

83. Jiang ZM, Wilmore DW, Wang XR, Wei JM, Zhang ZT, Gu ZY, Wang S, Han SM, Jiang H, Yu K. Randomized clinical trial of intravenous soybean oil alone versus soybean oil plus fish oil emulsion after gastrointestinal cancer surgery. Br J Surg. 2010;97:804-9. 
84. Ordemann J, Jacobi CA, Schwenk W, Stösslein R, Müller JM. Cellular and humoral inflammatory response after laparoscopic and conventional colorectal resections. Surg Endosc. 2001;15:600-8.

85. Mason RP, Jacob RF, Shrivastava S, Sherratt SCR, Chattopadhyay A. Eicosapentaenoic acid reduces membrane fluidity, inhibits cholesterol domain formation, and normalizes bilayer width in atherosclerotic-like model membranes Biochim Biophys Acta. 2016;1858:3131-40.

86. Gary R. Oilseed composition and modification for health and nutrition, in Functional Dietary Lipids, 2016;pp 23-46.

87. Calder PC. Docosahexaenoic Acid. Ann Nutr Metab. 2016;69:8-21.

88. Langlois PL, Hardy G, Manzanares W. Omega-3 polyunsaturated fatty acids in cardiac surgery patients: An updated systematic review and metaanalysis. Clin Nutr. 2017;36:737-46.

89. Li NN, Zhou Y, Qin XP, Chen Y, He D, Feng JY, Wu XT. Does intravenous fish oil benefit patients post-surgery? A meta-analysis of randomised controlled trials. Clin Nutr. 2014;33:226-39.

90. Wei C, Hua J, Bin C, Klassen K. Impact of lipid emulsion containing fish oil on outcomes of surgical patients: systematic review of randomized controlled trials from Europe and Asia. Nutrition. 2010;26:474-81.

91. Chen B, Zhou Y, Yang P, Wan HW, Wu XT. Safety and efficacy of fish oilenriched parenteral nutrition regimen on postoperative patients undergoing major abdominal surgery: a meta-analysis of randomized controlled trials. JPEN J Parenter Enteral Nutr. 2010;34:387-94.

92. Zhao $\mathrm{Y}$, Wang $\mathrm{C}$. Effect of $\omega-3$ polyunsaturated fatty acid-supplemented parenteral nutrition on inflammatory and immune function in postoperative patients with gastrointestinal malignancy: A meta-analysis of randomized control trials in China. Medicine (Baltimore). 2018;97: e0472. 


\section{ARTIGO SUBMETIDO À REVISTA JPEN - JOURNAL OF PARENTERAL AND ENTERAL NUTRITION}

Title: Infusion time for fish oil-containing parenteral lipid emulsions in surgery: A study on the omega-3 fatty acids dynamics in different body pools of Lewis rats that had undergone surgical central venous access

Authors: Antunes MS, Pharmacist, M.e ${ }^{1}$; Waitzberg DL, Physician, $\mathrm{PhD}^{1}$; Tesser A, Dietist, M.e ${ }^{1}$; Aprobato F, Biologist, GCert ${ }^{1}$; Tamanaha EM, Biologist, GCert ${ }^{1}$; Oliveira R, Dietist, Gcert'; Sampaio GR, Biologist, $\mathrm{PhD}^{2}$; Torres E, Agronomist Engineer, PhD²; Garla PC, Dietist, M.e ${ }^{1}$, Calder PC, Dietist, $\mathrm{PhD}^{3}$, Torrinhas RS, Biologist, $\mathrm{PhD}^{1}$.

Affiliations: ${ }^{1}$ Laboratory of Nutrition and Metabolic Surgery (LIM-35), Department of Gastroenterology, Faculty of Medicine, University of São Paulo, São Paulo, Brazil; '2Laboratory of Bromatology, Department of Nutrition, Faculty of Public Health, University of São Paulo, São Paulo, Brazil; ${ }^{3}$ Human Development \& Health, Faculty of Medicine, University of Southampton, Southampton, United Kingdom and NIHR Southampton Biomedical Research Centre, University Hospital Southampton NHS Foundation Trust and University of Southampton, Southampton, UK

Corresponding author: Raquel Susana M. M. Torrinhas. Av. Dr. Arnaldo, 455, 2 andar, sala 2208, Cerqueira César, São Paulo - SP, Brazil. CEP: 01246-903. Phone: 3061-7459. E-mail: rtorrinhas@gmail.com

Acknowledgments: We thank Lívia Samara Rodrigues Okada for the standardization of chromatographic analyses in the leukocyte pool and Guaraci 
Requena for the statistical discussion of the data. We also thank LBB-BBraun Brazil, which kindly donated the parenteral lipid emulsions, provided the peristaltic infusion pumps in lending, and offered financial aid for the acquisition of reagents

Financial Disclosure: The study was supported by LBB-BBraun Brazil, which kindly donated the parenteral lipid emulsions, provided the peristaltic infusion pumps in lending, offered financial aid for the acquisition of reagents, and did not interfere in the study design, data collection, analysis and interpretation, manuscript draft or in the decision to submit this for publication.

Conflicts of interest: None declared 


\section{CLINICAL RELEVANCY STATEMENT}

Although several meta-analysis have showed that parenteral infusion of fish oilcontaining lipid emulsions (FOLE) may improve clinical outcomes in surgical patients, the optimal infusion length to achieve these benefits remains unknown. Here, we have confirmed a favorable modulation of polyunsaturated fatty acids (PUFA) concentration after the parenteral FOLE supply, reflected by an increase of the n-3:n-6 ratio in plasma, liver and blood leukocytes of Lewis rats. However, the increase of n-3 PUFA in leukocytes was no more detectable 2 hours after the infusion ceased. Our findings suggest that FOLE should not be infused only at the preoperative and/or for postoperative periods shorter than the entire dynamic of the postoperative immune-inflammatory response to better benefit from their immunomodulatory properties. 


\section{ABSTRACT}

Background: To contribute to the design of specialized parenteral nutrition protocols in surgery, we evaluated the dynamics of polyunsaturated fatty acid (PUFA) concentrations in different body pools following the infusion of fish oilcontaining parenteral lipid emulsion (FOLE) in rats that had undergone surgical central venous catheterization (CVC). Methods: After 5-day adaptation in metabolic cages, 78 male Lewis rats $(300-450 \mathrm{~g})$ fed a standard diet were sacrificed (baseline control) or had only CVC (surgical control) or also received a 72-hour infusion of lipid emulsions with or without fish oil. The catheterized animals were sacrificed 0 (T0), 2 (T2), 6 (T6) and 12 (T12) hours after the infusion ended. Gas chromatography was used to determine the concentrations of eicosapentaenoic (EPA), docosahexaenoic (DHA) and arachidonic (ARA) acids and the n-3:n-6 ratio in plasma, liver and blood leukocytes. Kruskal-Wallis and Wilcoxon tests were applied to plasma and liver data and descriptive analysis to leukocyte data. Results: Plasma, liver and leukocytes exhibited undetectable EPA and DHA and detectable ARA concentrations at baseline, except for a low EPA concentration in mononuclear leukocytes. Immediately after FOLE infusion (T0), these PUFAs changed in all pools, resulting in a higher n-3:n-6 ratio compared to rats with no FOLE infusion $(p<0.05)$. These changes remained until T6 in plasma and T12 in liver but were no longer observed in leukocytes after T2. Conclusion: Our data suggest that leukocytes clear n-3 PUFAs early after the end of FOLE infusion. When FOLE is applied for immunomodulatory purposes in surgery, this should be considered. 


\section{INTRODUCTION}

The inflammatory response to surgery is associated with poor prognosis, which can be minimized by the administration of eicosapentaenoic (EPA) and docosahexaenoic (DHA) acids. ${ }^{1-3}$ These omega-3 (n-3) polyunsaturated fatty acids (PUFAs) are associated with anti-inflammatory and tissue reparative properties by serving as precursors of eicosanoids with low inflammatory potential and/or specialized pro-resolution mediators, as well as modulating cell signaling processes and the activity of transcription factors. ${ }^{4-6}$ The influence of dietary fatty acids on endogenous phospholipid profiles, mainly resident and circulating leukocytes, links PUFA intake and immunity. ${ }^{5,7}$

Infusion of fish oil-containing lipid emulsions (FOLEs) as a source of EPA and DHA is a potential strategy for the adjuvant treatment of surgical patients under parenteral nutrition therapy, with the main purpose of attenuating the harmful consequences of the postoperative immune response.$^{5}$ Compared to the infusion of conventional lipid emulsions (LEs), FOLEs have been shown to favor a less inflammatory and immunosuppressive profile of circulating cytokines and eicosanoids, as well as to attenuate the negative impact of surgery on leukocyte biology. ${ }^{8-17}$ These improvements in immune-inflammatory markers are largely accompanied by better clinical outcomes, but a lack of significant impact on clinical outcomes has also been reported. ${ }^{18}$

Reasons for the limited clinical benefits after FOLE infusion may include insufficient length of the supplementation for surgical patients to benefit from the biological properties of EPA and DHA. The European and American guidelines in the area of specialized clinical nutrition do not include recommendations in this 
field. ${ }^{19,20}$ Aiming to contribute to evidence that guides the future planning of clinical protocols for specialized nutrition, we evaluated the plasma, liver and leukocyte PUFA profiles at different periods after ending the parenteral infusion of a FOLE. Our intention was to characterize the dynamics of EPA and DHA concentrations after FOLE infusion in order to know more about the time period over which this should be extended to favor immunological benefits.

\section{MATERIALS AND METHODS}

\section{Ethical statement}

All interventional procedures were conducted according to the standards of protection and care of experimental animals of the Research Ethics Committee of the University of São Paulo Medical School (CEP - FMUSP), which approved our experimental protocol ( $\left.N^{\circ}: 126 / 12\right)$.

\section{Animals and interventional procedures}

Male Lewis rats weighing $300-450 \mathrm{~g}(\mathrm{n}=78)$ were purchased from the Multidisciplinary Center for Biological Research (CEMIB) of the Universidade Estadual de Campinas (UNICAMP). All animals remained in individual metabolic cages for 5 days at $20-25^{\circ} \mathrm{C}$ controlled temperature and day/night cycles of light and feeding AIN-93M ad libitum for adaptation to the experimental conditions. After this period, 6 of the animals were sacrificed by cardiac puncture to serve as the baseline control for PUFA concentrations (BC group). The remaining animals $(n=72)$ were subjected to central venous system access by a previously described surgical technique ${ }^{21}$ and to a $24-\mathrm{h}$ infusion $(0.25 \mathrm{~mL} / \mathrm{h})$ of $6 \mathrm{~mL}$ of saline solution $(0.9 \%)$ for recovery. After this period, 24 of the catheterized animals remained feeding only on 
the oral AIN-93M diet ad libitum to serve as surgical controls (SC group). The other catheterized animals $(n=48)$ remained feeding on the oral AIN-93M diet ad libitum but also received parenteral infusion (72 hours, $4.3 \mathrm{~g}$ fat $/ \mathrm{kg}$ body weight) ${ }^{22}$ of a control LE without fish oil (EC group, $n=24$ ) or a FOLE (FOLE group, $n=24$ ). Parenteral infusion was performed using a gravity infusion pump (Space® perfusor, BBraun, Melsugen, Germany), and the LEs applied were Lipofundin ${ }^{\circledR} 20 \%$ (BBraun, Melsugen, Germany) containing 50\% soybean oil and $50 \%$ MCT from coconut oil (EC group) and Lipidem ${ }^{\circledR}$ 20\% (BBraun, Melsugen, Germany) containing 40\% soybean oil, $50 \%$ MCT from coconut oil and 10\% fish oil (FOLE group), whose compositions are described in Table 1. Sacrifice of all the catheterized animals occurred 0 (T0), 2 (T2), 6 (T6) and 12 (T12) hours after the end of the surgical followup (SC group) or after the end of the LE infusion period (EC and FOLE groups). Each group/sacrifice period comprised 6 animals (24 animals of each group / 4 time periods). Sacrifices and surgical procedures were performed under anesthesia by intraperitoneal injection of $80 \mathrm{mg} / \mathrm{kg}$ ketamine hydrochloride and $8 \mathrm{mg} / \mathrm{kg}$ xylazine hydrochloride. Figure 1 illustrates the study design.

\section{Samples obtained and processed}

At sacrifice, all animals were submitted to blood (cardiac puncture into a 0.2$\mathrm{mL}$ heparin vacuum tube) and liver tissue (ventral incision) sampling. Blood samples were processed to yield plasma (10 min, $1800 \mathrm{rpm}, 20^{\circ} \mathrm{C}$ centrifugation), and mononuclear and polymorphonuclear leukocytes were obtained from blood diluted in saline solution (1:1 v/v) by density gradient centrifugation (30 min, $1800 \mathrm{rpm}$, room temperature) with 1:1 v/v Histopaque $\AA^{\circledR} 1083$ or Polymorphpred $\AA$ 1113, respectively 
(both from Sigma-Aldrich, USA). All samples were immediately frozen at $-80^{\circ} \mathrm{C}$ until PUFA profile analysis.

\section{PUFA analysis}

Concentrations of EPA, DHA and arachidonic acid (ARA), as well as the n3:n-6 ratio, were assessed in plasma, liver and leukocytes by gas chromatography. We were unable to obtain a sufficient amount of the leukocyte populations for analysis from individual blood samples, so the leukocyte evaluation was performed in duplicates of pools from 6 rats, as determined by a previous pilot study. For PUFA analysis of liver, $100 \mathrm{~g}$ of hepatic tissue was added to $500 \mu \mathrm{L}$ of $0.88 \% \mathrm{KCl}$ solution (Synth $\circledast$, Synth, Diadema, Brazil) and homogenized in a mini Turrax homogenizer. Subsequently, lipids were extracted from the liver homogenate and from plasma and leukocytes. For all samples, the methyl esters of fatty acids were produced according to the protocol of Shirai et al. ${ }^{23}$. Chromatographic analyses of fatty acid methyl esters were performed with an Agilent 7890A GC System (Agilent Technologies, California, USA) equipped with a $60 \mathrm{~m} \times 250 \mu \mathrm{m} \times 0.15 \mu \mathrm{m}$ capillary column (Agilent 122-2361 J \& W DB-23, Agilent Technologies, California, USA), high resolution and flame ionization detector (FID). Chromatographic conditions were performed according to Iverson et al. ${ }^{24}$ with specific adaptations: 50:1 split mode injection; injector temperature $250^{\circ} \mathrm{C}$; and detector temperature $280^{\circ} \mathrm{C}$. The operating conditions of the column corresponded to the initial temperature of $80^{\circ} \mathrm{C}$ (1 minute) and later of $230^{\circ} \mathrm{C}$ (5 minutes), with a total running time of 45 minutes. Data on PUFA concentrations (mg/L) were obtained by external standardization using commercial reference standards to construct the calibration curve (Sigma®, Sigma-Aldrich, Missouri, USA). 


\section{Statistical analysis}

For plasma and liver, the analysis of PUFA concentrations along the time points was performed in an intragroup approach and compared to the baseline concentrations (i.e., the BC group) by the application of the Kruskal-Wallis and Wilcoxon tests. Analyses of pooled leukocyte samples resulted in the generation of only one representative result for each group studied, so the analyses of the leukocyte concentrations of PUFAs in leukocytes were only descriptive. The analysis and generation of graphs were performed using the R program (version 3.2.2; R Core Team, Vienna, Austria), considering a significance level of $5 \%$.

\section{RESULTS}

\section{PUFA concentrations in plasma and liver}

According to the analysis of the $\mathrm{BC}$ group, Lewis rats exhibited undetectable EPA and DHA but detectable ARA concentrations in plasma (Figure 2A) and liver (Figure 2B) at baseline. Following surgical and nutritional interventions, EPA was higher in the FOLE group at T0 and T2 in plasma $(p=0.003)$ and at all times studied in liver $(p=0.002)$ compared to levels in the other groups. In the liver, DHA was higher in the FOLE group at all times studied $(p=0.002)$ and in the EC group at T0 $(p=0.002)$ than that in the BC and SC groups. Furthermore, liver DHA was higher in the FOLE group than that in the EC group at T2, T6 and T12 $(p \leq 0.050)$. Intragroup comparative analysis showed a time-dependent decrease in plasma and liver EPA concentrations (except between T2 and T6 in liver) and liver DHA concentrations in the FOLE group (Table 2). The same was observed for liver DHA in the EC group (Table 2). Following surgical and nutritional interventions, the 
plasma and liver concentrations of ARA were higher in both the FOLE and EC groups than that in the BC group at T0 $(p=0.003)$ and lower in the SC group at all times studied than those in all other groups $(p \leq 0.005)$. However, compared to the EC group, plasma ARA was lower in the FOLE group from T2 $(p=0.002)$ and liver ARA was higher in the FOLE group at T0, T2 and T6 but lower at T12 ( $\leq \leq 0,005)$. Intragroup comparative analysis showed that in both plasma and liver, ARA concentrations decreased from T0 to T2 in the FOLE and EC groups $(p=0.002)$, but only the FOLE group exhibited a time-dependent decrease in plasma and liver levels of ARA, except between T2 and T6 in the liver (Table 2). Specifically, in hepatic tissue, the SC group had higher ARA concentrations at T2 than at T0 $(p=$ 0.041). Changes in the concentrations of EPA, DHA and ARA influenced the n-3:n6 ratio. In plasma, a higher n-3:n-6 ratio was found in the FOLE group at T0 and T2 compared to that in all other groups $(p \leq 0.005)$. In the liver, the $n-3: n-6$ ratio was higher at T0, T2 and T6 in the EC group $(p=0.003)$ and at all times studied in the FOLE group $(p=0.003)$ compared to those in the BC and SC groups. However, this ratio was significantly higher in the FOLE group than that in the EC group from T2 $(p=0.002)$. Intragroup analyses showed that the plasma $n-3: n-6$ ratio was higher in the FOLE group at T0 and T2 than at T6 and T12 ( $\leq \leq 0.003)$; however, it was lower at T0 than at T2 $(p=0.002)$. In the liver, intragroup analyses showed that the $n-3: n-$ 6 ratio decreased significantly and in a time-dependent manner in the FOLE group from T2, except between T2 and T6. A time-dependent decrease in the liver n-3:n6 ratio was also observed in the EC group $(p \leq 0.003)$.

\section{PUFA concentrations in leukocytes}


According to the analysis of the BC group, blood mononuclear (Figure $3 \mathrm{~A}$ ) and polymorphonuclear (Figure 3B) leukocytes from Lewis rats exhibited almost undetectable levels of EPA and DHA and high levels of ARA at baseline. Compared to the BC group, at T0 the SC group exhibited higher DHA levels in both leukocyte populations and lower EPA in the mononuclear population, the EC group exhibited higher EPA and DHA in mononuclear leukocytes, and the FOLE group exhibited higher DHA in both leukocyte populations and lower EPA in the mononuclear population. On the other hand, mononuclear leukocytes exhibited higher EPA in the FOLE group than that in the SC and EC groups at T2, where all the differences in n-3 PUFAs observed at T0 were no longer present. In comparison to the BC group, all groups exhibited lower ARA concentrations but differed in their dynamics: this occurred from T2 (mononuclear) and T0 (polymorphonuclear) in the SC group; from T2 (both leukocyte populations) for the EC group; and from T0 (both leukocyte populations) for the FOLE group. Specifically, in mononuclear leukocytes, the ARA concentration was higher in the SC group at T0 and T2 than the concentration in the other groups. Changes in the concentrations of EPA, DHA and ARA resulted in higher n-3:n-6 ratios at T0 in both leukocyte populations for the FOLE and SC groups and only in mononuclear leucocytes for the EC group compared to the ratio in the $\mathrm{BC}$ group. However, the $n-3: n-6$ ratio was higher in the FOLE group than that in the other groups at T0 (both leukocyte populations) and T2 (mononuclear leukocytes). The T12 time-point was not examined for leukocyte populations. 


\section{DISCUSSION}

Here, we confirmed a favorable modulation of PUFA concentrations after the parenteral supply of FOLE, marked by a higher n-3:n-6 ratio in the plasma, liver and blood leukocytes. In addition, we show for the first time that this effect was labile in leukocytes, which demonstrated rapid loss of n-3 PUFAs once infusion of FOLE ceased. Our findings suggest that immunomodulatory benefits favored by the parenteral supply of n-3 PUFAs may not be fully achieved if FOLE is infused only at the preoperative and/or postoperative periods for a short time; such infusion needs to be tailored to the dynamics of the immune response to surgical trauma. This observation may shed some light on the design of protocols for specialized parenteral nutrition therapy with n-3 PUFAs in surgical patients.

In this study, Lewis rats (CB group) were fed a standard diet that has soybean oil as the fat source and thus has a relatively low n-3:n-6 PUFA ratio (1:7), very similar to the human Western dietary pattern. ${ }^{25,26}$ At baseline, these animals exhibited almost undetectable EPA and DHA but readily detectable ARA concentrations in liver, plasma and leukocytes (CB group). These PUFAs were quite sensitive to FOLE infusion: a higher n-3:n-6 ratio was observed after its infusion in all pools studied compared to that in animals that did not receive FOLE intervention.

Notably, the effect on n-3 PUFAs and the n-3:n-6 PUFA ratio observed immediately upon cessation of FOLE infusion decreased over time for all pools, but the n-3:n-6 PUFA ratio remained elevated in liver at 12 hours, in plasma and mononuclear leukocytes at 2 hours, and was no longer detectable in polymorphonuclear leukocytes at 2 hours. Therefore, leukocytes (especially polymorphonuclear leukocytes) did not retain n-3 PUFAs as well as the liver. This 
finding suggests that leukocytes use n-3 PUFAs at very high rates, making their bioavailability labile in these cells. Although differences between the metabolism of Lewis rats and humans cannot be disregarded, this observation raises the question of whether the preoperative infusion of FOLE should be applied in elective surgery. Nevertheless, a classic retrospective study involving 256 surgical patients reported a larger clinical benefit from infusing FOLE perioperatively compared with just postoperatively. ${ }^{27}$

Surgical patients often have pathologies involving changes in the immune response (i.e., cancer, inflammatory bowel diseases). In this scenario, preoperative FOLE infusion may aid improvement in the general clinical condition of the patient prior to surgical trauma, which can positively impact postoperative outcomes. Accordingly, a recent study in bariatric patients showed that exclusive preoperative oral supplementation with n-3 PUFAs was associated with greater preoperative weight and lower postoperative pain and C-reactive protein levels. ${ }^{28}$

Our data cannot exclude the relevance in supplying FOLE as an n-3 PUFA source in the preoperative period but calls attention to the potential need to extend this intervention for adequate postoperative periods to achieve immune-modulatory benefits. Protocols previously applied to investigate the effect of postoperative parenteral infusion of the same FOLE as studied here on lipid and lipid-derived immune mediator profiles and/or clinical outcomes ranged from 4 to 5 postoperative days. ${ }^{14-17,29,30}$ Data from these reports suggest that parenteral infusion of this FOLE for 4 postoperative days may be less effective in decreasing the length of hospital stay (LOS) and infection rates than extending this infusion for 5 days. $14,16,17,29$ However, it is noteworthy that different effects on LOS were observed among these 
previous reports even when applying identical periods for the postoperative infusion of FOLE. ${ }^{14,16,17}$ These discrepancies may be a reflection of the highly heterogeneous dynamics of the immune response, with postoperative humoral and cellular immune responses being subject to different factors influencing their course. One well-known factor is the type of surgical procedure applied (conventional or laparoscopic), but others are also potentially relevant, such as age, underlying disease and stage of its development. ${ }^{31}$

The period for LE infusion used in the current study was based on the study of Hagi et al. ${ }^{22}$, which reported that the concentrations of n-3 PUFAs in splenocytes nearly reached a plateau after a 3-day infusion of FOLEs with different n-3:n-6 PUFA ratios in rats. In the surgical control (SC) group at T0, plasma and liver had very low ARA, but mononuclear leukocytes had high ARA. These findings suggest that 4 days after a moderate surgical intervention, ARA could still be required for immunological purposes, likely due to the synthesis of inflammatory mediators.

Compared to baseline, at T0 plasma and liver concentrations of ARA were high in both the EC and FOLE groups, but animals from the EC group had lower liver ARA than animals from the FOLE group. In the other hand, high leukocyte concentrations of ARA were found in the EC group at T0, while ARA was undetectable in leukocytes following FOLE infusion. These findings suggest that in animals from the EC group, ARA was more required by leukocytes than by the liver, probably for the synthesis of immune mediators. Control lipid emulsion and FOLE contain soybean oil, although in different amounts, which may explain the increase in ARA levels in liver after their infusion.

Immediately after FOLE infusion there was an absence of circulating DHA, 
but it was present in mononuclear and polymorphonuclear leukocytes. DHA has a unique structural role by conferring a high fluidity to cell membranes, which is required for phagocytosis. ${ }^{32}$ Major polymorphonuclear leukocytes are phagocytic cells and have a shorter half-life (i.e., minutes for neutrophils) than mononuclear leukocytes (i.e., months for lymphocytes) ${ }^{33}$ It is possible that fast DHA clearance can sustain the synthesis of new leukocytes, which is compatible with immunological activity and may be an advantage after FOLE infusion as a DHA source. This may also explain why leukocytes from the SC and EC groups also displayed higher DHA concentrations than those found in the $\mathrm{BC}$ group. For both the $\mathrm{SC}$ and $\mathrm{EC}$ groups, DHA may be derived from the high content of soybean oil present in the oral diet and the control LE, which provides the plant n-3 PUFA alpha-linolenic acid, which could be converted to DHA in these animals. ${ }^{34}$

Incorporation and loss of EPA are both faster than DHA into different biological pools. ${ }^{35}$ We found high EPA concentrations in plasma and liver after FOLE infusion, but significant changes in EPA were not observed in leukocytes. EPA and ARA are both precursors of eicosanoids involved in the activation and prolongation of the inflammatory response, although the eicosanoids of different origins may have different potencies. ${ }^{4,5}$ Low EPA in leukocytes at postoperative day 4 (T0) in the FOLE group may suggest an intense use of EPA rather than ARA for eicosanoid synthesis. In contrast to the FOLE group, higher EPA concentrations were observed in mononuclear leukocytes after the infusion of control LE than at baseline (EC vs. BC groups). This finding supports that, as in animals from the SC group, leukocytes of animals in the EC group use ARA as an eicosanoid precursor. It is important to note that, in general, eicosanoids derived from EPA have a lower proinflammatory 
potential than those derived from ARA, so leukocytes from the FOLE group are more likely to develop a less detrimental inflammatory response. ${ }^{4,5}$

The strengths of the current study are the use of controls for the background diet (BC group) and for the surgical procedure (SC group) and the inclusion of multiple time points. The main methodological limitation was the need to pool leukocytes for analysis due to the small blood volume available.

Although several meta-analysis studies have confirmed that parenteral infusion of FOLE may improve clinical outcomes in surgical patients, the optimal infusion length to achieve these benefits remains unknown. ${ }^{36-39}$ Our data suggest that the bioavailability of n-3 PUFAs in leukocytes after this practice is highly labile, and therefore, the supply of n-3 PUFAs should cover the entire period of the postoperative immune-inflammatory response dynamic. Studies on this dynamic may help in the future design of customized protocols for parenteral FOLE infusion, according to the type of surgical intervention and the specific clinical condition of the patient.

\section{REFERENCES}

1. Jing Yu, Lian Liu, Yue Zhang, Jia Wei, and Fan Yang. Effects of omega-3 fatty acids on patients undergoing surgery for gastrointestinal malignancy: a systematic review and meta-analysis. BMC Cancer. 2017;17:271.

2. Klek S, Waitzberg DL. Intravenous lipids in adult surgical patients. World Rev Nutr Diet. 2015;112:115-9. 
3. McCarthy MS, Morgan BB, Heineman JT, Martindale RG. Nutritional armor for the injured warfighter: omega-3 fatty acids in surgery, trauma, and intensive care. Mil Med. 2014;179:88-94.

4. Calder PC. Functional Roles of Fatty Acids and Their Effects on Human Health. JPEN J Parenter Enteral Nutr. 2015;39:18S-32S.

5. Waitzberg DL, Torrinhas RS. Fish oil lipid emulsions and immune response: what clinicians need to know. Nutr Clin Pract. 2009;24:487-99.

6. Dalli J, Ramon S, Norris PC, Colas RA, Serhan CN. Novel proresolving and tissue-regenerative resolvin and protectin sulfido-conjugated pathways. FASEB J. 2015;29:2120-36.

7. Healy DA, Wallace FA, Miles, EA, Calder, PC, Newsholm P. Effect of low-tomoderate amounts of dietary fish oil on neutrophil lipid composition ad function. Lipids. 2000;35:763-8.

8. Weiss G, Meyer F, Matthies B, Pross M, Koenig W, Lippert H. Immunomodulation by perioperative administration of $\mathrm{n}-3$ fatty acids. $\mathrm{Br} \mathrm{J}$ Nutr. 2002;87:S89-94.

9. Liang B, Wang S, Ye Ying-Jiang, Yang Xiao-Dong, Wang You-Li, Qu J, Xie Qi-Wei, Yin Mu-Jun Impact of postoperative omega-3 fatty acidsupplemented parenteral nutrition on clinical outcomes and immunomodulations in colorectal cancer patients. World $J$ Gastroenterol. $2008 ; 14: 2434-9$.

10. Schauder P, Röhn U, Schäfer G, Korff G, Schenk HD. Impact of fish oil enriched total parenteral nutrition on DNA synthesis, cytokine release and receptor expression by lymphocytes in the postoperative period. $\mathrm{Br} \mathrm{J}$ Nutr. 
2002;87:S103-10.

11. Cury-Boaventura MF, Torrinhas RS, Godoy AB, Curi R, Waitzberg DL. Human Leukocyte Death After a Preoperative Infusion of Medium/LongChain Triglyceride and Fish Oil Parenteral Emulsions: A Randomized Study in Gastrointestinal Cancer Patients. JPEN J Parenter Enteral Nutr. 2012;6:677-84.

12. Long $\mathrm{H}$, Yang $\mathrm{H}$, Lin $\mathrm{Y}$, Situ $\mathrm{D}$, Liu W. Fish oil-supplemented parenteral nutrition in patients following esophageal cancer surgery: effect on inflammation and immune function. Nutr Cancer. 2013;65:71-5.

13. de Miranda Torrinhas RS, Santana R, Garcia T, Cury-Boaventura MF, Sales MM, Curi R, Waitzberg DL. Parenteral fish oil as a pharmacological agent to modulate post-operative immune response: a randomized, double-blind, and controlled clinical trial in patients with gastrointestinal cancer. Clin Nutr. 2013;32:503-10.

14. Wichmann MW, Thul P, Czarnetzki HD, Morlion BJ, Kemen M, Jauch KW. Evaluation of clinical safety and beneficial effects of a fish oil containing lipid emulsion (Lipoplus, MLF541): data from a prospective, randomized, multicenter trial. Crit Care Med. 2007;35:700-6.

15. Köller M, Senkal M, Kemen M, König W, Zumtobel V, Muhr G. Impact of omega-3 fatty acid enriched TPN on leukotriene synthesis by leukocytes after major surgery. Clin Nutr. 2003;22:59-64.

16.Zhang CH, Li N, Wang XY, Li GL, Fan CG, Li JS. Influence of Lipoplus fat emulsion on postoperative nutritional status and early inflammatory response in patients with gastrointestinal malignancies. Zhonghua Wei Chang Wai Ke 
Za Zhi. 2012;15:448-51.

17. Wang J, Yu JC, Kang WM, Ma ZQ. Superiority of a fish oil-enriched emulsion to medium-chain triacylglycerols/long-chain triacylglycerols in gastrointestinal surgery patients: a randomized clinical trial. Nutrition. 2012;28:623-9.

18. Honeywell S, Zelig R, Rigassio Radler D1. Impact of Intravenous Lipid Emulsions Containing Fish Oil on Clinical Outcomes in Critically III Surgical Patients: A Literature Review. Nutr Clin Pract. 2019;34:112-122.

19. McClave SA, Taylor BE, Martindale RG, Warren MM, Johnson DR, Braunschweig C, McCarthy MS, Davanos E, Rice TW, Cresci GA, Gervasio JM, Sacks GS, Roberts PR, Compher C; Society of Critical Care Medicine; American Society for Parenteral and Enteral Nutrition. Guidelines for the Provision and Assessment of Nutrition Support Therapy in the Adult Critically III Patient: Society of Critical Care Medicine (SCCM) and American Society for Parenteral and Enteral Nutrition (A.S.P.E.N.).JPEN J Parenter Enteral Nutr. 2016;40:159-211.

20. Braga M, Ljungqvist O, Soeters $P$, Fearon K, Weimann A, Bozzetti F; ESPEN. ESPEN Guidelines on Parenteral Nutrition: surgery. Clin Nutr. 2009;28:378-86.

21. Yamaguchi N, Lima-Gonçalves E, Waitzberg DL, Diniz Filho AM, Goffi FS. Effects of parenteral nutrition on tumor growth: experimental aspects. Rev Hosp Clin Fac Med Sao Paulo. 1990;45:115-22.

22. Hagi A, Nakayama M, Shinzaki W, Haji S, Ohyanagi H. Effects of the omega6:omega-3 fatty acid ratio of fat emulsions on the fatty acid composition in 
cell membranes and the anti-inflammatory action. JPEN $J$ Parenter Enteral Nutr. 2010;34:263-70.

23. Shirai T, Matsuzaki K, Kuzumoto M, Nagahisa K, et.al. Precise metabolic flux analysis of coryneform bacteria by gas chromatography-mass spectrometry and verification by nuclear magnetic resonance. $J$ Biosci Bioeng. 2006;102:413-24.

24. Iverson SJ. Comparison of the Bligh and Dyer and Folch methods for total lipid determination in a broad range of marine tissue. Lipids. 2001;36:12837.

25. Waitzberg DL, Torrinhas RS, Jacintho TM. New parenteral lipid emulsions for clinical use. JPEN J Parent Enteral Nutr. 2006;30:351-67.

26. Simopoulos AP. The importance of the ratio of omega-6/omega-3 essential fatty acids. Biomed Pharmacother. 2002;56:365-79.

27. Tsekos E, Reuter C, Stehle P, Boeden G. Perioperative administration of parenteral fish oil supplements in a routine clinical setting improves patient outcome after major abdominal surgery. Clin Nutr. 2004;23:325-30.

28. Ruiz-Tovar J, Blanca M, Garcia A, Gonzalez J, Gutierrez S, Paniagua A, Prieto MJ, Ramallo L, Llanos L, Duran M. Preoperative administration of Omega-3 fatty acids on postoperative pain and acute-phase reactants in patients undergoing Roux-en-Y gastric bypass: A randomized clinical trial. Clin Nutr. 2019;38:1588-1593.

29. Berger MM, Tappy L, Revelly JP, Koletzko BV, Gepert J, Corpataux JM, Cayeux MC, Chiolero RL. Fish oil after abdominal aorta aneurysm surgery. Eur J Clin Nutr. 2008;62:1116-22. 
30. Senkal M, Geier B, Hannemann M, Deska T, Linseisen J, Wolfram G, Adolph M. Supplementation of omega-3 fatty acids in parenteral nutrition beneficially alters phospholipid fatty acid pattern. JPEN J Parenter Enteral Nutr. 2007;31:12-7.

31. Ordemann J, Jacobi CA, Schwenk W, Stösslein R, Müller JM. Cellular and humoral inflammatory response after laparoscopic and conventional colorectal resections. Surg Endosc. 2001;15:600-8.

32. Mason RP, Jacob RF, Shrivastava S, Sherratt SCR, Chattopadhyay A. Eicosapentaenoic acid reduces membrane fluidity, inhibits cholesterol domain formation, and normalizes bilayer width in atherosclerotic-like model membranes Biochim Biophys Acta. 2016;1858:3131-40.

33. Gibney MJ, Hunter B. The effects of short- and long-term supplementation with fish oil on the incorporation of $n-3$ polyunsaturated fatty acids into cells of the immune system in healthy volunteers. Eur J Clin Nutr. 1993;47:255-9.

34. Gary R. Oilseed composition and modification for health and nutrition. In: Sanders TAB ed. Functional Dietary Lipids: Food Formulation, Consumer Issues and Innovation for Health. Cambridge, UK: Woodhead Publishing; 2016:23-46.

35. Calder PC. Docosahexaenoic Acid. Ann Nutr Metab. 2016;69:8-21.

36. Chen B, Zhou Y, Yang P, Wan HW, Wu XT. Safety and efficacy of fish oilenriched parenteral nutrition regimen on postoperative patients undergoing major abdominal surgery: a meta-analysis of randomized controlled trials. JPEN J Parenter Enteral Nutr. 2010;34:387-94. 
37.Zhao $\mathrm{Y}$, Wang $\mathrm{C}$. Effect of $\omega-3$ polyunsaturated fatty acid-supplemented parenteral nutrition on inflammatory and immune function in postoperative patients with gastrointestinal malignancy: A meta-analysis of randomized control trials in China. Medicine (Baltimore). 2018;97:e0472.

38. Langlois PL, Hardy G, Manzanares W. Omega-3 polyunsaturated fatty acids in cardiac surgery patients: An updated systematic review and meta-analysis. Clin Nutr. 2017;36:737-46.

39. Li NN, Zhou Y, Qin XP, Chen Y, He D, Feng JY, Wu XT. Does intravenous fish oil benefit patients post-surgery? A meta-analysis of randomised controlled trials. Clin Nutr. 2014;33:226-39.

40. Wei C, Hua J, Bin C, Klassen K. Impact of lipid emulsion containing fish oil on outcomes of surgical patients: systematic review of randomized controlled trials from Europe and Asia. Nutrition. 2010;26:474-81. 
Table 1. Fatty acid composition (\% of total fatty acids) of the control (Lipofundin® $20 \%$ ) and fish oil-containing (Lipidem ${ }^{\circledR} 20 \%$ ) parenteral lipid emulsions studied

\begin{tabular}{|c|c|c|}
\hline Fatty Acids & Lipofundin $\AA 20 \%$ & Lipidem ${ }^{\circledR} 20 \%$ \\
\hline Caprylic acid (C8:0) & 25.6 & 26.1 \\
\hline Capric acid (C10:0) & 19.3 & 19.7 \\
\hline Palmitic acid (C16:0) & 7.2 & 6.1 \\
\hline Stearic acid (C18:0) & 2.8 & 2.6 \\
\hline Oleic acid (C18:1n-9) & 13.0 & 11.4 \\
\hline Linoleic acid (C18:2n-6) & 26.8 & 21.9 \\
\hline Alpha-linolenic acid (C18:3n-3) & 3.4 & 2.8 \\
\hline Stearidonic acid (C18:4n-3) & - & 0.2 \\
\hline Eicosatetraenoic acid (C20:4n-3) & - & 0.2 \\
\hline Arachidonic acid (C20:4n-6) & 0.3 & 0.4 \\
\hline Eicosapentaenoic acid (C20:5n-3) & - & 3.3 \\
\hline Docosanoic acid (C22:0) & - & 0.2 \\
\hline Docosapentaenoic acid (C22:5n-3) & 0.2 & 0.6 \\
\hline Docosahexaenoic acid (C22:6n-3) & & 2.5 \\
\hline Others & 1.4 & 2.0 \\
\hline Medium-chain triglycerides & 52.1 & 51.9 \\
\hline Omega-9 monounsaturated fatty acids & 13.0 & 11.4 \\
\hline Omega- 6 polyunsaturated fatty acids & 27.1 & 22.3 \\
\hline Omega-3 polyunsaturated fatty acids & 3.6 & 9.4 \\
\hline Omega-3:Omega-6 ratio & $1: 7.5$ & $1: 2.4$ \\
\hline
\end{tabular}

Data were provided by the manufacturer (BBraun, Melsungen, Germany). 


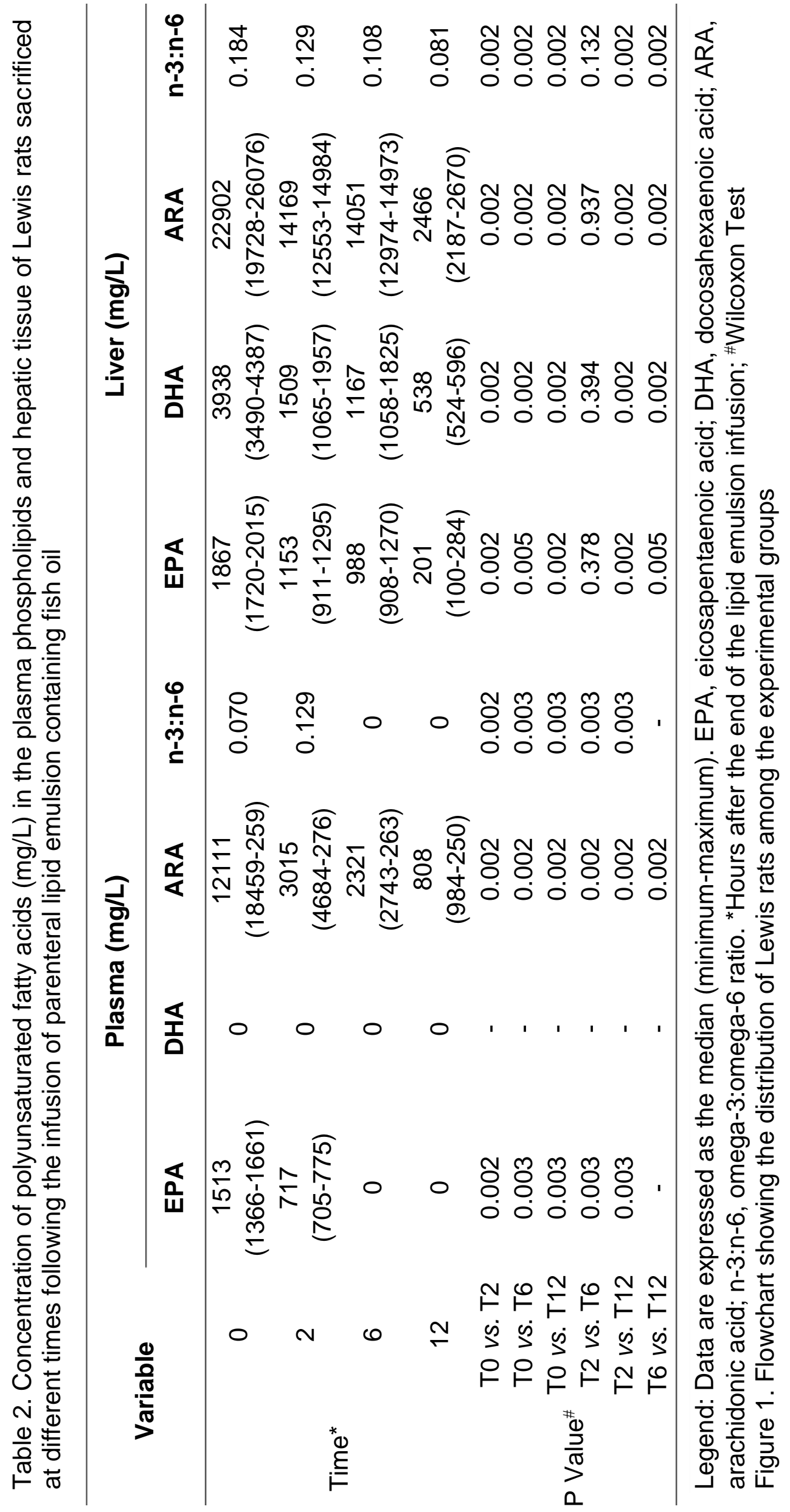




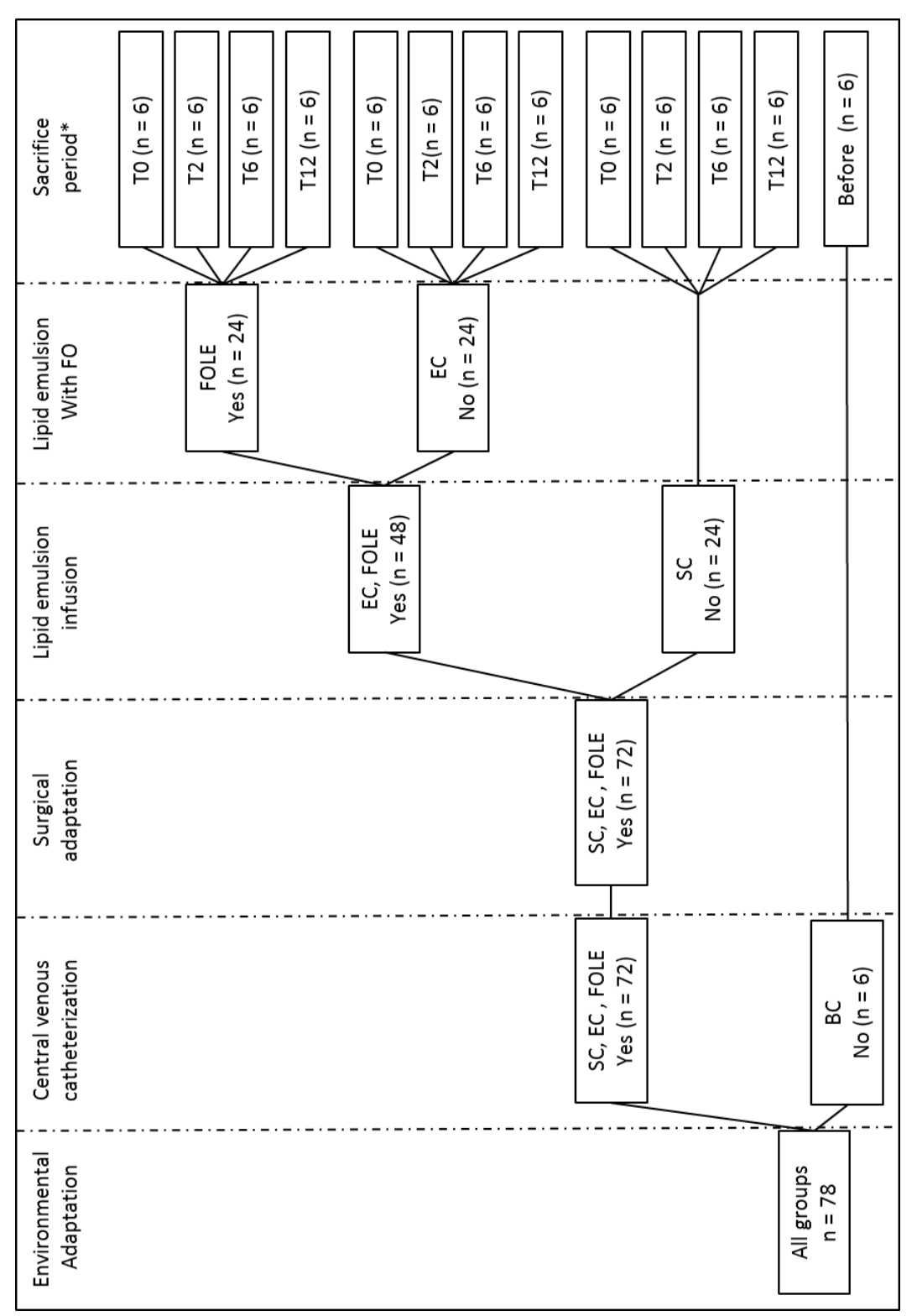

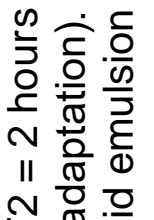

$\because \frac{\pi}{\sigma}: \frac{0}{=}$

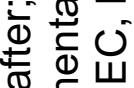

$\geq$ 을

뜬

헝 웅

悉产紊

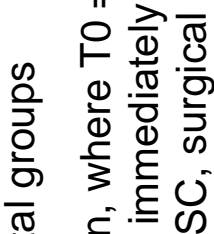

要

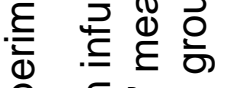

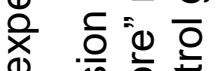

(

$\mp$ ह

응 응 옥 $\frac{0}{0}$

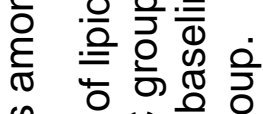

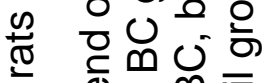

क 0 ब

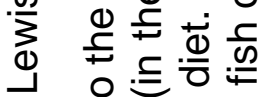

¿

을

은 융 0 으

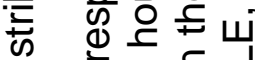

흥 훙등

잉 인.

응 은 늠

을

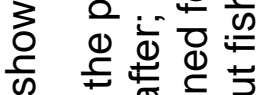

क 专市

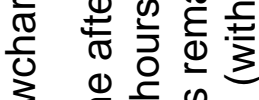

은

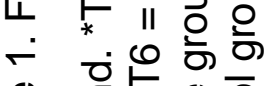

产

은 过恋完 


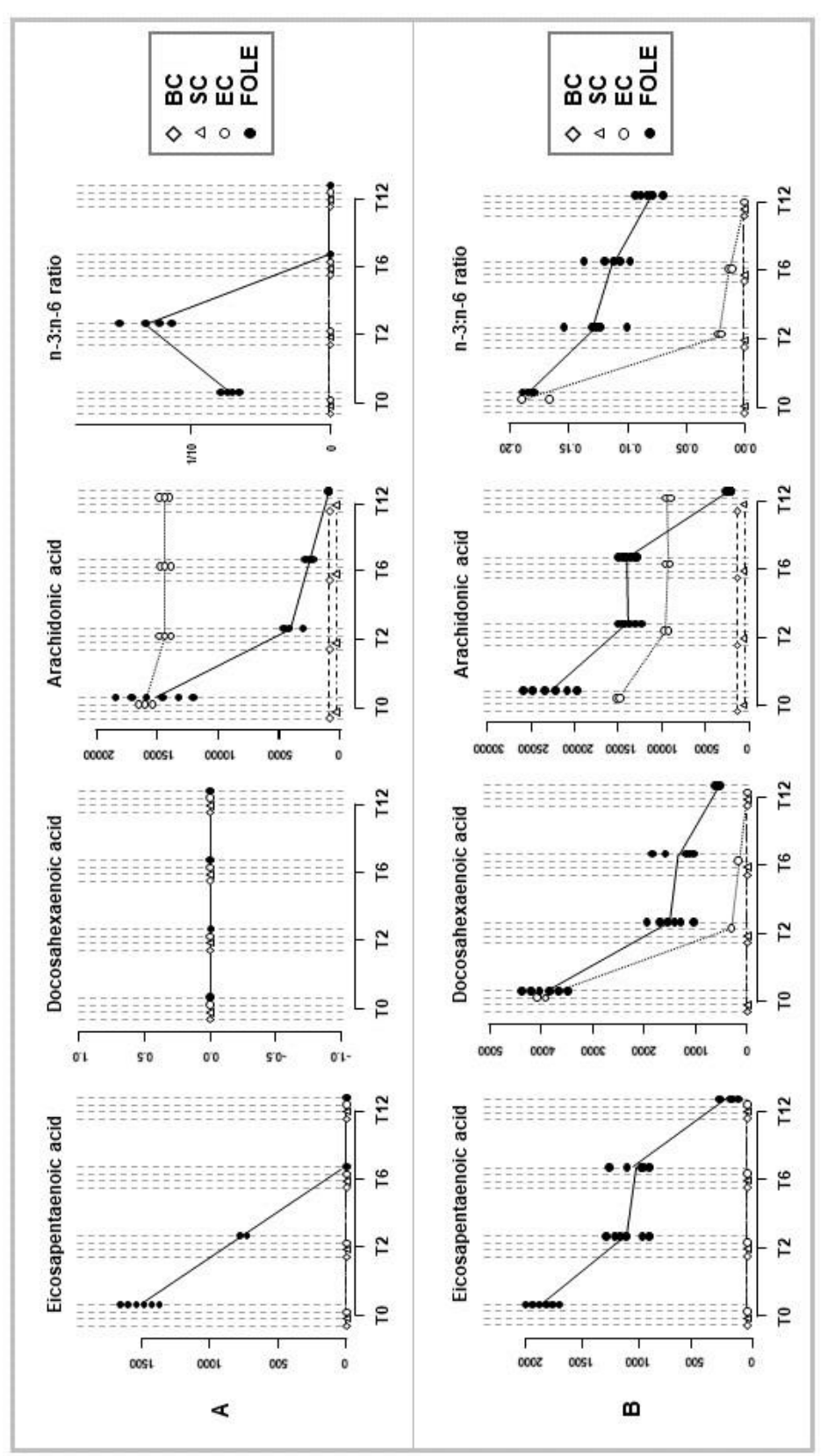

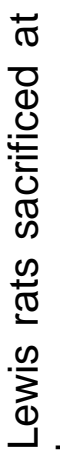

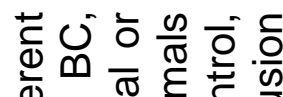
包. 可

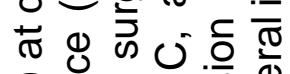
की ج山 क्ष শ $\succ \infty$

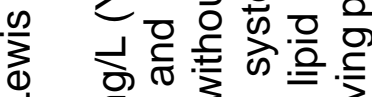

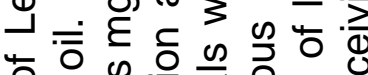
둥ำ

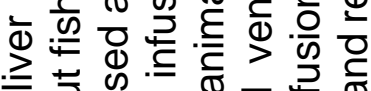
$\geq$

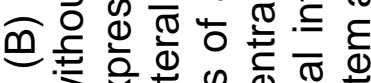

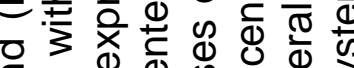
के

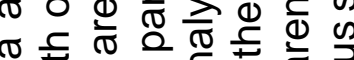

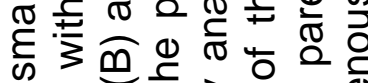

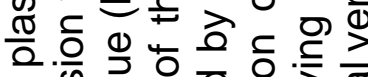

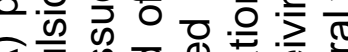
过

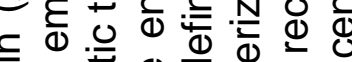
응

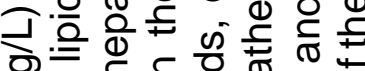

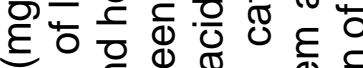

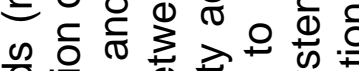

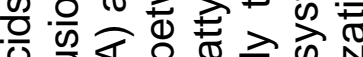

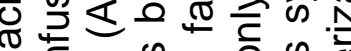

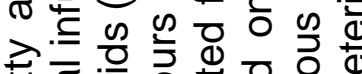

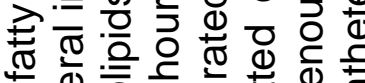

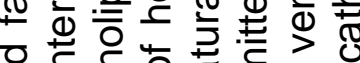

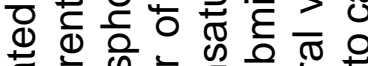

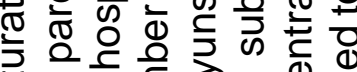
拧 क O

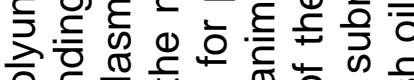
응 $\frac{\pi}{0} \frac{\pi}{0}$

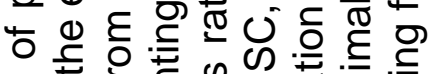

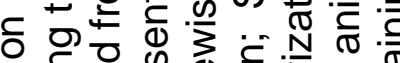

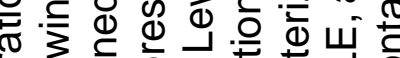

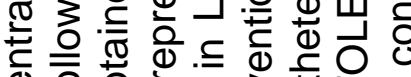

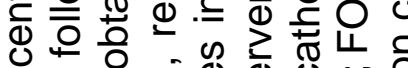

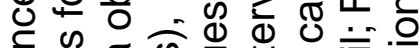

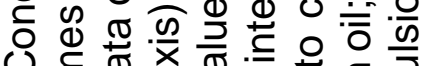

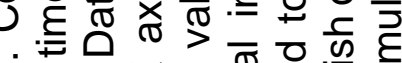
人

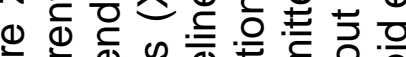

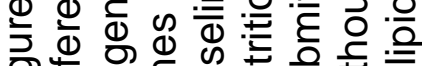

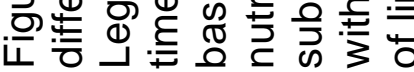




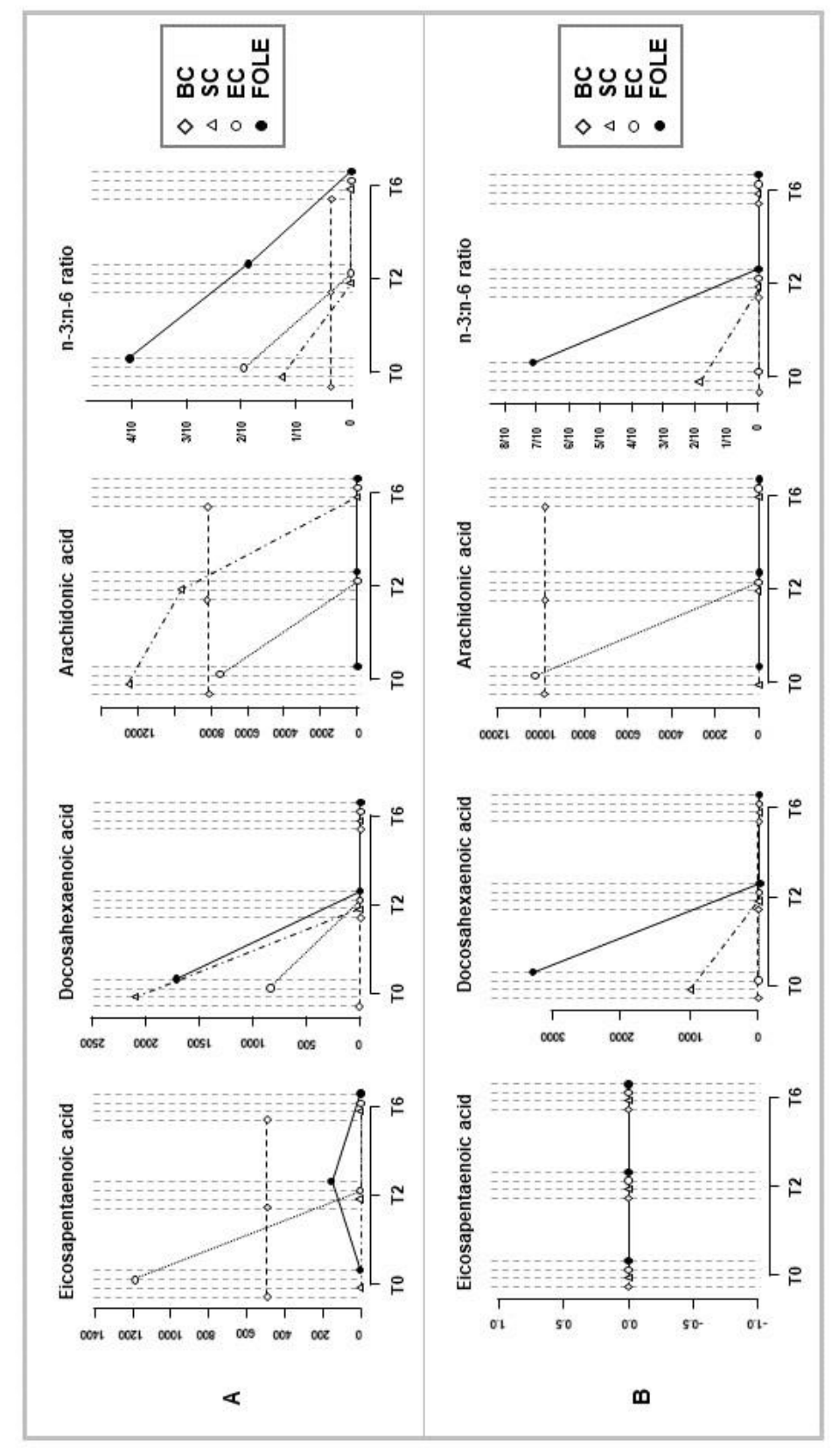

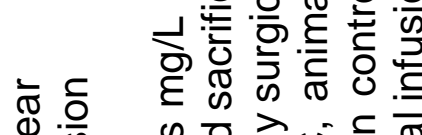

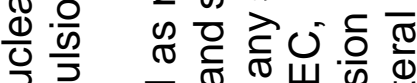

टे ह

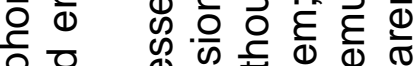

은흥 क

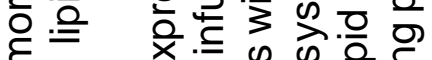

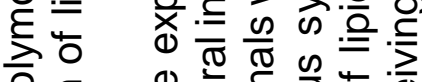

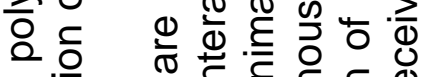

बิ?

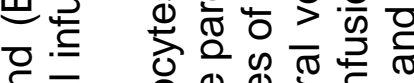

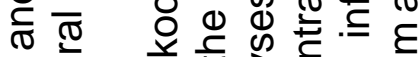

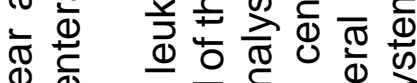

ब ब

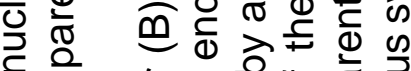

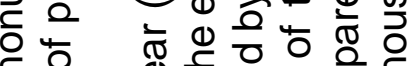

이잉

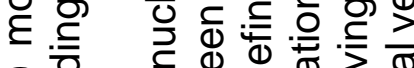

这定

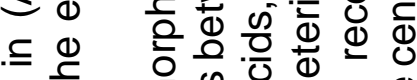

声

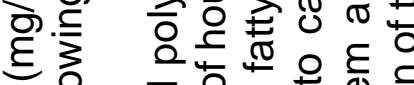

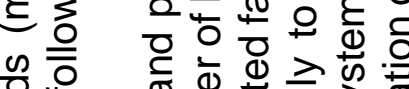

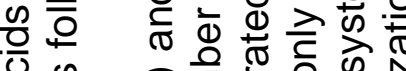

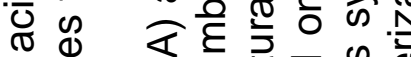

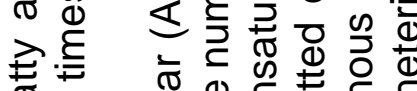

焉壱

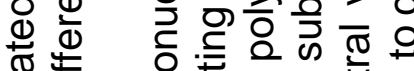

뜬 은

究市

足完

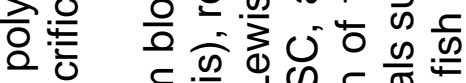

ర๐

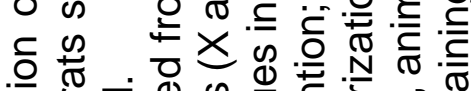

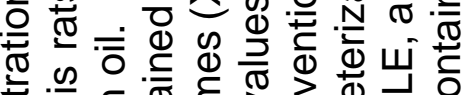

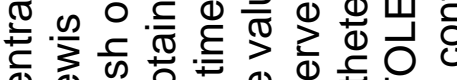
ঠ ర人 \& 正

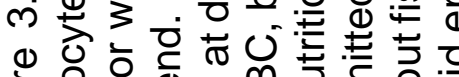

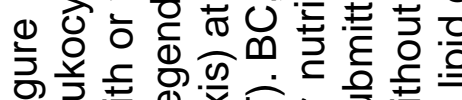

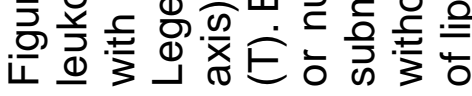

